\title{
Electrode Materials for High-Performance Sodium-Ion Batteries
}

\author{
Santanu Mukherjee *,+, Shakir Bin Mujib +(D), Davi Soares $\mathbb{D}$ and Gurpreet Singh * \\ Department of Mechanical and Nuclear Engineering, Kansas State University, Manhattan, KS 66503, USA; \\ sbmujib@ksu.edu (S.B.M.); soares@ksu.edu (D.S.) \\ * Correspondence: j.santanu.mukherjee@gmail.com (S.M.); gurpreet@ksu.edu (G.S.) \\ † Equal contributions as first author.
}

Received: 1 May 2019; Accepted: 7 June 2019; Published: 17 June 2019

\begin{abstract}
Sodium ion batteries (SIBs) are being billed as an economical and environmental alternative to lithium ion batteries (LIBs), especially for medium and large-scale stationery and grid storage. However, SIBs suffer from lower capacities, energy density and cycle life performance. Therefore, in order to be more efficient and feasible, novel high-performance electrodes for SIBs need to be developed and researched. This review aims to provide an exhaustive discussion about the state-of-the-art in novel high-performance anodes and cathodes being currently analyzed, and the variety of advantages they demonstrate in various critically important parameters, such as electronic conductivity, structural stability, cycle life, and reversibility.
\end{abstract}

Keywords: sodium ion batteries; anodes; cathodes; 2D materials; MXenes; alloys; prussian blue; NASICON

\section{Introduction}

\subsection{Current Global Energy Scenario}

The progressively increasing demands for energy to meet the needs of the steadily growing population has led to huge global increases in the consumption of fossil fuels [1]. However, this large demand and ever-growing consumption of fossil fuels has led to significant undesirable consequences, primarily the large quantities of greenhouse gases (e.g., $\mathrm{CO}_{2}$ ) being liberated into the atmosphere as a result of the combustion of these fuels, leading to global warming and climate change [2,3]. Another challenge is the gradual dwindling of fossil fuel reserves, with only coal expected to last approximately another 100 years, and oil and gas for a much shorter time, which raises important questions about energy security in the long term $[4,5]$. As a result, a concerted effort is being taken to move away from fossil fuels and toward renewable energy providing systems (e.g., solar, wind, water (hydroelectricity), and geothermal energy) [6]. These energy systems have the advantage of being abundant (almost inexhaustible), inexpensive, and most importantly, produce no greenhouse gases $[7,8]$. However, most of these renewable sources, such as solar and wind, are intermittent, and, therefore, robust, reliable, and economically viable storage systems are necessary. Different energy storage types exist, such as pumped-hydro (accounting for $98 \%$ of U.S. energy storage), thermal energy storage, and compressed air $[7,9]$. However, electrochemical energy storage systems, by virtue of their longevity, low establishment and capital expenditure, and ease of set-up, are considered the best candidates for energy storage from renewables $[9,10]$. Among these rechargeable electrochemical storage systems, lithium ion battery (LIB) systems have come to play a pivotal role [11]. 


\subsection{Current Perspective on LIBs for Energy Storage}

Ever since they were first commercialized by Sony in 1991, LIBs have transformed the way electrochemical energy is stored [12,13]. The consistent specific energies around $120 \mathrm{Wh} \mathrm{kg}^{-1}$, low reduction potentials $(-3.04 \mathrm{~V}$ vs. SHE), and rather small ionic size of $\mathrm{Li}(0.76 \tilde{\mathrm{A}})$, which facilitates smooth intercalation and fast electrochemical kinetics, are some of the important aspects that make LIBs the gold standard in rechargeable metal ion electrochemical storage systems [14,15].

These advantages notwithstanding, certain aspects of LIBs need closer scrutiny. Most importantly, $\mathrm{Li}$ resources are rather rare in the earth's crust $(\sim 20 \mathrm{ppm})$, and coupled with its uneven geographical availability, this scarcity makes for unfavorable LIB economics [16]. Secondly, economical constraints hinder the application LIBs in large and very large scale storage systems, such as grid storage [17]. Also, another important concern regarding LIB systems is environmental, as the usage of certain electrodes that are toxic and the flammability of certain electrolytes have been reported [18].

With this perspective in mind, alternative rechargeable battery systems are being studied to overcome the said challenges with lithium-based systems. It is in this scheme that sodium ion batteries (SIBs) fit in, and it is hoped that they will carve out a niche of their own in the greater metal-ion based rechargeable electrochemical energy storage ecosystem.

\subsection{Rationale for SIBs for Energy Storage}

SIBs provide several unique advantages and are, therefore, increasingly studied as a feasible alternative to LIBs [19]. One of the most important factors is the abundant availability of Na metal in the earth's crust (it is the 6th most abundant element), consequently making its procurement and processing relatively inexpensive [20]. Also, SIB systems have good performance in aqueous systems, unlike their LIB counterparts, and this greatly helps to bring down costs as inexpensive electrolytes and less complicated fabrication processes can be used [20,21]. Another advantage is that SIB systems, to a large extent, mimic LIB systems in their electrochemical working, which proves beneficial from a theoretical modeling standpoint, as a considerable body of knowledge already exists for LIBs [22]. All these factors lead to greater potential for SIBs to be applied in systems where large quantities of sodium are required, making them prime candidates for grid scale storage [21].

Despite these advantages, SIB systems still have not been able to be commercialized as several important hurdles still remain. Firstly, the large size of the $\mathrm{Na}^{+}$ion $(1.02 \tilde{\mathrm{A}})$ makes for considerably sluggish kinetics [23,24]. Also, this large ionic size results in significant constraints for smooth intercalation in the host electrode interstices, often resulting in large and undesirable volume changes, thereby reducing cycle life and lowering longevity and performance [24,25]. Scientists and researchers have been adopting different approaches to overcome these challenges, and one of the most important avenues ahead for SIB systems is from the perspective of materials engineering, i.e., developing newer and better electrodes with novel morphologies to enhance performance and longevity [26,27].

The main parameters to evaluate the high performance of an electrode material are broadly classified into the four categories: (a) energy density, (b) rate capability, (c) cycleability, and (d) thermodynamic stability [28]. Energy density is defined as the product of average operating potential $(\mathrm{V})$ and the total amount of charge transfer $(\mathrm{Ah})$ and is expressed in $\mathrm{Wh} \mathrm{g}^{-1} / \mathrm{Wh} \mathrm{L}^{-1}$. In general, for a high-performance electrode, it is desired that the electrode materials undergo fast charge and discharge while maintaining high-energy density. On the other hand, the ability of the anode material to reversibly cycle Na-ions with the least irreversible capacity (IRC) is the cycleability of the material. To achieve thermodynamic stability and prevent the possible change in anode structure, the addition of external matrix material or similar chemical modifications are desired for a high-performance electrode material.

This manuscript, therefore, devotes itself to providing a substantial discussion on the current state-of-the-art anodes (negative electrodes) and cathodes (positive electrodes) used for high performance SIB systems, as well as the different types and classes of materials used and their 
motivation, novel fabrication techniques, their performance, the advantages and disadvantages of each, and what future research aims to be in this regard.

\section{Anodes}

With respect to anode materials for Na-ion batteries, it is a major challenge to develop high performance anode materials with a high reversible capacity, stable cycling performance, and high rate capability. In this review, the development of high performance of anode materials (carbons, alloy-based materials, oxides, and 2D materials) for Na-ion battery systems are discussed. The strategies to improve electrochemical performance in terms of materials fabrication, surface modification, electrolyte optimization, applying a favorable voltage window, and electrochemical performance are summarized.

\subsection{Carbons}

Carbon based materials have been studied extensively for SIBs because of their sustainability and natural abundance. Graphite had been studied for Na ion batteries in the 1980s, but it did not allow significant $\mathrm{Na}^{+}$insertion and its capacity was much lower. Therefore, soft carbons (SCs), like petroleum coke, carbon black, pitch, and PVC, were tested during the 1990s, but also showed limited capacities [29-31]. Later in 2011, the interest of Na-ion batteries was renewed with the study of $\mathrm{Na}$ intercalation in hard carbon [32]. Since then, many families of hard carbons, such as sucrose, cellulose, wood, argan shells, and peanut shells, have been studied for use as anodes, and their performance reached beyond $300 \mathrm{mAh} \mathrm{g}^{-1}$. Also, interest in soft carbons (SCs) has been growing in recent years [33-36]. However, considerable work remains in improving carbon-based anodes for Na-ion batteries.

Carbon-based materials are insertion-based materials which insert/extract a certain amount of $\mathrm{Na}^{+}$during charge/discharge process. However, graphitic carbons hinder the intercalation of Na-ions due to their large radius [37]. A minimum interlayer distance of $\sim 0.37 \mathrm{~nm}$ is required for Na-ion insertion, whereas the interlayer spacing of graphite is $\sim 0.335 \mathrm{~nm}$ [23]. In contrast, other alkali metals, such as $\mathrm{K}, \mathrm{Rb}, \mathrm{Cs}$, etc., are found to intercalate into graphite, even though they have larger ionic sizes than $\mathrm{Na}[38,39]$. K-ion based Graphite intercalation compounds (GICs) have shown the ability to adsorb molecular hydrogen and have good conductive properties [38]. The authors have reported the successful formation of stage-I $\mathrm{KC}_{8}$ [38]. Alkali metals are shown to become less stable as ion size decreases from $\mathrm{Cs}$ to $\mathrm{Na}$ because of reduced ionic bonding. Although, $\mathrm{Li}$ is an exception, as it forms covalent bonds with $\mathrm{C}$, resulting in negative formation energy. For this reason, graphite is a good intercalation material for $\mathrm{Li}$ and $\mathrm{K}$ but not for the $\mathrm{Na}$ [39].

Jache and Adelhelm showed that, using co- intercalation phenomena in a diglyme-based electrolyte, results in a stage-I ternary intercalation compound with an estimated stoichiometry of $\mathrm{Na}$ (diglyme) ${ }_{2} \mathrm{C}_{20}$ and the electrode showed a superior cycle life with capacities close to $100 \mathrm{mAh} \mathrm{g}^{-1}$ at a current density of $37.2 \mathrm{~mA} \mathrm{~g}^{-1}$ for 1000 cycles and coulombic efficiencies $>99.87 \%$ [40]. Wen et al. utilized another strategy by expanding the interlayer distance of graphite to $0.43 \mathrm{~nm}$ through a process of oxidation and partial reduction on graphite and reported a high reversible capacity of $284 \mathrm{mAh} \mathrm{g}^{-1}$ at $20 \mathrm{~mA} \mathrm{~g}^{-1}$ and retained $73.92 \%$ of its capacity at $100 \mathrm{~mA} \mathrm{~g}^{-1}$ after 2000 cycles [37].

Mesoporous soft carbon (MSC) was prepared by Cao et al. form mesophase pitch using nano- $\mathrm{CaCO}_{3}$, which consists of a disordered region with a large interlayer distance [35]. As an anode in Na-ion batteries, this MSC delivered a reversible capacity of $331 \mathrm{mAh} \mathrm{g}^{-1}$ at a current density of $30 \mathrm{~mA} \mathrm{~g}^{-1}$ and retained a capacity of $103 \mathrm{mAh} \mathrm{g}^{-1}$ at $500 \mathrm{~mA} \mathrm{~g}^{-1}$ after 3000 cycles. Recently, Yao et al. fabricated microporous soft carbon nanosheets (SC-NS) through microwave assisted exfoliation [41]. According to the authors, micropores and defects at the edges of as-prepared SC-NS contributed to enhanced kinetics and extra Na storage sites and exhibited a high reversible capacity of $232.2 \mathrm{mAh} \mathrm{g}^{-1}$ at $1000 \mathrm{~mA} \mathrm{~g}^{-1}$ and $128.7 \mathrm{mAh} \mathrm{g}^{-1}$ at $800 \mathrm{~mA} \mathrm{~g}^{-1}$ after 3500 cycles.

Hard carbons have also been utilized as anodes for Na-ion batteries due to their disordered structure and large interlayer distance [42]. Further, Hard carbon can deliver high capacity and low voltage plateau near $0.1 \mathrm{~V}\left(\mathrm{vs}\right.$. $\left.\mathrm{Na} / \mathrm{Na}^{+}\right)[43,44]$. Luo et al. derived carbon nanofibers from 
cellulose nanofibers and investigated them as materials for an anode [45]. A high reversible capacity of $255 \mathrm{mAh} \mathrm{g}^{-1}$ was obtained at a current density of $50 \mathrm{~mA} \mathrm{~g}^{-1}$ and an excellent cycling ability of $176 \mathrm{mAh} \mathrm{g}^{-1}$ was reported at $200 \mathrm{~mA} \mathrm{~g}^{-1}$ for over 600 cycles. Cao et al. prepared hollow carbon nanowires (HCNWs) through the pyrolization of a hollow polyaniline nanowire precursor [23]. The HCNWs used as an anode for Na-ion batteries delivered a high reversible capacity of $251 \mathrm{mAh} \mathrm{g}^{-1}$ at $50 \mathrm{~mA} \mathrm{~g}^{-1}$ and showed a capacity retention of $82.2 \%$ over 400 cycles between 1.2 and $0.01 \mathrm{~V}$ (vs. $\mathrm{Na}^{+} / \mathrm{Na}$ ). Li et al. also reported porous carbon nanofibers (P-CNFs) that delivered an reversible capacity of $\sim 140 \mathrm{mAh} \mathrm{g}^{-1}$ at a current density of $500 \mathrm{~mA} \mathrm{~g}^{-1}$ after 1000 cycles [46]. P-CNFs were prepared by pyrolysis of PAN-F127/DMF nanofibers via an electrospinning process. Lotfabad et al. utilized pyrolyzed banana peel pseudographite (BPPG) as the anode for Na-ion batteries and reported a gravimetric capacity of $355 \mathrm{mAh} \mathrm{g}^{-1}$ at $50 \mathrm{~mA} \mathrm{~g}^{-1}$ and a stable charge capacity of $221 \mathrm{mAh} \mathrm{g}^{-1}$ at $500 \mathrm{~mA} \mathrm{~g}^{-1}$ after 600 cycles [47]. The authors attributed this performance of BPPG to the dilated intergraphene spacings for Na intercalation and near-surface nanopores.

For room temperature Na-ion batteries, Zhang et al. synthesized hard carbon, under an ultrahigh temperature $\left(2500^{\circ} \mathrm{C}\right)$, from switchgrass [48]. The authors reported that because of its three-dimensional porous hierarchical structure and large interlayer spacing of $0.376 \mathrm{~nm}$, carbonized grass showed a specific capacity of $210 \mathrm{mAh} \mathrm{g}^{-1}$ as the anode of Na-ion batteries at a current density of $0.1 \mathrm{~A} \mathrm{~g}^{-1}$, and when cycled at $50 \mathrm{~mA} \mathrm{~g}^{-1}$, a stable capacity of $200 \mathrm{mAh} \mathrm{g}^{-1}$ was retained over 800 cycles with $\sim 100 \%$ coulombic efficiency after the first few cycles. Figure 1 represents a summary of the results of this group as representative of the performance of the carbon-based anode material for high performance Na-ion batteries. Figure 1a-f shows the microporous feature of the carbonized switchgrass and highlights the array structure and micro/nanoscale holes for ion transport. Graphitic layer structures can be seen from XRD and Raman in Figure 1i-j. Figure 1k-r shows the representative cyclic voltammogram (CV), voltage profiles, and galvanostatic charge-discharge (GCD) of the carbon anodes for the 1st, 2nd, 5th, and 10th cycles, at a current density of $50 \mathrm{~mA} \mathrm{~g}^{-1}$ in a potential range of $0.01-2 \mathrm{~V}$ versus $\mathrm{Na} / \mathrm{Na}^{+}$. The initial coulombic efficiencies for the GC-1000 and GC-2050 anode are calculated to be $42 \%$ and $64 \%$, respectively. Compared to GC-1000, the capacity of GC-2050 in both the sloping and plateau regions reduced slightly, which is, according to the authors, due to a decrease of active sites of electrochemical adsorption/desorption to sodium ions.

Large area phosphorous-doped carbon nanosheets (P-CNSs) were obtained from carbon dots (CDs) and analyzed by Hou et al. [49]. A high reversible capacity of $328 \mathrm{mAh} \mathrm{g}^{-1}$ was obtained at $0.1 \mathrm{~A} \mathrm{~g}^{-1}$ with a stable capacity of $149 \mathrm{mAh} \mathrm{g}^{-1}$ at a current density of $5 \mathrm{~A} \mathrm{~g}^{-1}$ after 5000 cycles for P-CNSs [49]. In the recent past, Hu et al. synthesized a nitrogen rich (17.72\%), hierarchically porous, and highly disordered carbonaceous material (N-HC), with an enlarged interlayer distance of $0.44 \mathrm{~nm}$ by spray drying and pyrolysis under $\mathrm{NH}_{3}$ [50]. This porous and nitrogen doped $\mathrm{N}-\mathrm{HC}$ was used as the anode in Na-ion batteries and showed a reversible discharge capacity of $255.9 \mathrm{mAh} \mathrm{g}^{-1}$ at $500 \mathrm{~mA} \mathrm{~g}^{-1}$ in the 3000th cycles [50]. A low-cost typha-derived hard carbon with acid activation was synthesized and analyzed in Na-ion batteries by Shen and coworkers [51]. They reported a high reversible capacity of $204.8 \mathrm{mAh} \mathrm{g}^{-1}$ at a current density of $100 \mathrm{~mA} \mathrm{~g}^{-1}$ after 4000 cycles [51]. Zhao et al. synthesized a low temperature $\left(1300^{\circ} \mathrm{C}\right)$ hard carbon with graphite crystals, using carbonized eggshell membranes, and sucrose-derived microsphere as precursors [52]. The hard carbon/graphite structure showed a discharge capacity of $310 \mathrm{mAh} \mathrm{g}^{-1}$ at $20 \mathrm{~mA} \mathrm{~g}^{-1}$ and $260 \mathrm{mAh} \mathrm{g}^{-1}$ after 1000 cycles at $100 \mathrm{~mA} \mathrm{~g}^{-1}$ [52].

Overall, Carbon based anodes are leading candidates for Na-ion batteries, but they need further study. Graphitic carbons limit the Na intercalation by forming a compound that is not energetically favorable, and solvation energy plays a role in intercalation, which needs to be further studied. Broad interlayer spacings of carbon can lead to a higher capacity. On the other hand, for hard carbons, it is believed that $\mathrm{Na}$ ion intercalations correspond to a low potential plateau. Additional study on the Na storage mechanism, especially the contribution of plateau regions, is needed to understand this intercalation. 

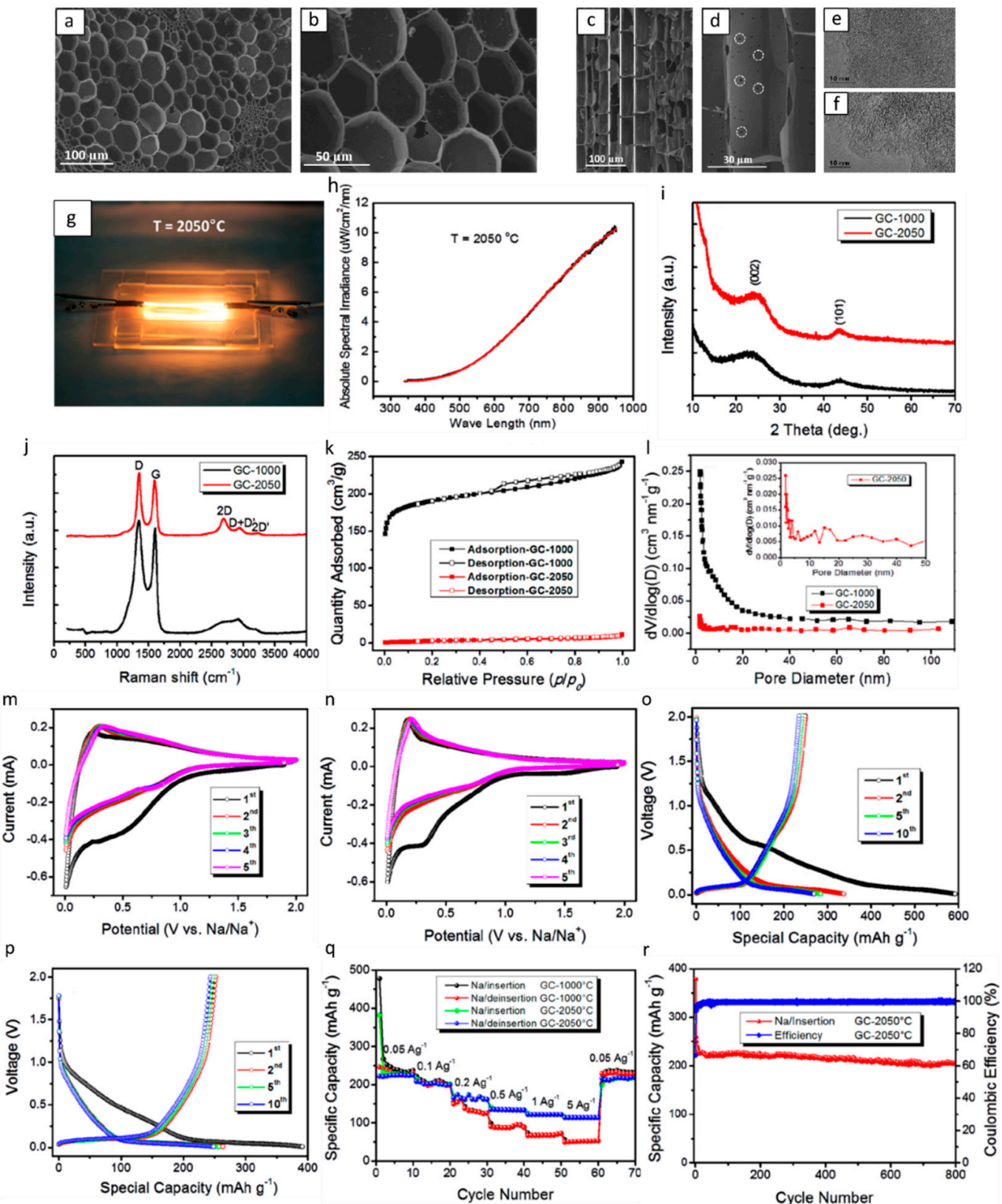

Figure 1. Structural characterization and electrochemical performance analysis of Hard Carbon (carbonized switchgrass, GC-1000 and GC-2050) as an anode in Sodium ion batteries (SIBs): (a) Low magnification SEM image from a cross section of GC-1000. (b) Corresponding higher magnification SEM image of GC-1000. (c) Low magnification SEM image from longitudinal section of GC-2050 where vertical lines are showing the array structure. (d) Higher magnification SEM image of GC-2050 where dashed circles highlight the micro/nanoscale holes for ion transport. (e,f) HRTEM (High-resolution transmission electron microscopy) images of GC-1000 and GC-2050. (g) Digital photograph of switchgrass derived carbon under Joule heating. (h) Light emission spectra of the carbonized switchgrass, here the temperature was fitted according to blackbody radiation equation. (i) XRD patterns of the GC-1000 (black) and Gc-2050 (red). Samples show identical twin broad peaks around $2 \theta=23.6^{\circ}$ and $43.6^{\circ}$, corresponding to the diffraction of graphitic layered structure. (j) Raman spectra of GC-1000 (black) and GC-2050 (red) confirmed the progressively ordered structure in the samples. (k,1) $\mathrm{N}_{2}$ adsorption/desorption isotherms and pore size distribution of GC-1000 and GC-2050, respectively. (m,n) Cyclic voltammogram (CV) curves for the first five cycles of GC-1000 and GC-2050, respectively at a scanning rate of $0.5 \mathrm{mV} \mathrm{s}^{-1}$. (o,p) Voltage profiles of GC-1000 and GC-2050 respectively at a current density of $50 \mathrm{~mA} \mathrm{~g}^{-1}$ in the potential range: $(0.01-2 \mathrm{~V})$. (q,r) Specific capacity, coulombic efficiency, and rate capability of GC-1000 and GC-2050 samples. Reprinted with permission from [48]. Copyright 2017 American Chemical Society. 
Table 1 lists the performance of several notable carbon-based anodes that have been used as anodes for Na-ion battery applications.

Table 1. High performance of carbon-based anodes in Na-ion battery systems.

\begin{tabular}{|c|c|c|c|c|}
\hline Type of Carbon Anode & Electrolyte Chemistry & $\begin{array}{c}\text { Voltage } \\
\text { Range (V) }\end{array}$ & Performance * & Reference \\
\hline Natural Graphite & $1 \mathrm{M} \mathrm{NaPF}_{6}$ in DEGDME (-) & $0.01-3.00$ & $150 / 2500 / 100$ & [53] \\
\hline $\begin{array}{l}\text { Carbon nanosheets derived } \\
\text { from peat moss }\end{array}$ & $1 \mathrm{M} \mathrm{NaClO}_{4}$ in EC/DEC (1:1) & $0.01-3.00$ & $255 / 210 / 100$ & [54] \\
\hline Soft Carbon & $1 \mathrm{M} \mathrm{NaPF}_{6}$ in EC/DEC (1:1) & $0.01-2.00$ & $114 / 300 / 1000$ & {$[33]$} \\
\hline $\begin{array}{c}\text { Nitrogen doped porous } \\
\text { carbon }\end{array}$ & $1 \mathrm{M} \mathrm{NaClO}_{4}$ in PC (-) & $0.01-3.00$ & $243 / 100 / 50$ & {$[55]$} \\
\hline Hollow carbon nanospheres & $1 \mathrm{M} \mathrm{NaClO}_{4}$ in $\mathrm{PC}(-)$ & $0.01-3.00$ & $160 / 100 / 100$ & [56] \\
\hline $\begin{array}{c}\text { Hard carbon } \\
\text { micro-spherules }\end{array}$ & $1 \mathrm{M} \mathrm{NaClO}_{4}$ in EC/DEC (1:1) & $0.01-3.00$ & $290 / 100 / 30$ & {$[57]$} \\
\hline $\begin{array}{l}\text { Wood fiber derived hard } \\
\text { carbon }\end{array}$ & $1 \mathrm{M} \mathrm{NaClO}_{4}$ in EC/DEC (1:1) & $0.01-2.5$ & $196 / 200 / 100$ & {$[58]$} \\
\hline Hard-soft composite carbon & $1 \mathrm{M} \mathrm{NaClO}_{4}$ in EC/DEC (1:1) & $0.01-2.5$ & $191 / 100 / 150$ & {$[59]$} \\
\hline $\begin{array}{l}\text { Hard carbon microtubes } \\
\text { (HCTs) }\end{array}$ & $0.8 \mathrm{M} \mathrm{NaPF}_{6}$ in $\mathrm{EC} / \mathrm{DMC}(1: 1)$ & $0.01-2.5$ & $305 / 100 / 30$ & {$[60]$} \\
\hline $\begin{array}{l}\text { Microstructure-controlled } \\
\text { amorphous carbon }\end{array}$ & $1 \mathrm{M} \mathrm{NaPF}_{6}$ in EC/DMC (1:1) & $0.01-3.00$ & $190 / 200 / 300$ & [61] \\
\hline
\end{tabular}

* Specific capacity $\left(\mathrm{mAh} \mathrm{g}^{-1}\right) /$ number of cycles/current density $\left(\mathrm{mA} \mathrm{g}^{-1}\right)$. DEGDME = Diethylene glycol dimethyl ether, $\mathrm{EC}=$ Ethylene carbonate, $\mathrm{DEC}=$ Diethyl carbonate, $\mathrm{PC}=$ Propylene carbonate, $\mathrm{DMC}=$ Dimethyl carbonate.

\subsection{Alloys}

Because of their high energy density and low redox potential, alloys have garnered considerable interest as anode materials for Na-ion batteries. Alloy-based materials can alloy with $\mathrm{Na}$ to form various Na-metal-alloy phases that contribute to higher capacities [19]. In 2011, Chevrier and Ceder reported that $\mathrm{Si}, \mathrm{Ge}, \mathrm{Sn}, \mathrm{Pb}$, and $\mathrm{Sb}$ could alloy with sodium and show theoretical capacities of 954, 369, 847, 485, and $660 \mathrm{mAh} \mathrm{g}^{-1}$, respectively [62]. However, $\mathrm{Si}$ was found to be nearly inactive with Na [63]. Further, the large volume expansion of the alloy anodes during the charge/discharge process can lead to poor cycle life, capacity fade, and degradation of the electrode coating [62]. A good binder, better nanostructures, and active material diluted with inactive materials are being incorporated to alloys to achieve cycling stability in Na-ion batteries [62,64]. During the last decade, researchers have started fabricating alloy based compounds for $\mathrm{Sn}, \mathrm{Sb}, \mathrm{Ge}, \mathrm{P}$, and some other elements from group IVA $(\mathrm{Pb}, \mathrm{Bi})$ with electrochemically inactive/active components, which help to alleviate volume variation during the charge/discharge processes and provide good cycleability [65-68].

\subsubsection{Sn-Based}

$\mathrm{Sn}$ is an attractive anode for Na-ion batteries, as it can provide a theoretical capacity of $\sim 850 \mathrm{mAh} \mathrm{g}^{-1}$ by forming $\mathrm{Na}_{15} \mathrm{Sn}_{4}$ [64,69]. In situ sodiation/desodiation TEM analysis of tin nanoparticles (80-400 nm) shows different phase transitions from amorphous $\mathrm{NaSn}_{2}$ to Na-rich amorphous phases, such as $\mathrm{aNa}_{9} \mathrm{Sn}_{4}$ and a-Na $\mathrm{Na}_{3} \mathrm{Sn}$, respectively. Crystalline $\mathrm{Na}_{15} \mathrm{Sn}_{4}$ is finally obtained after full sodiation [70]. However, the Sn particles expand by $420 \%$ after sodiation, thus reducing the cycling performance of the anode [42].

Hu et al. deposited thin film of Sn on a hierarchical wood fiber substrate and showed that the soft nature of the wood fibers releases the mechanical stresses associated with the electrochemical process. Moreover, their mesoporous structure works as an electrolyte reservoir [71]. They reported an initial discharge capacity of $339 \mathrm{mAh} \mathrm{g}^{-1}$ at a current density of $84 \mathrm{~mA} \mathrm{~g}^{-1}$ and $145 \mathrm{mAh} \mathrm{g}^{-1}$ after 400 cycles [71]. Liu et al. prepared ultra-small $\mathrm{Sn}$ nanoparticles $(\sim 8 \mathrm{~nm})$, homogenously embedding them in the spherical carbon network by the spray analysis method, and the as-prepared 8-Sn@C delivered an initial reversible capacity of $493.6 \mathrm{mAh} \mathrm{g}^{-1}$ at a current density of $200 \mathrm{~mA} \mathrm{~g}^{-1}$ and a stable capacity 
of $415 \mathrm{mAh} \mathrm{g}^{-1}$ after 500 cycles at $1000 \mathrm{~mA} \mathrm{~g}^{-1}$ [72]. According to the authors, the well-dispersed ultra-small Sn nanoparticles and the conductive carbon network contribute to the high performance of 8-Sn@C as anode in Na-ion batteries [72].

In addition, to alleviate the volume change, pipe-wire $\mathrm{TiO}_{2}-\mathrm{Sn} @$ carbon nanofibers $\left(\mathrm{TiO}_{2}-\mathrm{Sn} @ \mathrm{CNFs}\right)$, synthesized by electrospinning and atomic layer deposition, were analyzed as an anode in Na-ion batteries by Mao et al. [73]. A high reversible capacity of $413 \mathrm{mAh} \mathrm{g}^{-1}$ at $100 \mathrm{~mA} \mathrm{~g}^{-1}$ after 400 cycles was reported, which, according to the authors, was due to the formation of the amorphous $\mathrm{Na}_{x} \mathrm{Sn}$ phase during charge/discharge, thus allowing Sn particles well-proportioned volume expansion in Na-ion batteries [73]. Sha et al. studied Sn nanoparticles on a nitrogen-doped carbon nanofiber composite (Sn@NCNFs), synthesized by electrospinning [74]. The results of this study indicate that, because of the uniform distribution of Sn nanoparticles on the surface of the nitrogen-doped carbon nanofibers, the material delivered a high specific capacity of $600 \mathrm{mAh} \mathrm{g}^{-1}$ at a current density of $84.7 \mathrm{~mA} \mathrm{~g}^{-1}$ and maintained a capacity of $390 \mathrm{mAh} \mathrm{g}^{-1}$ at a high density of $847 \mathrm{~mA} \mathrm{~g}^{-1}$ over 1000 cycles [74]. Similarly, Pan et al. distributed Sn nanodots ( $3.2 \mathrm{~nm}$ ) in a sheet-like nitrogen-doped carbon framework (Sn@SNC) and reported a high mass loading up to $20 \mathrm{mg} \mathrm{cm}^{-2}$ with a reversible areal capacity of $1.0 \mathrm{mAh} \mathrm{cm} \mathrm{cm}^{-2}$ at $3 \mathrm{~mA} \mathrm{~cm}{ }^{-2}$ after 700 cycles [75].

Figure 2 demonstrates the important findings of Pan et al.'s work in greater detail [75]. Figure 2a-c shows the synthesis of hierarchically porous Sn@SNCs, which are beneficial for achieving high $\mathrm{Na}^{+}$ storage. The interconnected 3D microporous structure and uniform distribution of Sn nanodots are confirmed by SEM (Scanning Electronic Microscopy) and TEM (transmission electron microscopy) in Figure $2 \mathrm{~d}-\mathrm{i}$. Figure $2 \mathrm{j}-\mathrm{n}$ investigates the crystallinity and co-existence of metallic $\mathrm{Sn}$ and SNC using XRD (X-ray diffraction), Raman, and XPS. A broad peak in the range of $0.4-0.1 \mathrm{~V}$ is recognized in all cathodic scans in Figure 2o, corresponding to the insertion of $\mathrm{Na}^{+}$into the Sn nanodots. From the 10th cycle on, the coulombic efficiency remains unaltered (Figure 2p), demonstrating the high structural stability and sufficient conductivity of the Sn@SNC foams. The high mass loading $\mathrm{Na}^{+}$storage of the hierarchically porous Sn@SNC foams is displayed in Figure 2q-s, indicating efficient diffusion of $\mathrm{Na}^{+}$ through thick porous electrodes.

In general, reducing the particle size of $S n$ to the nanoscale effectively mitigates the pulverization of the electrode materials. Sn/carbon composites or carbon coated Sn show improved electrochemical performance compared to bare $\mathrm{Sn}$. The carbon matrix acts as a buffer for volume change and enhances the electrical conductivity. As an effective approach to alleviate the volume changes of Sn-based electrodes, electrically conductive CNT (carbon nanotube)-coated soft cellulose fibers are utilized to release the mechanical stress caused by the volume change of Sn during sodiation and desodiation, resulting in improved cycle performance. In addition, the porous nature of the substrates functions as a reservoir that helps in the ion transportation of electrolytes. Crystalline Sn/carbon composites formed by the carbonization of tin oxide nanoparticles and Sn nanoparticles dispersed in carbon nanofibers in an argon atmosphere have also been effective in reducing volume change and showing high capacity.

However, Sn/carbon composites and Sn nanoparticles embedded in carbon show poorer kinetics and rate performance in Na-ion batteries than Li-ion batteries. Therefore, optimized electrolytes need to be developed along with Sn-based materials to decrease their charge transfer resistance, which results from the formation of different solid electrolyte interphases (SEIs). 

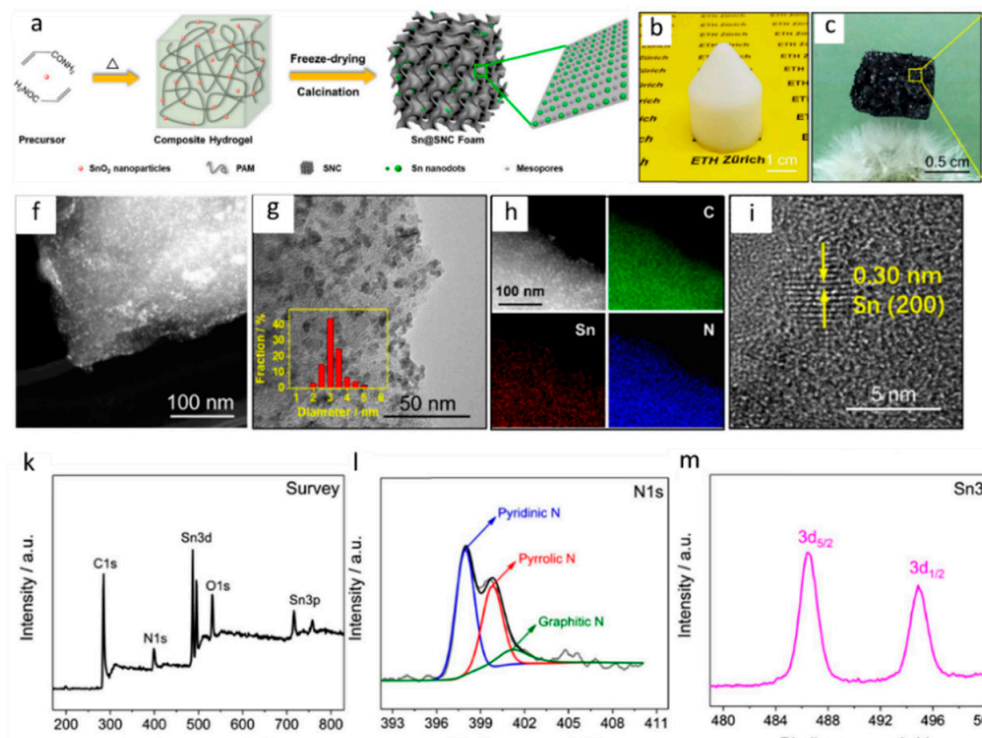

Binding energy $/ \mathrm{eV}$
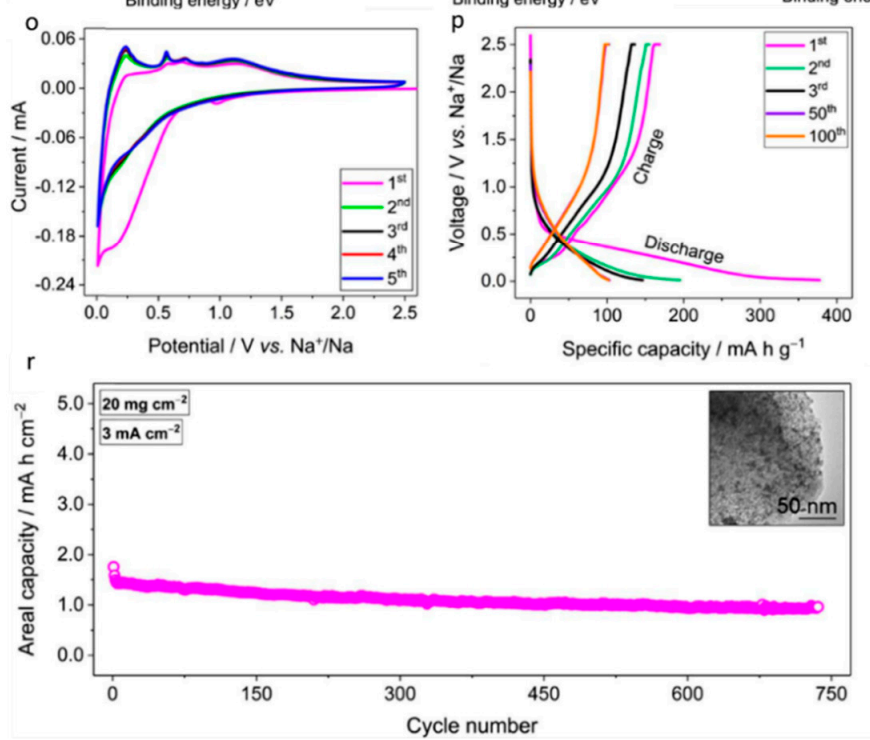

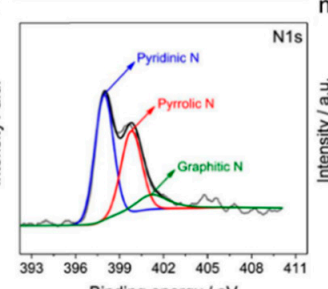

Binding energy / $\mathrm{eV}$
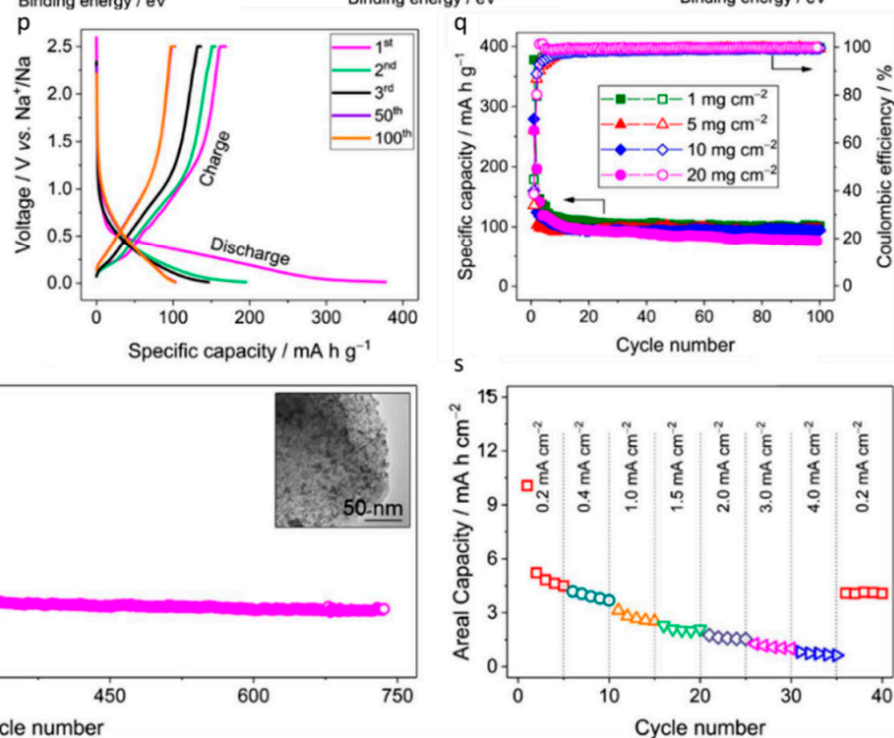

Figure 2. Structural characterization and electrochemical performance analysis of Sn-based alloy (Sn@SNC) as an anode in SIBs: (a) Synthetic procedure of Sn@SNC foam from $\mathrm{SnO}_{2}$ /polyacrylamide composite hydrogel. $(\mathbf{b}, \mathbf{c})$ Photographs of $\mathrm{SnO}_{2} / \mathrm{PAM}$ composite hydrogel and hierarchically porous Sn/SNC foams. (d,e) SEM image of Sn@SNC structures show a 3D interconnected microporous structure and confirm the sheet-like carbon structure. $(\mathbf{f}, \mathbf{g})$ STEM \& TEM images confirm the uniform distribution of Sn nanodots in the SNC. Inset shows the diameter of Sn nanodots are $\sim 3.2 \mathrm{~nm}$. (h) STEM with element mappings also confirm the homogenous distribution of the Sn nanodots throughout the SNC. (i) HRTEM image of Sn@SNC shows the lattice spacing of $0.30 \mathrm{~nm}$, distinctive to the (200) plane of metallic Sn. (j) XRD patterns of the Sn@SNC shows the co-existence of metallic Sn and amorphous SNC. (k-n) XPS survey spectrum demonstrates the presence of $\mathrm{C}, \mathrm{N}$, and $\mathrm{Sn}$, confirming the disordered structure and successful doping of N in SNC. (o) CV curves for the initial five cycles of Sn@SNC at a scanning rate of $0.1 \mathrm{mV} \mathrm{s}^{-1}$. (p) Voltage profiles of Sn@SNC at a current density of $100 \mathrm{~mA} \mathrm{~g}^{-1}$ delivering an initial discharge capacity of $377.6 \mathrm{mAh} \mathrm{g}^{-1}$ with $44.7 \%$ coulombic efficiency. (q) The Sn@SNC foams deliver a specific capacity of $101.8 \mathrm{mAh} \mathrm{g}^{-1}$ at a mass loading of $1 \mathrm{mg} \mathrm{cm}^{-2}$ after 100 cycles at a current density of $100 \mathrm{~mA} \mathrm{~g}^{-1}$. At a higher mass loading of $20 \mathrm{mg} \mathrm{cm}^{-2}$, the anode shows a capacity decrease of $25 \%$ with a specific capacity of $76.3 \mathrm{mAh} \mathrm{g}^{-1}$. (r) The Sn@SNC anode shows a good cycling ability, delivering a high reversible areal capacity of $1 \mathrm{mAh} \mathrm{cm}^{-2}$ at a current rate of $3 \mathrm{~mA} \mathrm{~cm}^{-2}$ after 700 cycles. (s) Rate capability of Sn@SNC foams (mass loading $=20 \mathrm{mg} \mathrm{cm}^{-2}$ ) at various current densities. A reversible areal capacity of $0.6 \mathrm{mAh} \mathrm{cm}^{-2}$ is achieved at a high current of $4 \mathrm{~mA} \mathrm{~g}^{-1}$. Reprinted with permission from [75]. Copyright 2018 Elsevier. 


\subsubsection{Sb-Based}

In addition to Sn, Antimony (Sb) is also a promising alloy anode for Na-ion batteries. Sb performs better as an anode in Na-ion batteries than in Li-ion batteries, which is believed to be due to the formation of an amorphous intermediate phase of $\mathrm{Na}_{3} \mathrm{Sb}[19,76]$. Allan et al. used operando pair distribution function (PDF) analysis and ex situ ${ }^{23} \mathrm{Na}$ magic-angle spinning solid-state nuclear magnetic resonance (MAS ssNMR) to explain the alloying mechanism of high capacity SB anodes for Na-ion batteries [77]. The authors identified two intermediate species: a- $\mathrm{Na}_{(3-\mathrm{x})} \mathrm{Sb}(\mathrm{x}=0.4-0.5)$, with a significant number of $\mathrm{Na}$ vacancies and $\mathrm{a}-\mathrm{Na}_{3} \mathrm{Sb}$, with a highly amorphous structure. According to the authors, sodium mobility within c-Na $\mathrm{Na}_{3} \mathrm{Sb}$ leads to the excellent rate capability of $\mathrm{Sb}$ anodes [77].

To overcome the volume changes during the charge/discharge process, Zhu et al. synthesized freestanding electrospun $\mathrm{Sb}-\mathrm{C}$ nanofiber mats (SbNP@C) without any binder, carbon black, or current collector [78]. This study found that SbNP@C can deliver an initial capacity of $422 \mathrm{mAh} \mathrm{g}^{-1}$ and could be sustained $350 \mathrm{mAh} \mathrm{g}^{-1}$ after 300 cycles at a current density of $100 \mathrm{~mA} \mathrm{~g}^{-1}$ [78]. Similarly, Wu et al. synthesized $\mathrm{Sb}-\mathrm{C}$ nanofibers through a single-nozzle electrospinning technique and calcination, where the $\mathrm{Sb}$ particles were distributed homogenously in the carbon nanofibers [79]. The authors reported that $\mathrm{Sb}-\mathrm{C}$ nanofiber electrode as anode material of $\mathrm{Na}$-ion batteries can deliver a high reversible capacity of $631 \mathrm{mAh} \mathrm{g}^{-1}$ at a current density of $40 \mathrm{~mA} \mathrm{~g}^{-1}$, good rate capability of $337 \mathrm{mAh} \mathrm{g}^{-1}$ at $3 \mathrm{~A} \mathrm{~g}^{-1}$, as well as cycling stability ( $446 \mathrm{mAh} \mathrm{g}^{-1}$ at $200 \mathrm{~mA} \mathrm{~g}^{-1}$ after 400 cycles, showing a capacity retention of 90\%) [79].

Zhao et al. dispersed ultrafine $\mathrm{Sb}$ nanoparticles in the Nitrogen-rich 3D conductive carbon network structure solving the problems of pulverization, loss of electrical contact and low utilization rate [80]. This study showed that, the full cell $\mathrm{Na}_{3} \mathrm{~V}_{2}\left(\mathrm{PO}_{4}\right)_{3} @ \mathrm{C} / / \mathrm{C} @ S b$ had high output potential of $2.75 \mathrm{~V}$ and a discharge capacity of $264.3 \mathrm{mAh} \mathrm{g}^{-1}$ at $1 \mathrm{~A} \mathrm{~g}^{-1}$ after 500 cycles [80]. Cui et al. utilized Sb nanorods encapsulated into highly conductive $\mathrm{N}$ and $\mathrm{S}$ codoped carbon frameworks $(\mathrm{Sb} @(\mathrm{~N}, \mathrm{~S}-\mathrm{C})$ ) as an anode for Na-ion batteries and demonstrated that the $\mathrm{Sb} @(\mathrm{~N}, \mathrm{~S}-\mathrm{C})$ anode can display a high discharge capacity of $812.7 \mathrm{mAh} \mathrm{g}^{-1}$ at $100 \mathrm{~mA} \mathrm{~g}^{-1}$ and maintain a reversible capacity of $390.8 \mathrm{mAh} \mathrm{g}^{-1}$ after 1000 cycles at a high current of $1 \mathrm{~A} \mathrm{~g}^{-1}$ [81]. The authors ascribed these impressive properties to the unique cross-linked carbon networks that provide highly conductive frameworks for fast ion transport and prevents the agglomeration of Sb nanorods during the electrochemical process [81].

Overall these studies highlight the beneficial aspects of $\mathrm{Sb}$ nanostructures well-dispersed in carbon frameworks, improving the performance of an $\mathrm{Sb}$ anode in Na-ion batteries by reducing the volume expansion and providing good electrical conductivity. As has been shown for $\mathrm{Sn}$, Sb-based compounds with carbon can suppress the deformation of alloy materials and enhance electrochemical performance. Further, it is important to find an optimized electrolyte for an electrode material with a large volume change to improve electrochemical performance.

A summary of Cui et al.'s results is presented in Figure 3, which is representative of the performance of Sb-based anodes in high performance Na-ion batteries [81]. Figure 3a-d shows Sem and TEM images of the Sb@(N, S-C). The "silk-like" carbon networks in the Sb@(N, S-C)-2 hybrid are distributed around the $\mathrm{Sb}$ nanorods, which can be regarded as a highly conductive bridge for each Sb@C nanorod. the elemental mappings of $\mathrm{Sb} @(\mathrm{~N}, \mathrm{~S}-\mathrm{C})-2$ in Figure 3e-i confirm the uniform distribution of N, S, $\mathrm{C}$, and $\mathrm{Sb}$, in the Sb@(N, S-C)-2 hybrid. The uniform distribution of N, S, C, and Sb are further confirmed by XRD, Raman, and XPS in Figure 3j-m. Figure 3n shows the initial five cycles of the cyclic voltammogram $(\mathrm{CV})$ curves of $\mathrm{Sb}(\mathrm{N}, \mathrm{S}-\mathrm{C})-2$ at a scan rate of $0.1 \mathrm{mV} \mathrm{s}^{-1}$ between 0.01 and $2.50 \mathrm{~V}$. During the first cathodic scan, a sharp peak at $\sim 0.27 \mathrm{~V}$ is clearly observed, which can be ascribed to the alloy of $\mathrm{Sb}$ with $\mathrm{Na}$ forming $\mathrm{Na}_{x} \mathrm{Sb}$. Figure 30 displays the galvanostatic charge/discharge curves of the $\mathrm{Sb} @(\mathrm{~N}, \mathrm{~S}-\mathrm{C})-2$ at a current density of $100 \mathrm{~mA} \mathrm{~g}^{-1}$, in a voltage range of $0.01-2.50 \mathrm{~V}$. In Figure 3p, the $\mathrm{Sb} @(\mathrm{~N}, \mathrm{~S}-\mathrm{C})-2$ electrodes at different states of charge/discharge are analyzed using in situ XRD. As shown in the figure, the intensities of the three main $\mathrm{Sb}$ peaks become weaker in subsequent cycles, demonstrating how amorphous $\mathrm{Sb}$ is accumulated during the sodiation-desodiation cycles. Figure $3 \mathrm{q}$ shows the cycleability of the sample at a current density of $1 \mathrm{~A} \mathrm{~g}^{-1}$. After 1000 cycles, the sample retains a reversible capacity of $390.8 \mathrm{mAh} \mathrm{g}^{-1}$. 

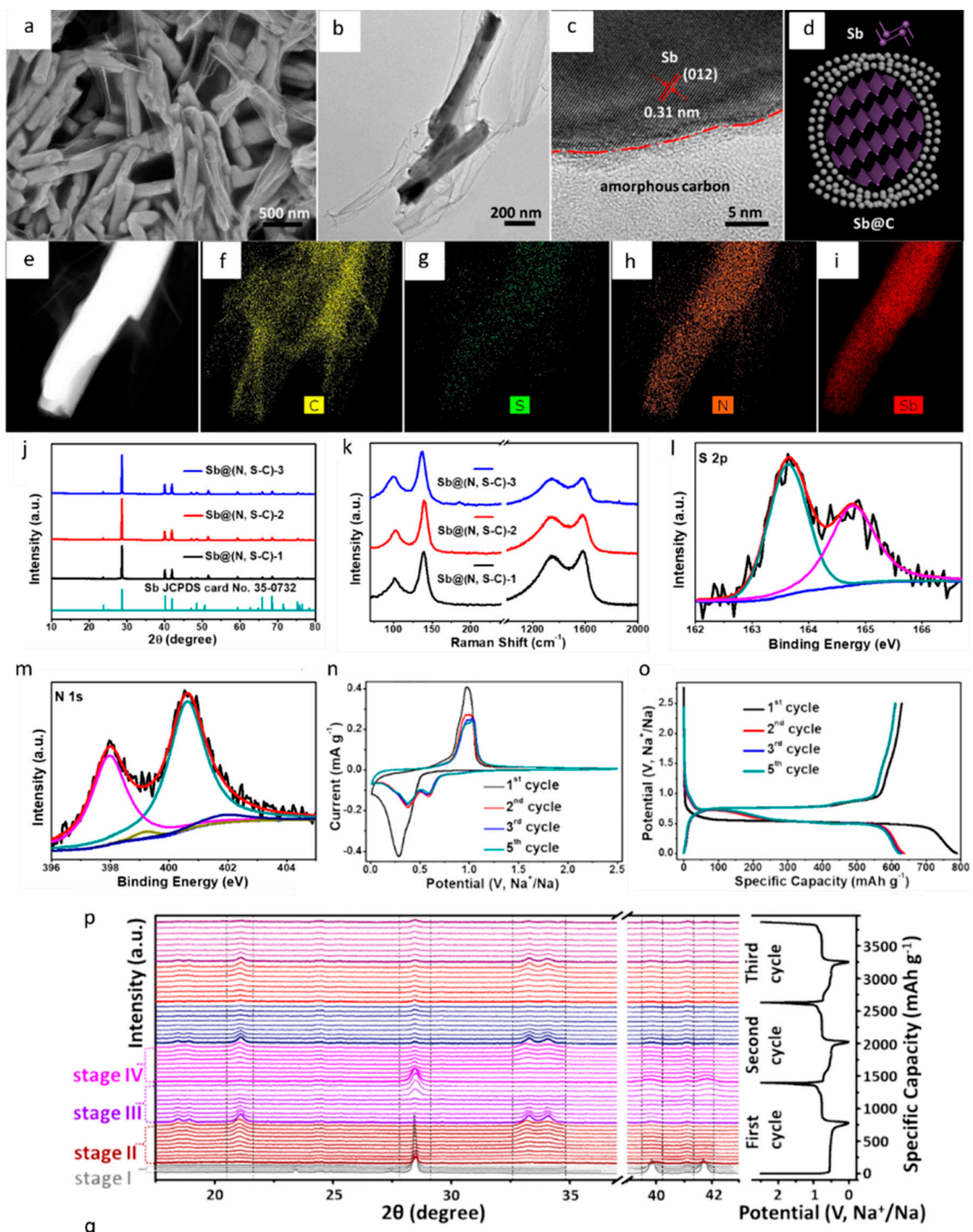

q
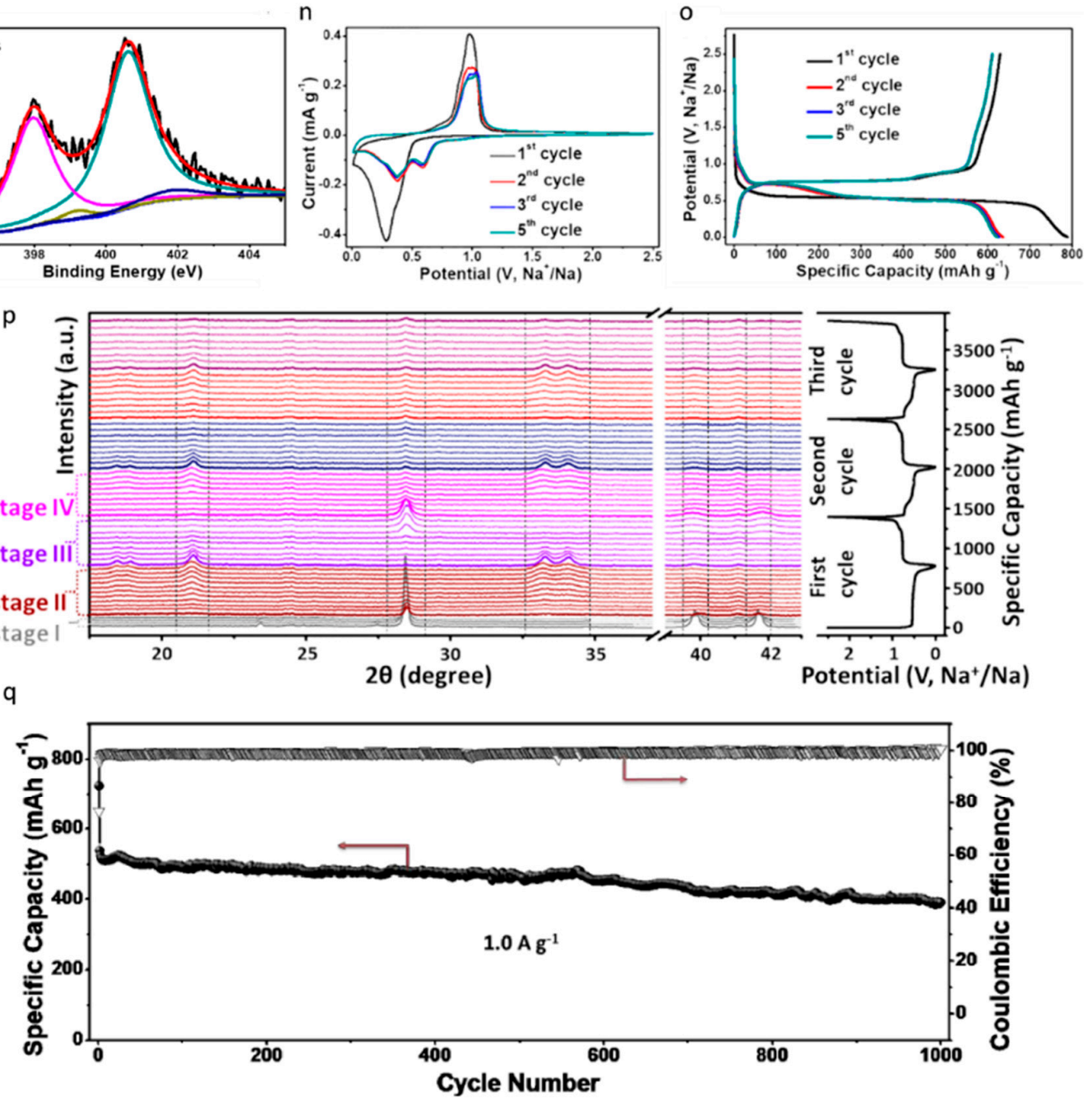

Figure 3. Structural characterization and electrochemical performance analysis of Sb-based alloy $(\mathrm{Sb} @(\mathrm{~N}, \mathrm{~S}-\mathrm{C}))$ as an anode in SIBs: (a) SEM image of Sb@(N, S-C)-2. (b) TEM image of Sb@(N, S-C)-2 
shows Sb nanorod diameter (120-160 nm). (c) HRTEM image of Sb@(N, S-C)-2 reveals the amorphous carbon and clear lattice corresponding to the plane (012) of Sb. (d) Schematic representation of Sb@(N, S-C)-2. (e-i) Elemental mapping of Sb@(N, S-C)-2 confirm the uniform distribution of C, S, N, and $\mathrm{Sb}$ in $\mathrm{Sb} @(\mathrm{~N}, \mathrm{~S}-\mathrm{C})-2$ hybrid. (j) XRD patterns of the $\mathrm{Sb}(\mathrm{N}, \mathrm{S}-\mathrm{C})-1$ (black), Sb@(N, S-C)-2 (red), and $\mathrm{Sb}(\mathrm{N}, \mathrm{S}-\mathrm{C})-2$ (blue) reveal the hexagonal structured Sb. (k) Raman spectra display the typical Sb signals $\left(\sim 101\right.$ and $\sim 138 \mathrm{~cm}^{-1}$ ) and Carbon (D-band $\sim 1343 \mathrm{~cm}^{-1}$ and G-band $\left.\sim 1581 \mathrm{~cm}^{-1}\right)$. (1,m) XPS spectra of the Sb@(N, S-C)-2 Show the characteristic S 2p3/2 at $\sim 161.7 \mathrm{eV}$ and S 2p1/2 at $\sim 162.9$, which are assigned to -C-S-C- covalent bond. In addition, the existence of pyridinic $\mathrm{N}$ at $\sim 398.0$, pyrrolic $\mathrm{N}$ at $\sim 400.7$, and graphitic $\mathrm{N}$ at $\sim 401.9 \mathrm{eV}$ is also confirmed in the XPS peaks of $\mathrm{Sb} @(\mathrm{~N}, \mathrm{~S}-\mathrm{C})-2$. (n) CV curves for the first five cycles of $\mathrm{Sb} @(\mathrm{~N}, \mathrm{~S}-\mathrm{C})-2$ at a scanning rate of $0.1 \mathrm{mV} \mathrm{s}^{-1}$. (o) Voltage profiles of Sb@(N, $\mathrm{S}-\mathrm{C})-2$ at a current density of $100 \mathrm{~mA} \mathrm{~g}^{-1}$ in the potential range: $(0.01-2.50 \mathrm{~V})$. The capacity loss in the first cycle is attributed to the SEI film formation. (p) In situ XRD measurements of Sb@(N, S-C)-2 for initial three cycles indicates the sodiation of $\mathrm{Sb}$ follows the mechanism of $\mathrm{Sb} \rightarrow \mathrm{Na}_{\mathrm{x}} \mathrm{Sb} \rightarrow \mathrm{Na}_{3} \mathrm{Sb} \rightarrow \mathrm{Sb}$. $(\mathbf{q}, \mathbf{r})$ Specific capacity and coulombic efficiency of Sb@(N, S-C)-2 sample at $1 \mathrm{~A} \mathrm{~g}^{-1}$. Reprinted with permission from [81]. Copyright 2019 American Chemical Society.

\subsubsection{Ge-Based}

Recently, Ge is being studied as a promising anode material for Na-ion batteries, as Ge has shown high lithium storage capacity and high lithium diffusivity [82,83]. However, Stojić et al. showed that $\mathrm{Na}$ diffusion in crystalline $\mathrm{Ge}$ is several orders of magnitude slower than lithium diffusion in germanium $[84,85]$. Abel et al. showed that using nanocolumnar germanium thin films, synthesized by evaporative deposition, can cause faster diffusion in sodium [84]. They were able to achieve a high initial sodium storage capacity of $430 \mathrm{mAh} \mathrm{g}^{-1}$, and $88 \%$ of this capacity was retained after 100 cycles at a current density of $74 \mathrm{~mA} \mathrm{~g}^{-1}$. In addition, the nanocolumnar germanium exhibited a high rate capability of $164 \mathrm{mAh} \mathrm{g}^{-1}$ at $10 \mathrm{~A} \mathrm{~g}^{-1}$. Comparing the dense germanium film with nanocolumnar germanium. From the ab initio molecular dynamics simulations, the authors suggested that nanoscale dimensions are essentially stable, and a high rate capability of germanium can be observed in Na-ion batteries [84].

To overcome the large volume change during charge/discharge, Wang et al. synthesized germanium@graphene@ $\mathrm{TiO}_{2}$ core-shell nanofibers (Ge@G@ $\mathrm{TiO}_{2} \mathrm{NFs}$ ) as an anode for Na-ion batteries through electrospinning and atomic layer deposition [86]. This Ge@G@ $\mathrm{TiO}_{2}$ NFs material, as an anode, showed an initial capacity of $368 \mathrm{mAh} \mathrm{g}^{-1}$ at a current density of $100 \mathrm{~mA} \mathrm{~g}^{-1}$ and retained $182 \mathrm{mAh} \mathrm{g}^{-1}$ after 250 cycles. According to the authors, graphene could naturally accommodate the volume change to release the stress in germanium, offer chemical stability, and provide more active site for sodium ion insertion. On the other hand, SEI accumulated on $\mathrm{TiO}_{2}$ on the outer surface instead of the Ge nanoparticles, thus increasing the stability of the anode [86].

\subsubsection{P Based}

Phosphorous $(\mathrm{P})$ has gained attention as a non-metallic anode material in Na-ion batteries because it exhibits a theoretical capacity of $\sim 2600 \mathrm{mAh} \mathrm{g}^{-1}$ by forming $\mathrm{Na}_{3} \mathrm{P}$ compounds with a redox potential of $0.4 \mathrm{~V}$ vs. $\mathrm{Na}^{+} / \mathrm{Na}[87,88]$. Kim et al. showed that the electrochemical performance of amorphous red phosphorous was dependent on volume expansion and electrical conductivity [89]. P has a low electrical conductivity of $10^{-14} \mathrm{~S} \mathrm{~cm}^{-1}$. The authors reported that obtaining red phosphorous/carbon composite powders by a simple ball milling process can provide a high specific capacity of $1890 \mathrm{mAh}^{-1}$, at $73 \%$ of the theoretical capacity [89]. Nearly at the same time, Qian et al. reported an amorphous phosphorous/carbon $(\mathrm{a}-\mathrm{P} / \mathrm{C})$ nanocomposite, synthesized by high-energy ball milling at an optimized ratio of 7:3 and showed a reversible capacity of $1764 \mathrm{mAh} \mathrm{g}^{-1}$ with a first cycle coulombic efficiency of $87 \%$, at a current density of $250 \mathrm{~mA} \mathrm{~g}^{-1}$ [88]. The authors showed that adding $10 \%$ fluoroethylene 
carbonate (FEC) in the electrolyte to enhance the stability of the SEI film on the anode can deliver $\sim 1000 \mathrm{mAh} \mathrm{g}^{-1}$ after 140 cycles.

Hollow nanoporous red phosphorous (HNPRP) with a little amount of iodine doping was synthesized by Liu et al. and utilized as an anode for Na-ion batteries [90]. The HNPRP electrode delivered a high capacity of $1658.2 \mathrm{mAh} \mathrm{g}^{-1}$ at a current density of $260 \mathrm{~mA} \mathrm{~g}^{-1}$ and an ultralong cycling ability generating $857.3 \mathrm{mAh} \mathrm{g}^{-1}$ at $2600 \mathrm{~mA} \mathrm{~g}^{-1}$ after 1000 cycles. The authors attributed this result to the hollow nanoporous structure that provides fast electronic transport and Na-ion accessibility [90]. Yao et al. also synthesized hollow porous carbon nanospheres with vaporization-condensation process to achieve low volume expansion and high sodium storage [91]. They reported a long cycle life of 1000 cycles with $548 \mathrm{mAh} \mathrm{g}^{-1}$ at $1000 \mathrm{mAh} \mathrm{g}^{-1}$ and a high reversible capacity of $1915 \mathrm{mAh} \mathrm{g}^{-1}$ at a current rate of $100 \mathrm{~mA} \mathrm{~g}^{-1}$ [91].

Very recently, Jin et al. proposed a ternary composite of black phosphorous (BP), graphite, and polyaniline, containing $65 \mathrm{wt} . \%$ of black phosphorous [92]. This BP based ternary composite provided an optimized ion pathway (electrolyte $\rightarrow$ polyaniline (PANI) $\rightarrow$ black phosphorous-graphite (BP-G) $\rightarrow$ $\mathrm{BP})$, which reduced the charge transfer resistance and allowed a higher sodiation/desodiation. This ternary composite showed a reversible gravimetric composite of $1530 \mathrm{mAh} \mathrm{g}^{-1}$ at a current density of $250 \mathrm{~mA} \mathrm{~g}^{-1}$ and a capacity retention of $520 \mathrm{mAh} \mathrm{g}^{-1}$ at a high current density of $4 \mathrm{~A} \mathrm{~g}^{-1}$ after 1000 cycles [92].

Figure 4 includes the important findings of Jin et al.'s work in details [92]. Figure 4a shows different steps in the fabrication of a ternary black phosphorous-graphite-PANI composite, where PANI offers a Na-ion pathway and the graphite reduces the ion charge transfer resistance. Raman and XRD confirm that BP remains intact in the composite in Figure $4 b$,c. In Figure $4 d-i$, the microstructure of the composite is characterized, and even the distribution of $\mathrm{C}, \mathrm{P}$, and $\mathrm{N}$ are shown by the HRTEM and TEM mappings. The function of graphite and PANI in the BP-based composite have been analyzed using ex-situ XAS (X-ray absorption spectroscopy) spectra and cross-sectional SEM images in Figure $4 j-n$. Figure 40 shows the voltage profiles of BP-G/PANI at different current densities in the range of $0.25-4 \mathrm{~A} \mathrm{~g}^{-1}$ within the voltage window of $0.01-2 \mathrm{~V}\left(\mathrm{vs} . \mathrm{Na} / \mathrm{Na}^{+}\right)$. The reversible capacity of BP-G/PANI is $2350 \mathrm{mAh} \mathrm{g}^{-1}$ in terms of BP mass, which corresponds to $90 \%$ BP utilization and delivers a capacity of $690 \mathrm{mAh} \mathrm{g}^{-1}$ at a higher current density of $4 \mathrm{~A} \mathrm{~g}^{-1}$ (Figure 4p). Similar measurements carried out for BP and BP-G electrodes as shown in Figure 4q, which shows that the reversible capacity of BP-G/PANI is almost contributed by the BP. Figure $4 \mathrm{r}$ proves the ultrastable cyclic capability of BP-G/PANI at a high rate of $4 \mathrm{~A} \mathrm{~g}^{-1}$ for 1000 cycles.

In general, therefore, it seems that high energy mechanical milling and vaporization-condensation strategies are effective processes. Phosphorous-Carbon nanostructures are well preserved and provide fast Na-ion accessibility, which leads to higher cycling performance. However, the higher the loading of $\mathrm{P}$, the higher the capacity. On the other hand, the high interlayer size of black phosphorous provides high intercalation of $\mathrm{Na}$ ions. Further, the conductive properties of black phosphorous $\left(\sim 300 \mathrm{~S} \mathrm{~m}^{-1}\right)$ promote electron transport within the composite.

\subsubsection{Other Alloys}

To date, outside of $\mathrm{Sn}, \mathrm{Sb}$, and $\mathrm{Ge}$, metal alloys have not been commonly utilized as anode materials for Na-ion batteries [93-95]. Among them, Bi-based alloys have shown promising properties. Wang et al. showed that bulk Bi coupled with glyme-based electrolytes can achieve $400 \mathrm{mAh} \mathrm{g}^{-1}$ at a current density of $50 \mathrm{~mA} \mathrm{~g}^{-1}$, and the capacity retention was $94.4 \%$ after 2000 cycles with $389 \mathrm{mAh} \mathrm{g}^{-1}$ at $400 \mathrm{~mA} \mathrm{~g}^{-1}$ [96]. This study showed that the bulk Bi electrode can gradually become porous during initial cycling, thus ensuring facile $\mathrm{Na}^{+}$transport and structural stability, which was in contrast with the $\mathrm{Na}^{+}$transport and structural stability in carbonate-based electrolytes [96]. Recently, encapsulated Bi spheres with a conductive porous $\mathrm{N}$-doped carbon shell (Bi@N-C) anode were synthesized by Yang et al. [97]. This Bi@N-C anode in Na-ion batteries exhibited an initial charge capacity of $327 \mathrm{mAh} \mathrm{g}^{-1}$ at $1 \mathrm{~A} \mathrm{~g}^{-1}$ and a high cycling capability of $235 \mathrm{mAh} \mathrm{g}^{-1}$ after 2000 cycles at $10 \mathrm{~A} \mathrm{~g}^{-1}$ [97]. 

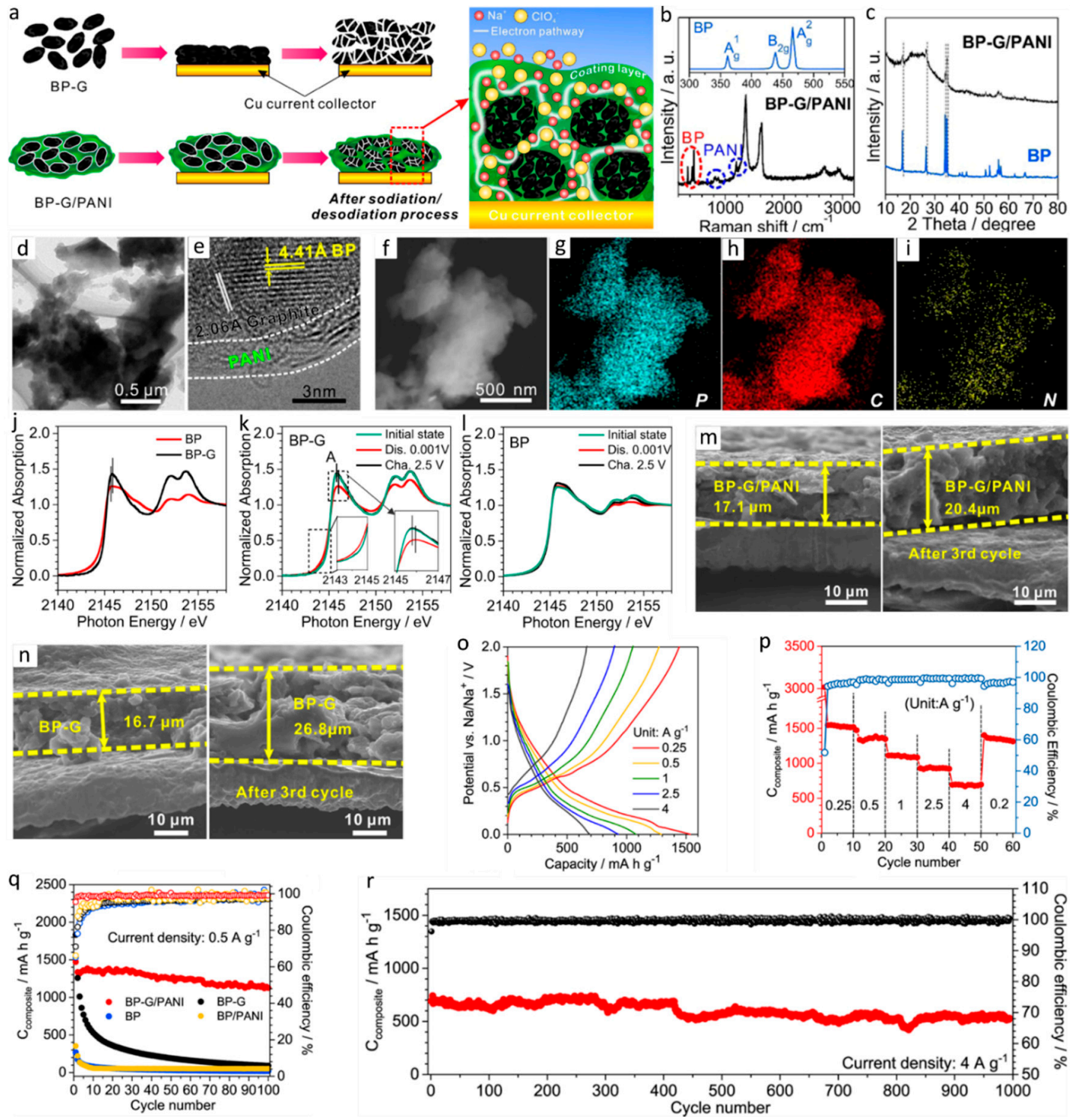

Figure 4. Structural characterization and electrochemical performance analysis of P-based anode (BP-G/PANI) in SIBs: (a) Schematic representation of sodiation process of black phosphorous-graphite (BP-G) and black phosphorous-graphite with polyaniline (BP-G/PANI). (b) Raman spectra shows the feature peaks of BP, graphite, and PANI. (c) XRD patterns show the characteristic diffraction peaks for BP at $2 \theta$ values of $16.8,26.5,34.1$, and $34.9^{\circ}$, a broad peak for PANI at $\sim 22^{\circ}$. Raman spectra and XRD patterns confirm that BP particles remain intact in the BP-G/PANI composite. (d) TEM image and (e) HRTEM image of BP-G/PANI characterize the micro-structure. TEM and HRTEM image confirm that the BP particle are well coated with PANI. (f-i) TEM mappings of BP-G/PANI confirm the uniform distribution of P, C, and N in BP-G/PANI. (j) X-Ray absorption spectra of P state in BP and BP-G shows higher absorption edge in BP-G corresponding to higher charge transfer. (k,l) Ex situ XAS of P K-edge of BP-G and BP indicate the formation NA $\mathrm{NA}_{\mathrm{x}} \mathrm{P}$ by sodiation in BP-G. $(\mathbf{m}, \mathbf{n})$ Cross-sectional SEM images of BP-G/PANI electrode and BP-G electrode show that PANI coatings attenuate the volume changes in electrode, providing a long cycling ability for BP-G/PANI. (o) The voltage profiles of BP-G/PANI at different current densities in the potential range: $(0.01-2.00 \mathrm{~V})$. The capacity loss in the first cycle is attributed to the SEI film formation. (p) Rate capability test of BP-G/PANI anode shows that it can deliver $690 \mathrm{mAh} \mathrm{g}^{-1}$ (45\% capacity retention) at high current rate of $4 \mathrm{~A} \mathrm{~g}^{-1}$. (q) The cycling stability and coulombic efficiency of BP, BP-G, BP-G/PANI at $0.5 \mathrm{~A} \mathrm{~g}^{-1}$ show that the reversible capacity of BP-G/PANI is mostly contributed by BP. (r) The cycling ability and coulombic efficiency of BP-G/PANI anode at $4 \mathrm{~A} \mathrm{~g}^{-1}$ show that it can deliver a reversible capacity $520 \mathrm{mAh} \mathrm{g}^{-1}$ after 1000 cycles. Reprinted with permission from [92]. Copyright 2019 American Chemical Society. 
Intermetallic composite anodes have also been investigated and show promising performance as anodes for Na-ion batteries. For instance, Ji et al. reported using porous carbon nanofiber supported $\mathrm{SnSb}$ nanocomposites as anodes for Na-ion batteries [98]. They showed that presence of fluoroethylene carbonate (FEC) improved the kinetics of $\mathrm{Na}$ ions and delivered a high reversible capacity of $350 \mathrm{mAh} \mathrm{g}^{-1}$ at a current density of $100 \mathrm{~mA} \mathrm{~g}^{-1}$ and a capacity retention of $99.4 \%$ for more than 200 cycles [98].

Liu et al. fabricated a yolk-shell structure for a high capacity and electrochemically stable $\mathrm{Sn}_{4} \mathrm{P}_{3}$ electrode surrounded by a thin carbon shell [99]. According to the authors, the void space between the $C$ shell and $\mathrm{Sn}_{4} \mathrm{P}_{3}$ nanoparticles allowed volume expansion without deforming the structure. Due to this unique structure, the $\mathrm{Sn}_{4} \mathrm{P}_{3} @ \mathrm{C}$ nanoparticles delivered a high reversible capacity of $790 \mathrm{mAh} \mathrm{g}^{-1}$ at a current density of $100 \mathrm{~mA} \mathrm{~g}^{-1}$ and were stable after 400 cycles, delivering $360 \mathrm{mAh} \mathrm{g}$ at $1500 \mathrm{~mA} \mathrm{~g}^{-1}$ [99].

$\mathrm{Li}$ et al. presented a carbon coated $\mathrm{Mo}_{3} \mathrm{Sb}_{7}$ composite $\left(\mathrm{Mo}_{3} \mathrm{Sb}_{7} @ \mathrm{C}\right)$ as an anode material for Na-ion batteries [100]. This study showed that $\mathrm{Mo}_{3} \mathrm{Sb}_{7} @ \mathrm{C}$ had an initial capacity of $400 \mathrm{mAh} \mathrm{g}^{-1}$ at $98.8 \mathrm{~mA} \mathrm{~g}^{-1}$ and maintained $338 \mathrm{mAh} \mathrm{g}^{-1}$ at $247 \mathrm{~mA}^{-1}$ after 800 cycles with a capacity retention of $91.8 \%$ [100].

Nanostructured iron distannide $\left(\mathrm{FeSn}_{2}\right)$-graphite composite was fabricated by Edison et al., and the influence of graphite concentration was studied for Na storage [101]. This composite $\mathrm{FeSn}_{2}-\mathrm{Gr}$ composite delivered a sodiation capacity of over $400 \mathrm{mAh} \mathrm{g}^{-1}$ at a current density of $100 \mathrm{~mA} \mathrm{~g}^{-1}$ and showed a high rate capability of $\sim 200 \mathrm{mAh} \mathrm{g}^{-1}$ at high current of $1 \mathrm{~A} \mathrm{~g}^{-1}$ [101].

In the recent past, Gao et al. fabricated a nanoporous bismuth-antimony alloy $\left(\mathrm{Bi}_{2} \mathrm{Sb}_{6}\right)$ and tested it as an anode. This $\mathrm{Bi}_{2} \mathrm{Sb}_{6}$ alloy demonstrated an excellent cycling performance of 10,000 cycles at $1 \mathrm{~A} \mathrm{~g}^{-1}$ with a capacity retention of only $0.0072 \%\left(\sim 150 \mathrm{mAh} \mathrm{g}^{-1}\right)$ [102]. The authors attributed the high performance of the $\mathrm{Bi}_{2} \mathrm{Sb}_{6}$ to the porous structure of the alloy and the proper $\mathrm{Bi} / \mathrm{Sb}$ atomic ratio. The authors also presented a sodiation process $\left((\mathrm{Bi}, \mathrm{Sb}) \rightarrow \mathrm{Na}(\mathrm{Bi}, \mathrm{Sb}) \rightarrow \mathrm{Na}_{3}(\mathrm{Bi}, \mathrm{Sb})\right)$ during the charge/discharge of the $\mathrm{Bi}_{2} \mathrm{Sb}_{6}$ alloy, using operando $\mathrm{X}$-ray diffraction and density functional theory calculations [102]. The main results of this work are shown in Figure 5 as a representative example of the bimetallic anode's high performance in Na-ion batteries. The scanning electron microscopy (SEM) images (Figure 5a-c) show that all three np-Bi-Sb samples exhibit typical three-dimensional bicontinuous ligament-channel structures. Transmission electron microscopy (TEM) is used to further confirm the nanoporous feature of the np-Bi-Sb (Figure $5 \mathrm{~d}-\mathrm{f}$ ), which are in good agreement with the SEM results. In Figure 5g, the XRD patterns of the three samples are indexed to the single phase of $\mathrm{BiSb}$ alloy, while the minor shifts of the peaks are attributed to the compositional difference between $\mathrm{Bi}$ and $\mathrm{Sb}$. Figure $5 \mathrm{~h}$ shows the Cyclic Voltammetry. In the first cathodic scan, one board peak at $0.69 \mathrm{~V}$ (vs. Na/Na ${ }^{+}$) and a strong broad peak at $0.20 \mathrm{~V}\left(\mathrm{vs} . \mathrm{Na} / \mathrm{Na}^{+}\right.$) can be seen. These values are attributed to the formation of a solid electrolyte interphase (SEI) film and the two-step alloying processes of (Bi, $\mathrm{Sb}) \rightarrow \mathrm{Na}(\mathrm{Bi}, \mathrm{Sb}) \rightarrow \mathrm{Na}_{3}(\mathrm{Bi}, \mathrm{Sb})$, respectively. Figure 5 i shows the galvanostatic discharge-charge curves of the $n p-\mathrm{Bi}_{2} \mathrm{Sb}_{6}$ electrode in different cycles at a current density of $200 \mathrm{~mA} \mathrm{~g}^{-1}$ over a potential window of $0.01-2.0 \mathrm{~V}$ (vs. Na/ $\mathrm{Na}^{+}$). Overlapping of the voltage profiles of the 1600th and 2000th cycles proves excellent cycle stability. Figure $5 \mathrm{j}$ demonstrates the comparison of cycling performances of the np- $\mathrm{Bi}_{2} \mathrm{Sb}_{6}$ with the np- $\mathrm{Bi}_{4} \mathrm{Sb}_{4}, \mathrm{np}-\mathrm{Bi}_{6} \mathrm{Sb}_{2}, \mathrm{np}-\mathrm{Bi}$, and np-Sb electrodes. The rate capability of the np-Bi-Sb electrodes at different current densities are shown in Figure 5k. After 10,000 cycles, the $\mathrm{np}-\mathrm{Bi}_{2} \mathrm{Sb}_{6}$ electrode still retains a moderate discharge capacity of $\sim 150 \mathrm{mAh} \mathrm{g}^{-1}$ (Figure $5 \mathrm{l}$ ). The phase evolution of the $\mathrm{np}-\mathrm{Bi}_{4} \mathrm{Sb}_{4}$ electrode is investigated by the operando XRD technique during the initial discharge-charge processes at $25 \mathrm{~mA} \mathrm{~g}^{-1}$ by contour and line plot (Figure $5 \mathrm{~m}, \mathrm{n}$ ). At the beginning of the discharge, the peaks at $28.0^{\circ}, 38.9^{\circ}$, and $40.9^{\circ}$ can be ascribed to the $(\mathrm{Bi}, \mathrm{Sb})$, then the appearance of peaks at $18.9^{\circ}, 26.4^{\circ}, 32.5^{\circ}, 37.8^{\circ}$, and $42.1^{\circ}$ are indexed as the $\mathrm{Na}(\mathrm{Bi}, \mathrm{Sb})$ formation, and the peaks at $18.9^{\circ}, 19.3^{\circ}, 20.6^{\circ}, 21.5^{\circ}, 25.3^{\circ}, 26.4^{\circ}, 33.6^{\circ}, 34.1^{\circ}, 38.6^{\circ}$, and $39.8^{\circ}$ are assigned to the $\mathrm{Na}_{3}(\mathrm{Bi}, \mathrm{Sb})$. 

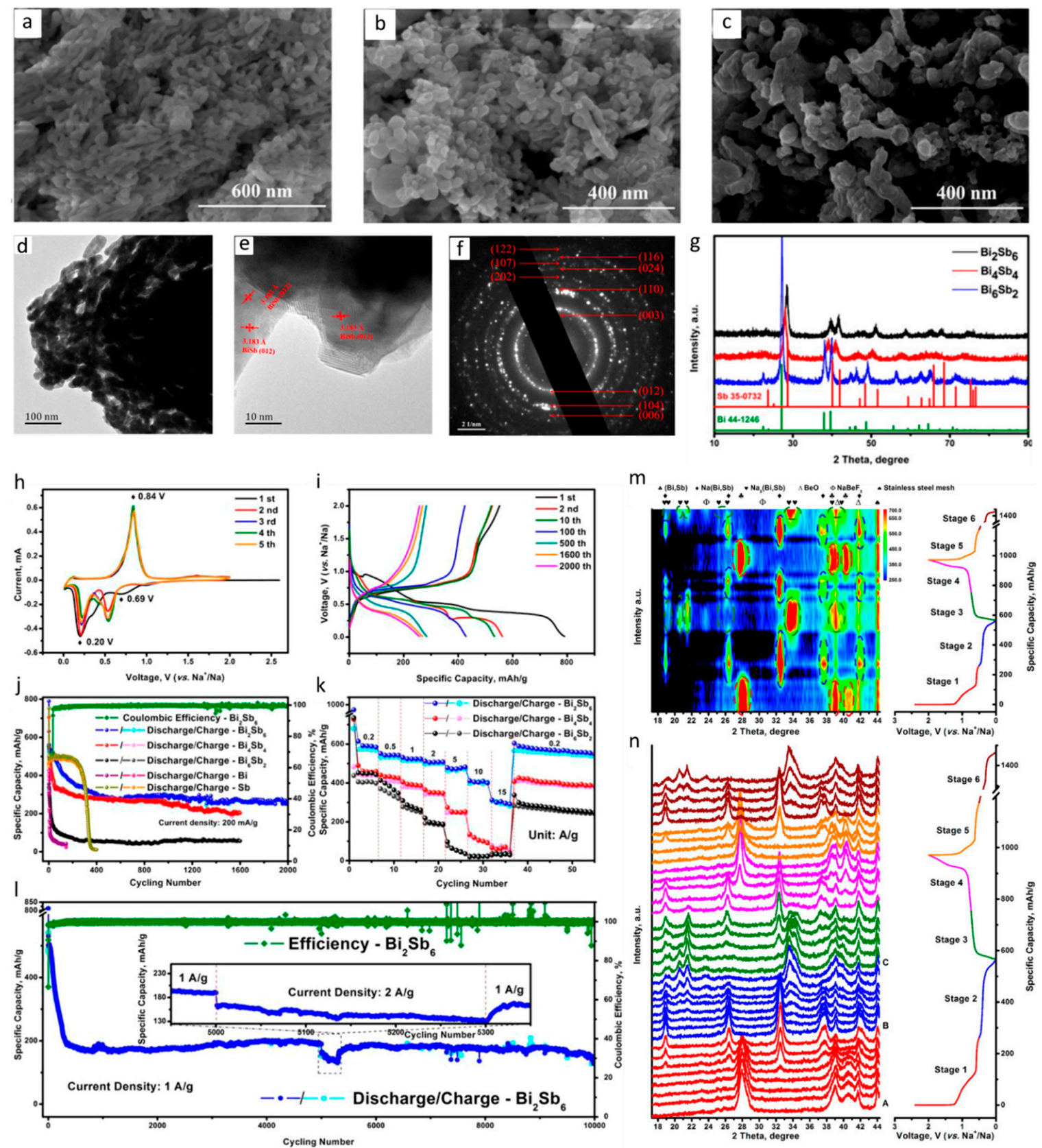

Figure 5. Structural characterization and electrochemical performance analysis of intermetallic alloy (np-Bi-Sb) as an anode in SIBs: (a-c) SEM images of the np- $\mathrm{Bi}_{2} \mathrm{Sb}_{6}, \mathrm{np}-\mathrm{Bi}_{4} \mathrm{Sb}_{4}$, and np-Bi $\mathrm{Sb}_{2}$ samples, respectively showing typical three-dimensional bi-continuous ligament-channel with various size of ligaments. (d) TEM image of the $\mathrm{np}-\mathrm{Bi}_{4} \mathrm{Sb}_{4}$ features the nanoporous structure of $\mathrm{np}$-Bi-Sb alloys. (e) The high resolution TEM (HRTEM) image shows that the crystal size ( $25 \mathrm{~nm})$ of the np-Bi-Sb alloys are approximately close to the ligament's sizes. (f) The selected-area electron diffraction (SAED) pattern of the np-Bi-Sb alloy further confirms the nanocrystalline structure of the selected region. (g) XRD patterns of the np-Bi-Sb alloys are indexed to the single phase of BiSb alloy. (h) Cyclic voltammograms $(\mathrm{CV})$ of the $\mathrm{np}-\mathrm{Bi}_{2} \mathrm{Sb}_{6}$ electrode at a scan rate of $0.1 \mathrm{mV} \mathrm{s}^{-1}$ over a potential window of $0.01-2.0 \mathrm{~V}$ (vs. $\mathrm{Na}^{+} / \mathrm{Na}$ ). (i) GCD curves of the $\mathrm{np}-\mathrm{Bi}_{2} \mathrm{Sb}_{6}$ electrode in different cycles at a current density of $200 \mathrm{~mA} / \mathrm{g}$. The overlap of the charge/discharge curves of the 1600th and 2000th cycles implies the excellent stability during the long cycling. $(\mathbf{j}, \mathbf{k})$ Excellent cycling performance and rate capability of the np-Bi-Sb alloys, respectively. (1) Cycling performance and coulombic efficiency of the $n p-\mathrm{Bi}_{2} \mathrm{Sb}_{6}$ electrode at $1 \mathrm{~A} \mathrm{~g}^{-1}$ exhibit amazing cycling capability. A zoom-in image (inset) illustrates the cycling performance at $2 \mathrm{~A} \mathrm{~g}^{-1}$ when the discharge capacity can remain about $150 \mathrm{mAh} \mathrm{g}^{-1}$ from 5000 to 5300 cycles. (m-n) 
Contour plot and line plot of the operando XRD of the np-Bi-Sb alloys during the charge/discharge processes reveals the sodiation/desodiation procedures of the alloy as the anode of the Na-ion batteries. Reprinted with permission from [102]. Copyright 2018 American Chemical Society.

Table 2 lists the performance of several notable alloy-based anodes, which have been used as anodes for Na-ion battery applications

Table 2. High performance of alloy-based anodes in Na-ion battery systems.

\begin{tabular}{|c|c|c|c|c|}
\hline $\begin{array}{c}\text { Type of Alloy-Based } \\
\text { Anode }\end{array}$ & Electrolyte Chemistry & $\begin{array}{c}\text { Voltage } \\
\text { Range (V) }\end{array}$ & Performance * & Reference \\
\hline $\begin{array}{l}\text { Sn coated viral } \\
\text { nanoforests }\end{array}$ & $1 \mathrm{M} \mathrm{NaClO}_{4}$ in EC/DEC (1:1) & $0.01-1.5$ & $405 / 150 / 50$ & [65] \\
\hline Sn nanofibers & $1 \mathrm{M} \mathrm{NaClO}_{4}$ in $\mathrm{PC}$ with $2 \% \mathrm{FEC}$ & $0.001-0.65$ & $776.26 / 100 / 84.7$ & [103] \\
\hline $\begin{array}{c}\mathrm{Sb} / \mathrm{MWCNT} \\
\text { (Multi-walled carbon } \\
\text { nanotube) }\end{array}$ & $\begin{array}{c}1 \mathrm{M} \mathrm{NaClO}_{4} \text { in } \mathrm{PC}(1: 1) \text { with } 5 / 10 \% \\
\text { FEC }\end{array}$ & $0.01-2.5$ & $\sim 382 / 120 / 200$ & [104] \\
\hline Sb nanocrystals & $1 \mathrm{M} \mathrm{NaPF}_{6}$ in EC/DMC (-) & $0.02-1.5$ & $\sim 550 / 100 / 660$ & [93] \\
\hline Sb@C microspheres & $1 \mathrm{M} \mathrm{NaPF}_{6}$ in EC/DEC (1:1) & $0.01-3.00$ & $\sim 584 / 100 / 200$ & [105] \\
\hline $\mathrm{Sb} @ \mathrm{TiO}_{2}$ & $1 \mathrm{M} \mathrm{NaClO}_{4}$ in $\mathrm{PC}(1: 1)$ with $5 \% \mathrm{FEC}$ & $0.01-3.00$ & $541 / 100 / 100$ & {$[106]$} \\
\hline $\mathrm{Zn}_{4} \mathrm{Sb}_{3}$ & $1 \mathrm{M} \mathrm{NaClO}_{4}$ in PC (1:1) with 5\% FEC & $0.01-2.0$ & $290 / 200 / 414$ & [107] \\
\hline $\mathrm{FeSb}_{2}$ & $1 \mathrm{M} \mathrm{NaClO}_{4}$ in PC with 5\% FEC & $0.01-1.2$ & $540 / 130 / 36$ & {$[108]$} \\
\hline SnSb@carbon nanocable & $1 \mathrm{M} \mathrm{NaClO}_{4}$ in $\mathrm{PC}(1: 1)$ with $5 \%$ FEC & $0.005-1.5$ & $360 / 100 / 100$ & [109] \\
\hline $\mathrm{Si} / \mathrm{Ge}$ nanorod & $1 \mathrm{M} \mathrm{NaPF}_{6}$ in $\mathrm{EC} / \mathrm{DEC}(1: 1)$ & $0.001-1.5$ & $\begin{array}{c}20 \mu \mathrm{Ah} \\
\mathrm{cm}^{-2 / 200 / 10} \\
\mu \mathrm{A} \mathrm{cm}\end{array}$ & [67] \\
\hline Bi@C microsphere & $1 \mathrm{M} \mathrm{NaClO}_{4}$ in EC/PC (1:1) & $0.01-2.0$ & $123.5 / 100 / 100$ & [110] \\
\hline $\mathrm{Sn}-\mathrm{Bi}-\mathrm{Sb}$ & $1 \mathrm{M} \mathrm{NaClO}_{4}$ in PC (1:1) with $5 \%$ FEC & $0.01-2.0$ & $621 / 100 / 200$ & [111] \\
\hline $\mathrm{Sn}_{4} \mathrm{P}_{3}$ & $1 \mathrm{M} \mathrm{NaClO}_{4}$ in EC/DEC (1:1) & $0.01-1.5$ & $\sim 700 / 100 / 100$ & [112] \\
\hline SnP nanocrystals & $5 \mathrm{M} \mathrm{NaFSI}$ in DME & $0.005-1.5$ & $600 / 200 / 100$ & [113] \\
\hline $\mathrm{Cu}_{2} \mathrm{P} / \mathrm{C}$ & $\begin{array}{l}1 \mathrm{M} \mathrm{NaClO}_{4} \text { in EC/DEC (1:1) with } 5 \% \\
\text { FEC }\end{array}$ & $0.01-1.5$ & $430 / 100 / 200$ & [114] \\
\hline
\end{tabular}

* Specific capacity $\left(\mathrm{mAh} \mathrm{g}^{-1}\right) /$ number of cycles/current density $\left(\mathrm{mA} \mathrm{g}^{-1}\right)$. FEC = Fluoroethylene carbonate.

\subsection{Metal Oxides}

Because of their high theoretical capacities, metal oxides are considered promising candidates for anodes in SIB batteries. The first known report of layered transition metal oxides for SIB was published in the 1980s [115]. Within this family, $\mathrm{Fe}_{2} \mathrm{O}_{3}$ provides a theoretical capacity of $\approx 1007 \mathrm{mAh} \mathrm{g}^{-1}$. Furthermore, $\mathrm{Fe}_{2} \mathrm{O}_{3}$ is an environmentally friendly and low-cost species due to its abundance [116-119]. Likewise, another example of a transition metal oxides species is $\mathrm{Fe}_{3} \mathrm{O}_{4}$, which presented a specific capacity of $522 \mathrm{~mA} \mathrm{~h} \mathrm{~g}^{-1}$ at $160 \mathrm{~mA} \mathrm{~g}^{-1}$ after 800 cycles [51]. In the work published by Zhao et al., in order to overcome the low conductivity of $\mathrm{Fe}_{3} \mathrm{O}_{4}$ and volume changes during sodiation and desodiation, the authors employed several techniques, such as a successive sol-gel process, the solvothermal method, and calcination, for instance, to obtain the material called HCM- $\mathrm{Fe}_{3} \mathrm{O}_{4} @$ void@N-C [51]. Then, by providing a void space within the material, the authors found a way to overcome the volume changes above mentioned. Apart from this, the nitrogen-doped carbon contributed to higher electronic conductivity. Further details of this work are depicted in Figure 6. Here Figure $6 a-c$ is the electron microscope images demonstrating the mesoporous composite nanospheres. Figure $6 \mathrm{~d}-\mathrm{g}$ are the EDX elemental maps demonstrating the constituent elements present uniformly. Figure $6 \mathrm{~h}, \mathrm{k}, \mathrm{m}$ is the schematic representation of the sodiation of the different spheres indicating the superiority of the 
$\mathrm{Fe}_{3} \mathrm{O}_{4} @$ void@NC spheres. Figure 6i,j,l are the GCD and capacity retention performance of the spheres as anodes in an SIB. Another attractive metal oxide for SIB anodes is the $\mathrm{CuO}$, due to its high theoretical capacity (674 $\left.\mathrm{mA} \mathrm{h} \mathrm{g}^{-1}\right)$ [120], low cost, and availability. In the work developed by Wang et al., $\mathrm{CuO}$ quantum dots of $\approx 2 \mathrm{~nm}$ were prepared and embedded in carbon nanofibers by the electrospinning deposition technique. The results show that the material called 2-CuO@C presented specific capacity of $401 \mathrm{~mA} \mathrm{~h} \mathrm{~g}^{-1}$ at a current density of $500 \mathrm{~mA} \mathrm{~g}^{-1}$ after 500 cycles, with an initial specific capacity of $528 \mathrm{mAh} \mathrm{g}^{-1}$ at $100 \mathrm{~mA} \mathrm{~g}^{-1}$ [121]. Accordingly, as it can be seen, metal oxides are usually employed as SIB anodes with carbon species, such as $\gamma-\mathrm{Fe}_{2} \mathrm{O}_{3} @ \mathrm{C}, 3 \mathrm{D}$ composite that presented a capacity of 358 $\mathrm{mA} \mathrm{h} \mathrm{g}^{-1}$ after 1400 cycles at $2000 \mathrm{~mA} \mathrm{~g}^{-1}$, with Coulombic efficiency near $100 \%$ [122]. In addition, $\mathrm{MnCoNiO}_{x} @$ double-carbnon nanofibers presented a specific capacitance of $230 \mathrm{~mA} \mathrm{~h} \mathrm{~g}^{-1}$ at $100 \mathrm{mAg}^{-1}$, with capacity retention of $96 \%$ for over 500 cycles. This work, developed by Wu et al., reveals another interesting result-a capacity retention of $89 \%$ after 6500 cycles (at $1000 \mathrm{~mA} \mathrm{~g}^{-1}$ ) with specific capacity of $107 \mathrm{mAh} \mathrm{g}^{-1}$ [123].

In comparison, when it comes to non-transition metal oxides, $\mathrm{Sb}_{2} \mathrm{O}_{4} @ \mathrm{rGO}$, in the work developed by Ramakrishnan et al., 500 cycles showed a reversible capacity of $626 \mathrm{mAh} \mathrm{g}^{-1}$ at $600 \mathrm{~mA} \mathrm{~g}^{-1}$ [124]. Additionally, for $\mathrm{Sb}_{2} \mathrm{O}_{4} @ \mathrm{rGO}$, the reactions that happen upon sodium accommodation are as follows:

$$
\begin{gathered}
\mathrm{Sb}_{2} \mathrm{O}_{4}+8 \mathrm{Na}^{+}+8 \mathrm{e}^{-} \rightarrow 2 \mathrm{Sb}+4 \mathrm{Na}_{2} \mathrm{O} \\
2 \mathrm{Sb}+6 \mathrm{Na}^{+}+6 \mathrm{e}^{-} \rightarrow 2 \mathrm{Na}_{3} \mathrm{Sb} .
\end{gathered}
$$

Another relevant aspect is the contribution of the electrolyte for high performance sodium ion batteries. In the work published by $\mathrm{Li}$ et al., rhombic $\mathrm{TiO}_{2}$ nanocrystals were synthesized and electrochemically characterized for two different electrolytes, i.e., $\mathrm{NaCF}_{3} \mathrm{SO}_{3}$ in ethylene carbonate and diethyl carbonate (EC/DEC), and $\mathrm{NaCF}_{3} \mathrm{SO}_{3}$ in diglyme. The results show that after 500 cycles at $100 \mathrm{~mA} \mathrm{~g}^{-1}$, the reversible capacity for the electrolytes with EC/DEC and diglyme were, respectively, $87 \mathrm{~mA} \mathrm{~h} \mathrm{~g}^{-1}$ and $165 \mathrm{~mA} \mathrm{~h} \mathrm{~g}^{-1}[125,126]$. A tabular listing of some other prominent results for the anodes discussed above is provided in Table 3 below.

Overall, metal oxides present high capacity values, when compared with hard carbon's theoretical capacity, low cost, nontoxicity, chemical stability, and also environmental friendly nature [127]. Nevertheless, the literature reports that these high capacity values are usually achieved at low current densities [128]. This happens because of the low conductivity of the metal oxide species and structural changes, which require several steps and energy for such reorganization to take place $[127,128]$. Furthermore, another concern when it comes to metal oxide anodes are the volume changes that occur during sodium insertion and extraction, which may lead to an agglomeration of metal oxide particles and even cracks or the pulverization of the active material causing loss of contact and an impedance increase in the cell $[129,130]$. Those facts combined may affect the cell performance, causing capacity and rate capability to decrease $[131,132]$. Regarding the future perspectives of metal oxide anodes, aiming to provide capacities closer to the theoretical capacity values for metal oxides, strategies using carbon materials and nanostructuring is expected to increase the mobility of $\mathrm{Na}^{+}$ions in these anodes, as well as the ability to accommodate volume expansion. Those aspects are crucial to the commercial feasibility of SIB employing metal-oxides anodes.

\begin{tabular}{|c|c|c|c|c|}
\hline Type of Metal Oxide Anode & Electrolyte Chemistry & Voltage Range & Performance * & Reference \\
\hline $\mathrm{P} 2-\mathrm{Na}_{2 / 3} \mathrm{Co}_{1 / 3} \mathrm{Ti}_{2 / 3} \mathrm{O}_{2}$ & $\begin{array}{c}1 \mathrm{M} \text { of } \mathrm{NaClO}_{4} \text { in } \mathrm{EC} / \mathrm{DEC} / 3 \\
\text { wt.\% FEC }\end{array}$ & $4.0-2.0$ & $64.9 / 400 / 1 C^{a}$ & [133] \\
\hline Tunnel- $\mathrm{Na}_{0.44} \mathrm{MnO}_{2}$ & $1 \mathrm{M} \mathrm{NaClO}_{4}$ in $\mathrm{PC}$ & $2-3.8$ & $82 / 1000 / 0.42 C^{a}$ & [134] \\
\hline $\mathrm{Fe}_{3} \mathrm{O}_{4} \mathrm{QD} @ \mathrm{C}-\mathrm{GN}$ & $1 \mathrm{M} \mathrm{NaFP}_{6}$ in $\mathrm{EC} / \mathrm{DMC}$ & $0-3.0$ & $343 / 1000 / 2000$ & [135] \\
\hline $\mathrm{Co}_{3} \mathrm{O}_{4} @ \mathrm{NC}$ & $1 \mathrm{M} \mathrm{NaClO}_{4}$ in PC/PEC & $0-3.0$ & $175 / 1100 / 1000$ & [136] \\
\hline
\end{tabular}

Table 3. High performance of metal oxides anodes in Na-ion battery systems. 
Table 3. Cont.

\begin{tabular}{|c|c|c|c|c|}
\hline Type of Metal Oxide Anode & Electrolyte Chemistry & Voltage Range & Performance * & Reference \\
\hline $\mathrm{SnO}_{2} / 3 \mathrm{D}$ graphene & $\begin{array}{c}1 \mathrm{M} \mathrm{NaPF}_{6} \text { in EC/DEC/10 } \\
\text { wt.\% FEC }\end{array}$ & $0-2.8$ & $223 / 350 / 80$ & [137] \\
\hline $\mathrm{T}-\mathrm{Nb}_{2} \mathrm{O}_{5} / \mathrm{CNF}$ & $\begin{array}{c}1 \mathrm{M} \mathrm{NaClO} \text { in } \mathrm{PC} / \mathrm{EC} / 5 \\
\text { wt.\% PEC }\end{array}$ & $0-2.8$ & $150 / 5000 / 1000$ & [138] \\
\hline $\mathrm{Na}_{2} \mathrm{Ti}_{6} \mathrm{O}_{13}$ nanorods & $1 \mathrm{M} \mathrm{NaClO}_{4}$ in PC and FEC & $0-2.5$ & $109 / 2800 / 1000$ & [139] \\
\hline $\mathrm{Sb}_{2} \mathrm{O}_{3} / \mathrm{Sb} @ \mathrm{Gr}-\mathrm{CSN}$ & $1 \mathrm{M} \mathrm{NaClO}_{4}$ in EC/DMC & $0-2.5$ & $487 / 275 / 100$ & [140] \\
\hline $\mathrm{V}_{2} \mathrm{O}_{3} / \mathrm{C}$ & $1 \mathrm{M} \mathrm{NaClO} 4$ in $\mathrm{DMC} / \mathrm{EC}$ & $0-3.0$ & $181 / 1000 / 2000$ & [141] \\
\hline 3-CCO@C & $1 \mathrm{M} \mathrm{NaClO} 4$ in $\mathrm{DMC} / \mathrm{EC}$ & $0-3.0$ & $314 / 1000 / 1000$ & [142] \\
\hline Inverse opal am- $\mathrm{TiO}_{2}$ & $1 \mathrm{M} \mathrm{NaPF}_{6}$ in DEG-DME & $0-3.0$ & $86.7 / 500 / 500$ & [143] \\
\hline Nickel-titanium oxide & $\begin{array}{c}1 \mathrm{M} \mathrm{NaPF}_{6} \text { in } \mathrm{DMC} / \mathrm{EC} / 5 \\
\text { wt.\% FEC }\end{array}$ & $0-2.5$ & $491 / 200 / 50$ & [144] \\
\hline $\mathrm{M}-\mathrm{Na}_{4} \mathrm{Ti}_{5} \mathrm{O}_{12} / \mathrm{CNT}$ & $1 \mathrm{M} \mathrm{NaClO}_{4}$ in $\mathrm{DMC} / \mathrm{EC}$ & $0.01-3.0$ & $84.4 / 500 / 100$ & [145] \\
\hline $\mathrm{Na}_{2} \mathrm{Ti}_{2} \mathrm{O}_{5} \cdot \mathrm{H}_{2} \mathrm{O} / \mathrm{MoS}_{2}-\mathrm{C}$ & $\begin{array}{c}1 \mathrm{M} \mathrm{NaClO}_{4} \text { in } \mathrm{DMC} / \mathrm{EC} / 5 \\
\text { wt.\% FEC }\end{array}$ & $0-3.0$ & $201.1 / 16,000 / 8000$ & [81] \\
\hline
\end{tabular}

* Specific capacity $\left(\mathrm{mAh} \mathrm{g}^{-1}\right) /$ number of cycles/current density $\left(\mathrm{mA} \mathrm{g}^{-1}\right) .{ }^{\text {a }} \mathrm{C}$ rate.
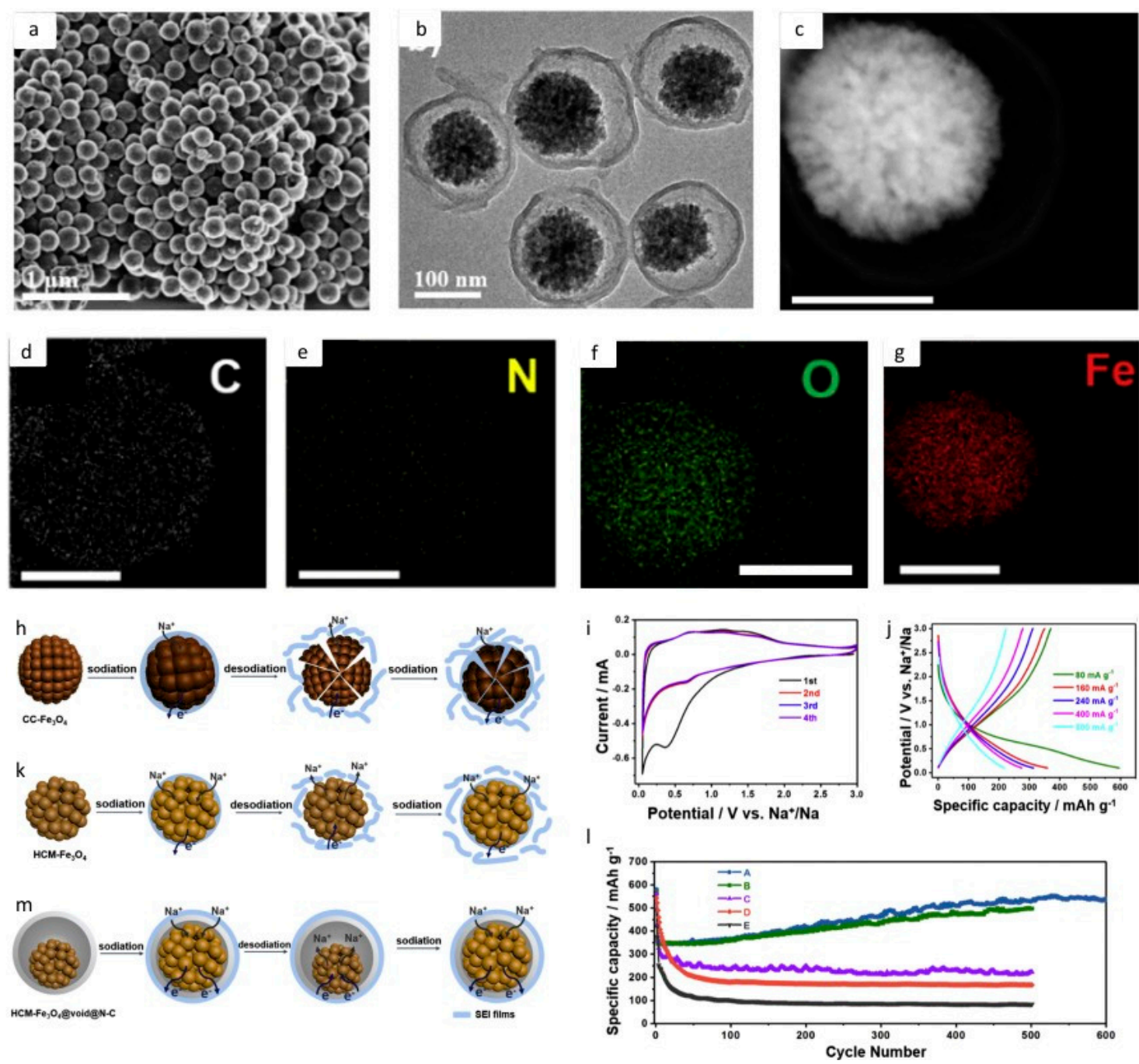

Figure 6. Structural characterization and electrochemical performance analysis of metal oxide yolk-shell structured $\mathrm{HCM}-\mathrm{Fe}_{3} \mathrm{O}_{4} @$ void@N-C nanospheres as an anode in SIBs: (a) field emission scanning electron microscope (FESEM) of the material, (b) transmission electron microscopy (TEM) of the material, (c) scanning transmission electron microscopy (STEM) of the material, (d-g) energy dispersive X-ray (EDX) elemental mappings of a $\mathrm{HCM}-\mathrm{Fe}_{3} \mathrm{O}_{4} @$ void@N-C nanosphere, (h) representation of the 
sodiation and desodiation processes of $\mathrm{CC}-\mathrm{Fe}_{3} \mathrm{O}_{4}$ and their characteristic volume increases, (i) cyclic voltammetry curves from 1 st to 4 th cycles for voltage range from 0.01-3.0 V. It is worth noting that the first cycle shape differs from the other cycles because of side reactions and Solid Electrolyte Interphase (SEI) formation, (j) charge-discharge curves for different current densities of $\mathrm{HCM}-\mathrm{Fe}_{3} \mathrm{O}_{4} @$ void@N-C nanospheres, (k) representation of the sodiation and desodiation processes of $\mathrm{HCM}-\mathrm{Fe}_{3} \mathrm{O}_{4},(\mathbf{l})$ specific capacity representation versus cycle number for current density of $160 \mathrm{mAg}^{-1}$ of the following materials: (A) HCM-Fe $\mathrm{O}_{4} @$ void@N-C, (B) HCM-Fe $3 \mathrm{O}_{4} @$ void@C, (C) HCM-Fe $3 \mathrm{O}_{4} @ \mathrm{C}$, (D) $\mathrm{HCM}-\mathrm{Fe}_{3} \mathrm{O}_{4}$, and (E) $\mathrm{CC}-\mathrm{Fe}_{3} \mathrm{O}_{4}$ nanospheres, and (m) representation of the sodiation and desodiation processes of $\mathrm{HCM}-\mathrm{Fe}_{3} \mathrm{O}_{4} @$ void@N-C nanospheres, showing the SEI film, which accommodates the volume expansion characteristic of $\mathrm{Fe}_{3} \mathrm{O}_{4}$ species. The bars of $(\mathbf{c}-\mathbf{g})$ are $100 \mathrm{~nm}$. Reprinted with permission from [51]. Copyright 2019 Elsevier B.V. All rights reserved.

\subsection{2-D Materials}

\subsubsection{Graphene}

In 2013, for the first time, reduced graphene oxide (rGO) as an anode was reported in SIB anodes [146]. In this work, published by Wang et al., rGO was prepared by first oxidizing graphite by a modified Hummers' method, followed by a heat-treatment. The presented capacity results for reversible Na storage in the $\mathrm{rGO}$ synthesized at $1.0 \mathrm{C}\left(200 \mathrm{~mA} \mathrm{~g}^{-1}\right)$ for the $2 \mathrm{nd}, 100 \mathrm{th}$, and 250 th cycles were $177 \mathrm{mAh} \mathrm{g}^{-1}, 110.3 \mathrm{mAh} \mathrm{g}^{-1}$, and $94.3 \mathrm{mAh} \mathrm{g}^{-1}$, respectively. Moreover, for over 1000 cycles, the discharge capacity, at $0.2 \mathrm{C}\left(40 \mathrm{~mA} \mathrm{~g}^{-1}\right)$, was $141 \mathrm{mAh} \mathrm{g}^{-1}$, presenting, therefore, steady cycle retention [146]. These results show the improvement of sodium insertion because of rGO, thereby providing higher capacity values, even for higher current densities, when compared to other carbon allotropes. This improvement was achieved due to the existence of defects that contribute towards an increase of the graphene interlayer distance [146,147].

Over the years, graphene has gained the attention of researchers due to its unique characteristics, such as large surface-area, high electronic and thermal conductivity, high elasticity, mechanical strength, and chemical stability [148-151]. Thus, for the aspects mentioned herein, graphene is usually employed as standalone anodes and conducting agent for electrodes of SIBs due to its ability to provide short diffusion length for ions, leading to their faster diffusion, and also because of graphene's large surface, which provides more channels for ion insertion [86,152-154].

Zhang et al. synthesized binder-free porous graphene film (PGF) electrodes for SIB, with pore sizes ranging from 38 to $450 \mathrm{~nm}$ [86]. For the electrochemical results, the work shows that the first reversible capacity for the PGF-1 film was $193 \mathrm{~mA} \mathrm{~h} \mathrm{~g}^{-1}$ at $50 \mathrm{~mA} \mathrm{~g}^{-1}$ in the first cycle, while at $1000 \mathrm{~mA} \mathrm{~g}^{-1}$ (for the 500th and 1000th cycles) the specific capacities were $156 \mathrm{mAh} \mathrm{g}^{-1}$ and $111 \mathrm{mAh} \mathrm{g}^{-1}$, respectively.

Furthermore, a strategy to develop a high performance anode for SIBs is to employ doped-graphene. In recently published work [155], co-doped graphene oxide nanosheets with heteroatoms were employed. By adding a polymer containing nitrogen and sulfur, the monomer was adsorbed on the surface of graphene oxide, following a polymerization reaction. The electrochemical results for the SIB anode unveil a capacity retention of $82 \%$ after 800 cycles and, for a current density of $500 \mathrm{mAg}^{-1}$, a specific capacity of $237.2 \mathrm{mAh} \mathrm{g}^{-1}$ [155]. The results of this work have been provided in Figure 7 as a representative. Here Figure $7 \mathrm{a}$ is the SEM image and $1 b, c$ are the TEM images of the polymer/rGO nanosheet composite. Figure $7 \mathrm{~d}-\mathrm{f}$ demonstrates the elemental and chemical characterization as seen in the EDS elemental map and the XPS graph. Figure $7 \mathrm{~g}-\mathrm{j}$ represent the electrochemical performance of the polymer/rGO composite as an anode in an SIB system. 

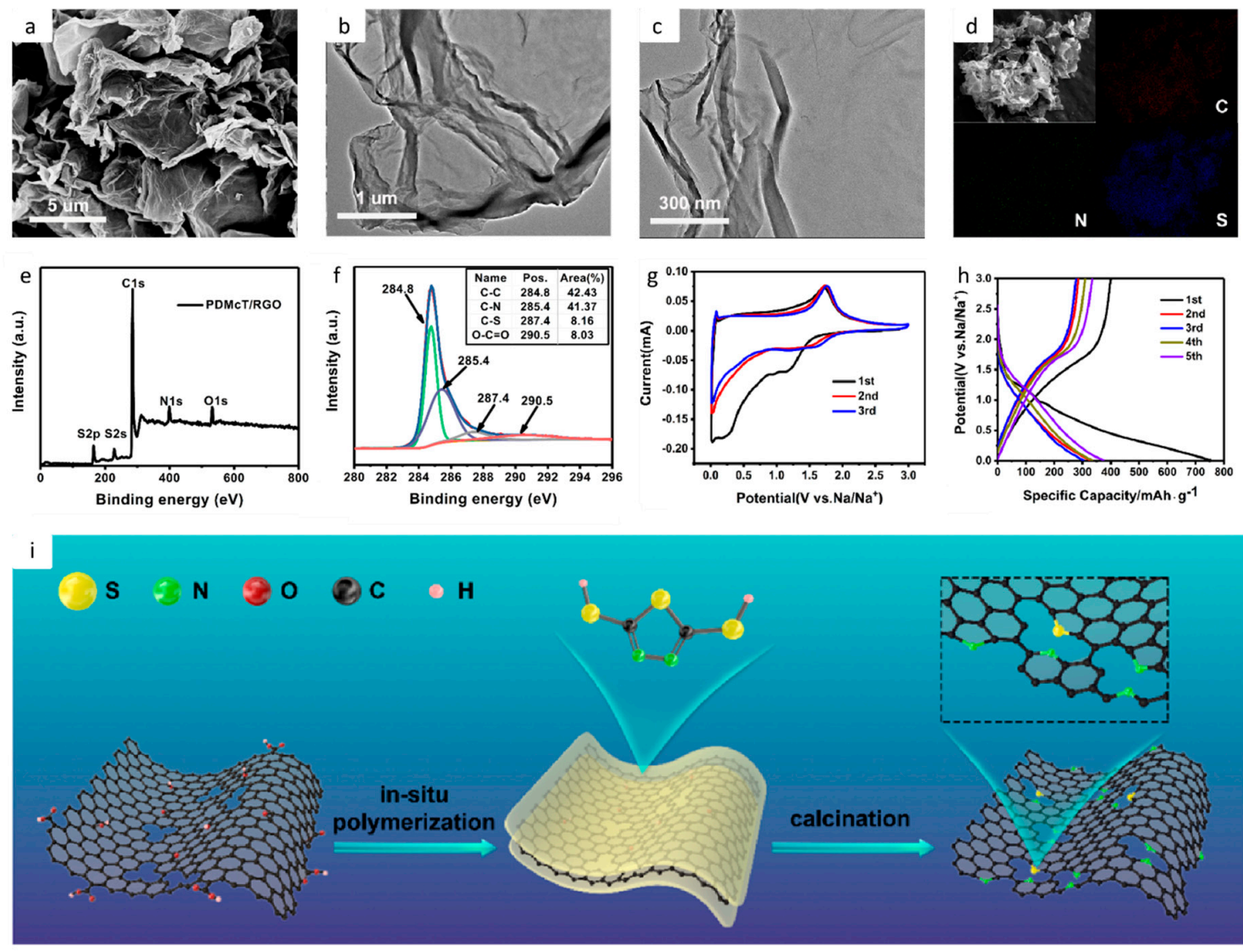

j

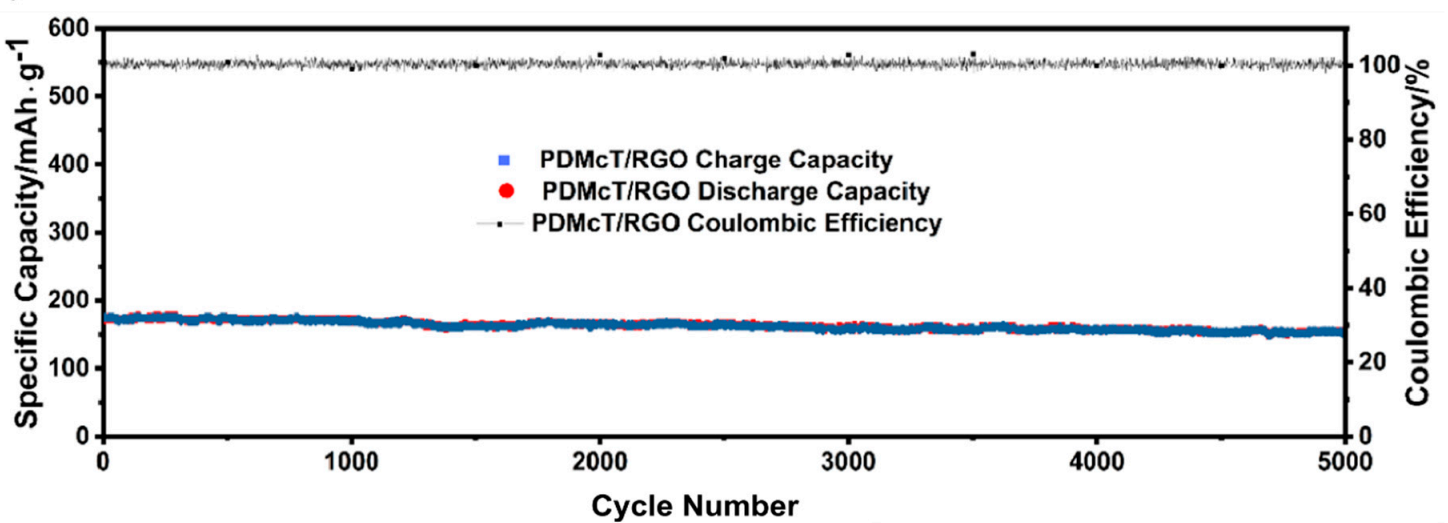

Figure 7. Characterization and electrochemical performance analysis of poly(2,5-dimercapto-1,3,4thiadiazole)(PDMcT)/reduced graphene oxide (RGO) (PDMcT/RGO) as an anode in SIBs: (a) scanning electron microscopy (SEM) of the material, $(\mathbf{b}, \mathbf{c})$ transmission electron microscopy (TEM) of the material, (d) energy dispersive X-ray (EDX) elemental mapping of the material indicating the homogeneous distribution of atoms $\mathrm{N}$, and $\mathrm{S}$ co-doping the graphene sheets, (e) X-ray photoelectron spectroscopy (XPS) survey of the material corroborating the results obtained at EDX, (f) high resolution XPS of $\mathrm{C}$ 1s showing the $\mathrm{C}-\mathrm{C}, \mathrm{C}-\mathrm{N}$, and C-S characteristic binding energies, (g) cyclic voltammetry curves from 1st to 3rd cycles for voltage range from $0.01-3.0 \mathrm{~V}$ at scan rate of $0.1 \mathrm{mV} \mathrm{s}^{-1}$. In the 1st cycle, at approximately $0.2 \mathrm{~V}$, the reduction peak may be assigned to the solid-electrolyte interphase (SEI) formation; additionally, at approximately 0 and $0.09 \mathrm{~V}$, redox peaks may be assigned, respectively, to $\mathrm{Na}^{+}$insertion/extraction from graphene layers, (h) charge and discharge curves at current density of $50 \mathrm{~mA} \mathrm{~g}^{-1}$, (i) representation of the synthesis of the material PDMcT/RGO, and (j) specific capacity representation versus cycle number for current density of $5000 \mathrm{~mA} \mathrm{~g}^{-1}$ showing the low drop in capacity even after 5000 cycles; thus, remaining at $153.3 \mathrm{mAh} \mathrm{g}^{-1}$. Reprinted with permission from [155]. Copyright 2018, American Chemical Society. 
It is also important to highlight that, in the literature, graphene is commonly employed with other materials aiming to enhance their desirable properties. This process can be illustrated by the synthesis of $\mathrm{SbPO}_{4}$ and $\mathrm{rGO}$, performed by Pan et al., through the solvothermal reaction of $\mathrm{SbCl}_{3}$ and $\mathrm{NH}_{4} \mathrm{H}_{2} \mathrm{PO}_{4}$ with graphene oxide, followed by a reducing atmosphere annealing with $\mathrm{Ar}$ and $\mathrm{H}_{2}$ [156]. In this work, the layered monoclinic $\mathrm{SbPO}_{4}$ structure was deposited on RGO aiming to enhance the electrochemical properties of the material. The results show a capacity of $100 \mathrm{mAh} \mathrm{g}{ }^{-1}$ at $1000 \mathrm{~mA} \mathrm{~g}^{-1}$ and its stability up to 1000 cycles. Moreover, the energy density at $1.2 \mathrm{~kW} \mathrm{~kg}^{-1}$ was $99.8 \mathrm{Wh} \mathrm{kg}^{-1}$.

In summary, graphene is usually employed as a support material in SIB anodes, due to its fast electron transport and mechanical properties [157-159]. Nevertheless, pristine graphene presents a low value of reversible capacity for $\mathrm{Na}^{+}$storage, which is the reason why graphene is usually employed with another species [158]. Furthermore, as stated by Ling et al., puregraphite is energetically unstable for intercalating $\mathrm{Na}^{+}$, and also for low concentrations, which is the reason why pristine graphene is not employed uniquely as active material anode for SIBs [160-162]. One alternative is to introduce topological defects aiming to increase the capacity and rate capability of graphene-based SIB anodes, or to use graphene as support for other 2D materials, such as Transition metal dichalcogenides (TMDs) and phosphorene (also reported herein) for example. Given the importance graphene has achieved nowadays, this material is expected to continue to have a strong presence within energy storage systems in the future, as a support material for high performance devices.

\subsubsection{Phosphorene}

Since 2014, Phosphorene, a single layer of black phosphorus, has recently emerged (since 2014) as a beyond graphene technologically relevant material owing to its superior mechanical and electronic properties, ease of fabrication through common low-cost exfoliation techniques. Applications of phosphorene as high capacity anode material for SIB has also been investigated. [163-166].

Therefore, although phosphorene has similarities to graphene, such as being a 2D material obtained through mechanical exfoliation of black phosphorous, graphene can be obtained through the exfoliation of graphite and possesses its layered structure in elemental form, unlike TMDs. [164,167-170]. Some of these properties include high carrier mobility $\left(\approx 200-1000 \mathrm{~cm}^{2} \mathrm{~V}^{-1} \mathrm{~s}^{-1}\right)$ and a direct band gap for one or several multi-layers $(0.3 \mathrm{eV}-2 \mathrm{eV})[169,170]$. It is also important to highlight that phosphorene is a candidate for SIB anodes, as its interlayer spacing is $5.4 \AA$, which is greater than graphite $(3.7 \AA)$ [171,172]. As a result, the specific capacity of phosphorene for SIB is theoretically $2596 \mathrm{mAh} \mathrm{g}^{-1}$, almost seven times hard carbon's specific capacity $[173,174]$. Sun et al. in [175] developed a phosphorene-graphene material that presented a specific capacity of $2440 \mathrm{mAh} \mathrm{g}^{-1}$ after 100 cycles at $50 \mathrm{~mA} \mathrm{~g}^{-1}$ (0.02 C), with a capacity retention of $83 \%$. In this work, graphene contributed to a faster charge transfer between its layers, and improved mechanical properties, allowing the anisotropic expansion of the phosphorene layers during cycling.

To summarize, phosphorene is a material of interest because of its high capacity values and its applicability to several fields, such as optoelectronics, solar cells, and biomedicine. However, the ways of obtaining this 2D material are still under investigation, as mechanical exfoliation and liquid-phase exfoliation are typically employed. Regarding those techniques, mechanical exfoliation presents a low yield, while liquid-phase exfoliation (ultralong sonication) is a high yield method, which may induce defects on the material [176]. Additionally, electrochemical exfoliation has recently been reported $[173,177,178]$. Therefore, even though phosphorene's properties are believed to be superior than graphene, showing the potential of this 2D material [176] for SIBs It is expected that phosphorene will represent a material of interest for the future of high-performance SIBs once it can deliver over $2000 \mathrm{mAh} \mathrm{g}^{-1}$, thereby providing high energy densities for SIBs.

\subsubsection{Transition Metal Dichalcogenides}

Similar to phosphorene and graphene (2D materials), transition metal dichalcogenides-also known as TMDs or TMDCs-may provide a two-dimensional layered structure with desirable 
applications for several research fields, such as energy storage, catalysis, lubrication, nanoelectronics, and optoelectronics [179-181]. Their chemistry is versatile-40 different types of layered TMDs have been identified, making TMDs a material that may be able to surpass graphene when it comes to 2D materials [182-184].

One of the most commonly studied TMD materials is molybdenum disulfide $\left(\mathrm{MoS}_{2}\right)$, whose structure was reported for the first time in 1923, even though it is believed to have existed on earth for over 2.9 billion years. Furthermore, one of the first works that reported $\mathrm{MoS}_{2}$ 's layered structure was published in 1986 [185,186]. Layered $\mathrm{MoS}_{2}$ was first reported an anode for SIBs in 2013 [187]. The reactions for sodiation, which are analogous to Li-based materials, are expressed by Equation (3). Moreover, the conversion reaction is expressed by Equation (4) [188,189]. $\mathrm{MoS}_{2}$ composite materials present high efficiency and capacity for acid functionalized $\mathrm{MoS}_{2}$ in graphene oxide [190]. This work, published by David et al., presented a charge capacity of $\approx 230 \mathrm{~mA} \mathrm{~h} \mathrm{~g}^{-1}$ at $25 \mathrm{~mA} \mathrm{~g}^{-1}$ with efficiency of $\approx 99 \%$. Other examples of $\mathrm{MoS}_{2}$ with carbon allotropes, for SIB, are $\mathrm{MoS}_{2}$ nanosheets aligned with carbon paper. This work concluded that the carbon assures the electronic conductivity of material [191]; and $\mathrm{MoS}_{2}$ /graphene, synthesized with phosphomolybdic acid (PMA), L-cysteine $\left(\mathrm{C}_{3} \mathrm{H}_{7} \mathrm{NO}_{2} \mathrm{~S}\right)$, and graphene oxide, the latter being reduced by the $\mathrm{H}_{2} \mathrm{~S}$ from the L-cysteine molecule [192]. The results from electrode sample MG-3 showed that after 300 cycles, the retained capacities of $\mathrm{Na}^{+}$storage were equal to $254 \mathrm{mAh} \mathrm{g}^{-1}$ and $227 \mathrm{mAh} \mathrm{g}^{-1}$ at $80 \mathrm{~mA} \mathrm{~g}^{-1}$ and $320 \mathrm{~mA} \mathrm{~g}^{-1}$, respectively [192,193]. Importantly, there are works $[188,194]$ that state that the sodiation peak that occurs at $1.4 \mathrm{~V}$ in cyclic voltammograms $(\mathrm{CV})$ happens due to the intercalation of sodium ions within $\mathrm{MoS}_{2}$ layers, following the reaction presented by (3):

$$
\mathrm{MoS}_{2}+\mathrm{xNa}^{+}+\mathrm{xe}^{-} \leftarrow-\rightarrow \mathrm{Na}_{x} \mathrm{MoS}_{2}
$$

On the other hand, the peak occurring at $0.7 \mathrm{~V}$ is characteristic of the reaction presented by (4):

$$
\mathrm{Na}_{x} \mathrm{MoS}_{2}+(4-\mathrm{x}) \mathrm{Na}^{+}+(4-\mathrm{x}) \mathrm{e}^{-} \leftarrow-\rightarrow \mathrm{Mo}+2 \mathrm{Na}_{2} \mathrm{~S}
$$

Likewise, one of the reported TMD materials for high performance SIBs is $\mathrm{MoTe}_{2}$, which can be obtained through the spray pyrolysis technique from C-MoO $\mathrm{M}_{x}$ [193]. This work reports the performance of $\mathrm{C} @ \mathrm{MoTe}_{2}$ and $\mathrm{C} / \mathrm{MoTe}_{2}$ and enhanced rate capabilities are obtained when carbon is employed, compared to bare $\mathrm{MoTe}_{2}$, mainly after $\approx 100$ cycles [193].

In short, TMDs materials offer a wide variety of composition and physical and chemical properties. When it comes to SIBs, the typical higher interlayer spacing of $\mathrm{MoS}_{2}$, for example (approximately $6.15 \mathrm{~A}$ ), is greater than that of the widely known graphite (approximately 3.3 A), which is an advantage over other material families with respect to expansion upon sodium insertion [195]. Furthermore, these unique chemical and physical properties may provide desirable properties for rate capability, such as the result presented in Figure 8, which includes the findings of Niu et al.'s work [196]. Here, Figure 8a demonstrates the schematic for the synthesis of the TMD composite. Figure 8b-e are the SEM and TEM images of the TMD nanocomposite demonstrating the characteristic morphology under high resolution. Figure $8 \mathrm{f}-\mathrm{h}$ represent the electrochemical performance of the cell i.e. GCD curves, capacity retention and rate capability. Another point to consider in terms of future perspective and challenges is that new techniques for improved synthesizing nanostructured TMDs are desirable. Moreover, there is a need to develop low-cost and scalable exfoliation techniques that would allow synthesis of TMD nanosheets with ontrolled properties. 

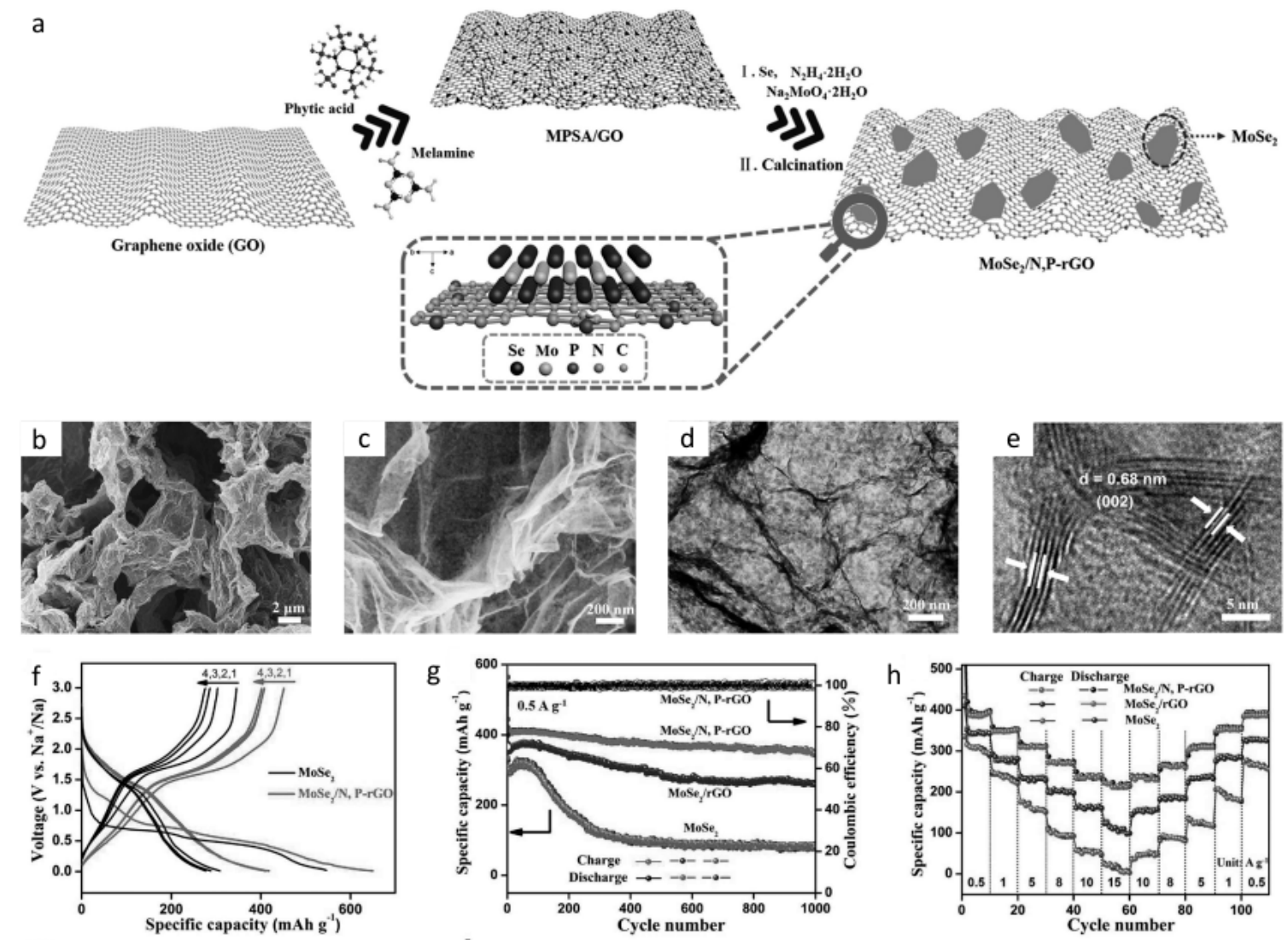

Figure 8. Structural characterization and electrochemical performance analysis of $\mathrm{MoSe}_{2}$-covered N,P-Doped carbon nanosheets as anode in SIBs: (a) schematics of the synthesis of $\mathrm{MoSe}_{2} / \mathrm{N}, \mathrm{P}-\mathrm{rGO}$, $(\mathbf{b}, \mathbf{c})$ scanning electron microscopy (SEM) images of the nanosheets showing the voids achieved in the material, which provide a network capable of withstanding the volume changes and space for electrolyte access, (d) transmission electron microscopy (TEM) image of the material showing the $\mathrm{MoSe}_{2}$ uniformly deposited on carbon nanosheets, (e) high resolution transmission electron microscopy (HRTEM) image of the material with interlayer spacing of approximately $0.68 \mathrm{~nm}$, (f) charge/discharge curves of $\mathrm{MoSe}_{2}$ pristine and $\mathrm{MoSe}_{2} / \mathrm{N}, \mathrm{P}-\mathrm{rGO}$ at $500 \mathrm{~mA} \mathrm{~g}^{-1},(\mathrm{~g})$ cycling performance for current density at $500 \mathrm{~mA} \mathrm{~g}^{-1}$, and (h) comparison of the work published by Niu et al. and other works. Reprinted with permission from [196]. Copyright 2017 John Wiley and Sons.

\subsubsection{MXenes}

Transition metal carbides, carbonitrides, and nitrides (MXenes) are 2D materials with a general formula of $M_{n+1} X_{n} T_{x}$, where $M$ is a transition metal, $X$ can be carbon and/or nitrogen, and $T$ stands for hydroxyl, oxygen, or fluorine. Thus, carbides provide a surface termination [25,197]. This family of materials was discovered in 2011 from the exfoliation of MAX phase materials in hydrofluoric acid (HF) [198]. MXenes are candidates for several applications due to their variety and properties [199,200]. Moreover, due to the fact that MXenes have inter-layer distances larger than graphite, they may enable the intercalation and deintercalation of non-Li-ion batteries, such as SIBs. [200] Examples of MXenes are $\mathrm{Ti}_{3} \mathrm{C}_{2}, \mathrm{Ti}_{3} \mathrm{C}_{2} \mathrm{~T}_{x}, \mathrm{Ti}_{2} \mathrm{C}, \mathrm{Ta}_{4} \mathrm{C}_{3}, \mathrm{TiNbC},\left(\mathrm{Ti}_{0.5} \mathrm{Nb}_{0.5}\right)_{2} \mathrm{C},\left(\mathrm{V}_{0.5} \mathrm{Cr}_{0.5}\right)_{3} \mathrm{C}_{2}$, and $\mathrm{Ti}_{3} \mathrm{CN}[198,201,202]$.

One of the most studied species for SIB MXene anodes is $\mathrm{Ti}_{3} \mathrm{C}_{2} \mathrm{~T}_{x}$. Xie et al. showed that for the first cycle discharge, this material presented a capacity of $370 \mathrm{mAh} \mathrm{g}^{-1}$ at $100 \mathrm{~mA} \mathrm{~g}^{-1}$. In contrast, after 120 cycles, the reversible capacity of $\mathrm{Na}^{+}$was $80 \mathrm{mAh} \mathrm{g}^{-1}$ [203,204]. In [205], Zhao et al. studied the electrochemical performance of MXene SIBs in 3D macroporous frameworks. By mixing MXene with poly(methyl methacrylate) (PMMA) 3D and making free-standing films of MXene/PMMA, the authors obtained pure MXene by heating the samples up to $450{ }^{\circ} \mathrm{C}$, thereby removing the PMMA. Three kinds of MXenes were synthesized: $\mathrm{Ti}_{3} \mathrm{C}_{2} \mathrm{~T}_{x}, \mathrm{~V}_{2} \mathrm{CT}_{x}$, and $\mathrm{Mo}_{2} \mathrm{CT}_{x}$. At $0.25^{\circ} \mathrm{C}$, the values of the reversible 
specific capacity were $\approx 330 \mathrm{mAh} \mathrm{g}^{-1}, \approx 340 \mathrm{mAh} \mathrm{g}^{-1}$, and $\approx 370 \mathrm{mAh} \mathrm{g}^{-1}$, respectively. Moreover, the coulombic efficiency after 1000 cycles was close to $100 \%$, and the reversible capacities at $2.5 \mathrm{C}$ were, for $\mathrm{Ti}_{3} \mathrm{C}_{2} \mathrm{~T}_{x}, \mathrm{~V}_{2} \mathrm{CT}_{x}$, and $\mathrm{Mo}_{2} \mathrm{CT}_{x}$, respectively, $295 \mathrm{mAh} \mathrm{g}^{-1}, 310 \mathrm{mAh} \mathrm{g}^{-1}$, and $290 \mathrm{mAh} \mathrm{g}^{-1}$ [205].

Recently, Xie et al. published about a porous $\mathrm{Ti}_{3} \mathrm{C}_{2} \mathrm{~T}_{x}$ electrode anode for SIBs [206], whose synthesis was performed as presented in Figure 9a. In this work, sulfur addition (being dissolved in ethlyenediamine (EDA)) and its removal after the precipitation of sulfur due to the addition of hydrochloric acid $(\mathrm{HCl})$, provided a porous surface made out of $\mathrm{p}-\mathrm{Ti}_{3} \mathrm{C}_{2} \mathrm{~T}_{x}$ nanosheets on the anode, which enhanced its capacity as well as its rate capability. The $\mathrm{p}-\mathrm{Ti}_{3} \mathrm{C}_{2} \mathrm{~T}_{x}$ presented pore sizes from $1-20 \mathrm{~nm}$ and a surface area of $84.2 \mathrm{~m}^{2} \mathrm{~g}^{-1}$. Regarding the electrochemical results, this work reports values for high current densities: for $1000 \mathrm{~mA} \mathrm{~g}^{-1}$, the specific capacitance achieved was $166 \mathrm{mAh} \mathrm{g}^{-1}$; while at $10 \mathrm{~A} \mathrm{~g}^{-1}$ it was $124 \mathrm{mAh} \mathrm{g}^{-1}$, outperforming works previously published $[47,207,208]$. Figure 9 includes the important findings of Xie et al.'s work in detail [206]. Figure 9b shows the raman spectra of the MXene before and after restacking, whereas Figure 9c-f are the SEM and TEM images of the layered structure. Figure $9 \mathrm{~g}, \mathrm{~h}$ represent the electrochemical performance of the MXene as an anode in SIB.
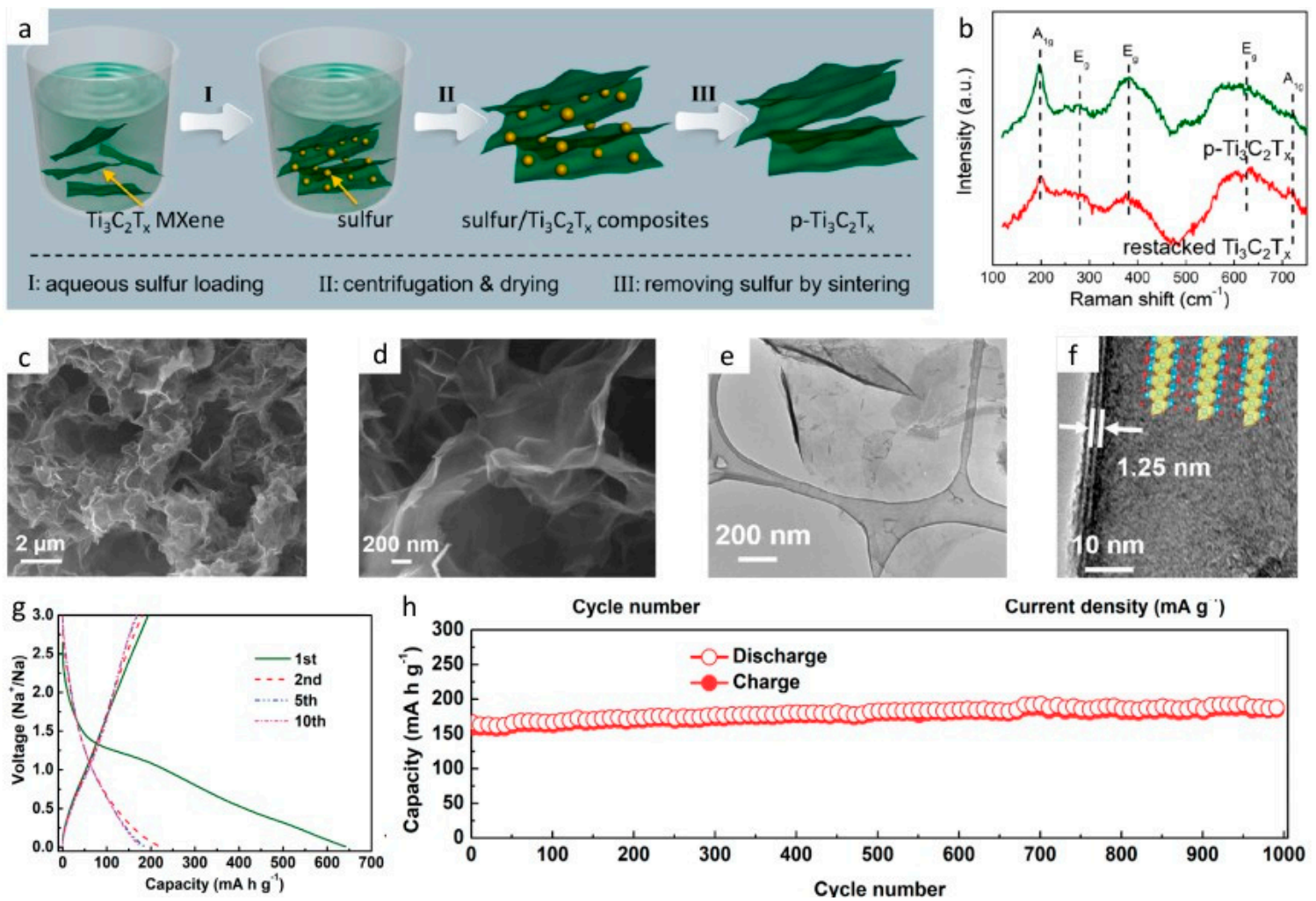

Figure 9. Structural characterization and electrochemical performance analysis of $\mathrm{p}-\mathrm{Ti}_{3} \mathrm{C}_{2} \mathrm{~T}_{x}$ as an anode in SIBs: (a) schematic preparation steps of $\mathrm{p}-\mathrm{Ti}_{3} \mathrm{C}_{2} \mathrm{~T}_{x},(\mathbf{b})$ Raman spectra of $\mathrm{p}-\mathrm{Ti}_{3} \mathrm{C}_{2} \mathrm{~T}_{x}$ (green curve) and the pristine restacked $\mathrm{Ti}_{3} \mathrm{C}_{2} \mathrm{~T}_{x}$ (red curve), (c,d) scanning electron microscopy (SEM) images of $\mathrm{p}-\mathrm{Ti}_{3} \mathrm{C}_{2} \mathrm{~T}_{x}$ as-prepared, $(\mathbf{e}, \mathbf{f})$ transmission electron microscopy (TEM) of $\mathrm{p}-\mathrm{Ti}_{3} \mathrm{C}_{2} \mathrm{~T}_{x}$ as-prepared, (g) charge-discharge curves of $\mathrm{p}-\mathrm{Ti}_{3} \mathrm{C}_{2} \mathrm{~T}_{x} 100 \mathrm{mAg}^{-1}$, and (h) cycling performance at current density of $1 \mathrm{~A} \mathrm{~g}^{-1}$ showing the cycle stability. Reprinted with permission from [206]. Copyright 2018, American Chemical Society.

Thus, MXenes are a promising family of anode materials for SIBs because of their variety, relative stability in dry air, hydrophilicity, and high conductivity [207,209-211]. In contrast, the restacking of MXene layers because of van der Waals forces, along with hydrogen bonds, hinders the accessibility of ions to active sites on the materials, thereby decreasing its electrochemical performance [207]. Moreover, mechanical methods for obtaining MXenes are generally not possible due to the strong bonds between 
layers, which are different from those of TMDs and graphite [197]. Finally, given the fact that MXenes are considered a new family of materials, their properties are yet not fully understood by the scientific community, which means that there are challenges and questions that need to be answered for their wide-scale applicability, and developing methods and strategies for preventing MXene nanosheets from restacking, thereby providing a path for ionic transport.

Table 4 lists the performance of several notable 2D materials which have been used as anodes for Na-ion battery applications.

Table 4. High performance of 2D materials as anodes in Na-ion battery systems.

\begin{tabular}{|c|c|c|c|c|}
\hline $\begin{array}{c}\text { Type of 2D Materials } \\
\text { Anode }\end{array}$ & Electrolyte Chemistry & $\begin{array}{l}\text { Voltage } \\
\text { Range (V) }\end{array}$ & Performance * & Reference \\
\hline $\mathrm{P} / \mathrm{N}$-doped graphene & $1 \mathrm{M} \mathrm{NaPF}_{6}$ in EC/DEC & - & $809 / 350 / 1500$ & [212] \\
\hline HRGO300 & $1 \mathrm{M} \mathrm{NaClO}_{4}$ in EC/DMC/FEC & $0-3.0$ & $163 / 3000 / 2000$ & [213] \\
\hline VSG2 & ester-based & $0-3.0$ & $402 / 300 / 500$ & [214] \\
\hline Nanoporous RP on rGO & $1 \mathrm{M} \mathrm{NaClO}{ }_{4}$ in $\mathrm{PC} / 5$ wt. $\%$ FEC & $0.01-2.0$ & $775.3 / 1500 / 5120$ & [215] \\
\hline $\mathrm{SbPO}_{4} / \mathrm{rGO}$ & $1 \mathrm{M} \mathrm{NaClO}_{4}$ in $\mathrm{PC}$ & $0-1.5$ & $100 / 1000 / 1000$ & [156] \\
\hline $\mathrm{Ti}_{2} \mathrm{Nb}_{2} \mathrm{O}_{9}$ nanosheets & $\begin{array}{l}1 \mathrm{M} \mathrm{NaPF}_{6} \text { in diethylene glycol } \\
\text { dimethyl ether }\end{array}$ & $\sim 0.1-3.0$ & $\sim 160 / 500 / 800$ & [216] \\
\hline $\mathrm{MoS}_{2} / \mathrm{S}$-doped graphene & $1 \mathrm{M} \mathrm{NaPF}_{6}$ in DEC/EC & $0.005-3.0$ & $309 / 500 / 1000$ & [217] \\
\hline Mesoporous $\mathrm{MoS}_{2} / \mathrm{C}$ & $\begin{array}{c}1 \mathrm{M} \mathrm{NaClO}_{4} \text { in } \mathrm{DMC} / \mathrm{EC} / 5 \text { wt.\% } \\
\text { FEC }\end{array}$ & $0.05-3.0$ & $390 / 2500 / 1000$ & [218] \\
\hline $\begin{array}{c}\mathrm{MoSe}_{2} @ \mathrm{~N}, \mathrm{P}-\text { carbon } \\
\text { nanosheet }\end{array}$ & $1 \mathrm{M} \mathrm{NaPF}_{6}$ in $\mathrm{DEC} / \mathrm{EC} / 5$ wt. $\% \mathrm{FE}$ & $0-3.0$ & $168 / 1000 / 500$ & [196] \\
\hline
\end{tabular}

* Specific capacity $\left(\mathrm{mAh} \mathrm{g}^{-1}\right) /$ number of cycles/current density $\left(\mathrm{mA} \mathrm{g}^{-1}\right)$.

\section{Cathodes}

Cathodes are a very important aspect of SIBs and should be able to reversibly intercalate the $\mathrm{Na}^{+}$ions, preferably at voltages greater than $2 \mathrm{~V}$ [219]. Ideally a cathode should exhibit low volume expansion upon intercalating $\mathrm{Na}+$ ions and structural stability [219]. It is also essential that they can be synthesized from low-cost and earth-abundant precursors and also be able to provide high specific capacities and energy densities $[1,22]$. Some of the prominent high-performance cathodes currently being studied for SIBs are discussed below in greater detail.

\subsection{Layered Transition Metal Oxides (TMOs)}

Layered TMOs have received significant attention and research as cathodes for LIBs and, therefore, have been applied to SIBs, as well. The most common layered TMO is usually of the form $\mathrm{NaMO}_{2}$ $(\mathrm{M}=\mathrm{Mn}, \mathrm{Fe}, \mathrm{Co}, \mathrm{Ni})$, which are notable because of their elevated redox potentials and energy densities [19,22]. Consequently, one of the first type of layered metal oxides to be studied for SIBs were of the type $\mathrm{AMO}_{2}$, where $\mathrm{A}=\mathrm{Li}, \mathrm{Na}$ and $\mathrm{M}$ is a transition metal, e.g., $\mathrm{Mn}, \mathrm{Fe}, \mathrm{Co}$, etc. [22]. These materials have the advantage of being relatively stable, easy to fabricate, and having a large body of research knowledge already available due to their applications in LIBs for a number of years [220,221]. A study by Delmas et al., published in 1981, compared the performance of different structural variants of $\mathrm{Na}_{\mathrm{x}} \mathrm{CoO}_{2}$, the P3 and the $\mathrm{O} 2$ [222]. Another important study was by Shibata, who determined the diffusion coefficient of $\mathrm{Na}^{+}$ions into the $\mathrm{Na}_{x} \mathrm{CoO}_{2}$ lattice at room temperatures [223]. Since then, Yabuuchi et al., have synthesized $\mathrm{NaFeO}_{2}$ as a cathode for SIB systems [224]. An important study in this area was published by Komaba et al., who studied the performance of $\mathrm{Na}_{2 / 3}\left[\mathrm{Fe}_{1 / 2} \mathrm{Mn}_{1 / 2}\right] \mathrm{O}_{2}$ as a cathode for SIBs [225,226].

The search for high energy cathode materials has led to the further development of more improved and innovative cathode systems, such as $\mathrm{O}$ and the $\mathrm{P}$ type layered oxides, where the $\mathrm{Na}^{+}$ion exists in prismatic and octahedral configurations, respectively [19]. Also, depending upon the type of stacking, they are further classified as O3 (ABCABC), P2 (ABBA), and P3 (ABBCCA) types [19,227]. 
A layered quaternary $\mathrm{O} 3$ type material, $\mathrm{Na}\left(\mathrm{Mn}_{0.25} \mathrm{Fe}_{0.25} \mathrm{Co}_{0.25} \mathrm{Ni}_{0.25}\right) \mathrm{O}_{2}$ has been demonstrated to work as a cathode in SIBs by Li et al. [228]. An initial capacity of $180 \mathrm{mAh} \mathrm{g}^{-1}$ and an effective specific energy density of $578 \mathrm{Wh} \mathrm{kg}^{-1}$ were obtained, which have been attributed to the excellent reversibility of $\mathrm{Na}+$ ions in the $\mathrm{O} 3$ layered structure. Zhou et al. have demonstrated that Co substitution enhances the performance of the $\mathrm{O} 3$ type material, $\mathrm{NaNi}_{0.45-\mathrm{x}} \mathrm{Mn}_{0.25} \mathrm{Ti}_{0.3} \mathrm{Co}_{\mathrm{x}} \mathrm{O}_{2}\left(\mathrm{NMTCo}_{\mathrm{x}}\right)$, with the optimum $x$ being 0.05 [229]. This cathode provides a specific capacity of $180 \mathrm{mAh} \mathrm{g}^{-1}$ at a current density of $10 \mathrm{~mA} \mathrm{~g}^{-1}$. Co enhances the performance by improving electronic conductivity and $\mathrm{Na}^{+}$kinetics [229]. The results of Zhou et al.'s work are provided in Figure 10 below. Here, Figure 10a is a SEM image showing the bead like morphology of the particles with a size range of approximately $1-2 \mu \mathrm{m}$, and Figure 10b is an HRTEM image of the same. Figure 10c shows the XRD stack of the various NMTC samples, Figure $10 \mathrm{~d}-\mathrm{i}$ is the elemental maps of the sample, showing a homogenous distribution. Figure $10 \mathrm{j}$ is the schematic representation of the synthesis process, and Figure 10k,1 is the CV and cycling performance of the material as a positive electrode in SIBs.
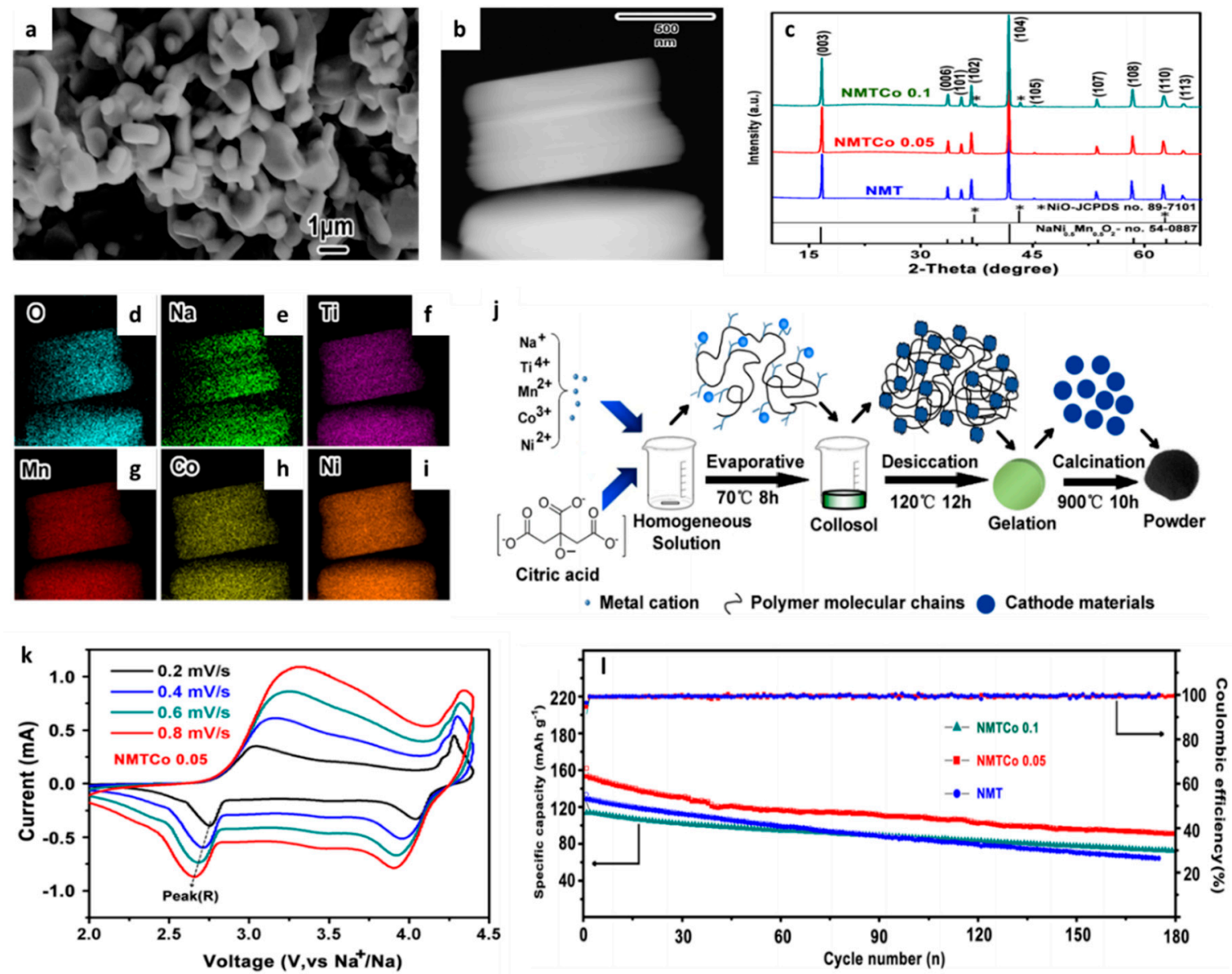

Figure 10. Structural characterization and electrochemical performance analysis of $\mathrm{NaNi}_{0.45-\mathrm{x}} \mathrm{Mn}_{0.25} \mathrm{Ti}_{0.3} \mathrm{Co}_{\mathrm{x}} \mathrm{O}_{2}$ (NMTCo ${ }_{\mathrm{x}}$ ) cathode in SIBs. (a) SEM images of the NMTCo $\mathrm{N}_{0.05}$ sample demonstrating particle sizes of approximately 1-2 $\mu \mathrm{m}$ with a bead like morphology. (b) HRTEM image showing the morphology of the microparticle in greater detail. (c) XRD pattern of NMT samples with varying Co concentration $(0,0.05,0.1)$ demonstrating the characteristic peaks, strong crystallinity and structural evolution. (d-i) Elemental maps of the microparticles with the constituent elements labeled. (j) Schematic representation of the steps in the synthesis process for the NMT samples. (k) Cyclic voltammetry curves of the NMTCo0.05 sample at progressively increasing scan rates $\left(0.2-0.8 \mathrm{mV} \mathrm{s}^{-1}\right)$ with the characteristic redox peaks clearly visible. (1) Capacity retention and coulombic efficiency plots of the NMT cathodes over 180 cycles. Copyright 2019, American Chemical Society. 
A P2 type cathode for SIB applications has been studied by Yabuuchi et al. [226], who synthesized $\mathrm{Na}_{\mathrm{x}}\left[\mathrm{Fe}_{0.5} \mathrm{Mn}_{0.5}\right] \mathrm{O}_{2}$ using a simple solid state reaction from its precursors $\left(\mathrm{Na}_{2} \mathrm{O}_{2}, \mathrm{Fe}_{2} \mathrm{O}_{3}\right.$, and $\left.\mathrm{Mn}_{2} \mathrm{O}_{3}\right)$. A maximum specific capacity of $190 \mathrm{mAh} \mathrm{g}^{-1}$ at $2.75 \mathrm{~V} \mathrm{vs}$. Na/Na ${ }^{+}$, and an energy density as high as $520 \mathrm{mWh} \mathrm{g}^{-1}$, comparable to $\mathrm{LiFePO}_{4}$, was obtained. The authors have attributed the beneficial results to the accessibility of the $\mathrm{Fe}^{3+} / \mathrm{Fe}^{4+}$ redox system by intercalating $\mathrm{Na}^{+}$ions. Further, this cathode provides the added advantage of utilizing elements ( $\mathrm{Fe}, \mathrm{Mn}$ ) that are abundant in the earth and are, therefore, cost efficient [226]. A high performance P2 type layered $\mathrm{Na}_{0.5}\left[\mathrm{Ni}_{0.23} \mathrm{Fe}_{0.13} \mathrm{Mn}_{0.63}\right] \mathrm{O}_{2}$ has been studied by Hasa et al. [230]. Here, too, the electrode was synthesized by a solid state reaction from its precursors and was able to deliver a $200 \mathrm{mAh} \mathrm{g}^{-1}$ at a current density of $15 \mathrm{~mA} \mathrm{~g}^{-1}$ with a coulombic efficiency of almost $100 \%$. The stability of the layered structure was deemed responsible for the superior performance [230].

Honeycomb layered $\mathrm{Na}_{3} \mathrm{Ni}_{2-x} \mathrm{Mg}_{x} \mathrm{SbO}_{6}$ compounds have been analyzed by You and coworkers. The electrodes were synthesized from their precursors by simple solid state reactions and a maximum capacity of $115 \mathrm{mAh} \mathrm{g}^{-1}$ was obtained for the compound with $\mathrm{x}=1$ [231]. All the cathodes show almost $100 \%$ coulombic efficiencies and capacity retentions greater than $70 \%$, even after 200 cycles [231]. A complex phase transition from $\mathrm{P} 3$ to $\mathrm{O} 1$ during the $\mathrm{Na}^{+}$ion intercalation process and the rearranging of the structure to improve kinetics and stability help to account to for the enhanced performance [231].

Layered TMOs have several advantages. They were one of the first cathodes, e.g., one of the first layered $\mathrm{NaMnO}_{2}$ products to be evaluated for application in SIBs, and, therefore, there is a significant body of knowledge available for varying synthesis procedures, especially those related to manipulating the interlayer spacings [19]. An important advantage of these oxides is that they use relatively low cost metals, such as $\mathrm{Mn}, \mathrm{Fe}, \mathrm{Ni}$, as their constituents [232,233]. These oxides also are able to withstand large strains and demonstrate considerable structural integrity [234].

Despite the above-mentioned performances and advantages, these compounds demonstrate some drawbacks as well. For example, their sensitivity to air and low electronic conductivity is an important issue [19]. Stability is sometimes another issue, with some of the electrodes demonstrating steady capacity decays, especially at high current rates. This is another aspect that needs improvement [219]. Many of these oxides, especially the Mn incorporated ones, tend to undergo a structural distortion-the Jahn-Teller effect that hinders a long cycle life [235].

It is expected that layered TMOs will continue to play a significant role as cathode materials for SIBs. Their easily procurable raw materials, multiple and varying synthesis methods, and different obtainable crystal structures will continue to play an important role in their favor [236]. Several techniques have been developed to overcome the Jahn-Teller distortion, substitution by $\mathrm{Mg}$ to suppress the polarization is one of the techniques that have been applied with some success [237]. Also being studied are vanadium based oxides, as the open framework provided by these cathodes allows ions to intercalate easily without much friction or hindrance within the structure, thereby helping to achieve greater stability and reversibility [238].

\subsection{Polyanionic Compounds}

Polyanionic materials provide a novel and diverse group of materials that have found widespread applications as high performance cathodes for SIBs [1]. Various different poly-anionic species, e.g., $\left(\mathrm{PO}_{4}\right)^{3-},\left(\mathrm{SO}_{4}\right)^{2-},\left(\mathrm{P}_{2} \mathrm{O}_{7}\right)^{4-}$, provide open framework structures that relatively enhance intercalation [1,227].

Sodium Superionic Conductors (NASICON) are a special class of polyanionic compounds that have 3D structures and large tunnels for the fast conduction of $\mathrm{Na}^{+}$ions $[19,227]$. A classical NASICON compound, $\mathrm{Na}_{3} \mathrm{~V}_{2}\left(\mathrm{PO}_{4}\right)_{3}$, has a $\mathrm{VO}_{6}$ octahedra and $\mathrm{PO}_{4}$ tetrahedra sharing a corner, thereby creating a $3 \mathrm{D} \mathrm{V}_{2} \mathrm{P}_{3} \mathrm{O}_{12}$ backbone, as well as multiple $\mathrm{Na}^{+}$ion interstitial sites [239]. Consequently, NASICONs have demonstrated promise as cathodes for SIBs. 


\subsubsection{Phosphates}

$\mathrm{NaFePO}_{4}$ have been synthesized and studied as an analogue, keeping the more popular and established $\mathrm{LiFePO}_{4}$ electrode in mind, which is generally used for LIBs. The initial synthesis of electrochemically active $\mathrm{LiFePO}_{4}$ was performed by low temperature $\mathrm{Li} / \mathrm{Na}$ ion exchange from $\mathrm{LiFePO}_{4}$ [240]. However, the $\mathrm{NaFePO}_{4}$ produced by this technique possess weak kinetics. An early work by $\mathrm{Lu}$ et al. proposed that for $\mathrm{Na}_{x} \mathrm{FePO}_{4}$, the solid solution phase was preferable for $\mathrm{x}>2 / 3$, whereas phase separation into $\mathrm{FePO}_{4}$ and $\mathrm{Na}_{2 / 3} \mathrm{FePO}_{4}$ occurs at $x<2 / 3$ [241]. Further important work in this area was done by Boucher et al., who first revealed the structure of $\mathrm{Na}_{2 / 3} \mathrm{FePO}_{4}$ using transmission electron microscopy (TEM) and synchrotron x-ray diffraction techniques [242]. A more recent, but pioneering, work in this area was done by Kim et al., who showed that maricite, an electrochemically inactive phase of $\mathrm{NaFePO}_{4}$, is electrochemically active when it is made of nanoparticles. A reversible capacity of $142 \mathrm{mAh} \mathrm{g}^{-1}$ was obtained, with $95 \%$ capacity retention over 200 cycles of operation [243]. More discussion of some of the important works in this area is provided in the paragraphs below.

Sun et al. have studied $\mathrm{NaFePO}_{4}$ as a reversible cathode material in SIBs [244]. An olivine electrode was synthesized using a galvanostatic reduction process and was able to provide a capacity of $125 \mathrm{mAh} \mathrm{g}^{-1}$ at a working voltage of $2.7 \mathrm{~V}$ with a current density of $7.5 \mathrm{~mA} \mathrm{~g}^{-1}$. Structural stability was maintained over 50 cycles of operation, and the authors have attributed this to the rather strong P-O polyanion bonds, which help to preserve the olivine structure [244]. Li et al. have studied hollow amorphous $\mathrm{NaFePO}_{4}$ nanospheres as positive electrodes in SIBs [245]. The spheres were prepared using a "hard template method" using iron (II) stearate, $\mathrm{NaH}_{2} \mathrm{PO}_{4}$, and sodium oleate as precursors. A maximum of $152 \mathrm{mAh} \mathrm{g}^{-1}$ was obtained at a $1 \mathrm{C}$ current density with more than $95 \%$ capacity retention over 300 cycles of operation [245]. The amorphous nature prevents lattice stresses and provides a non-disruptive conductive pathway for the sodium ions, which, as per the authors, enables superior electrochemical performance [245].

$\mathrm{NaFePO}_{4}$ has also been used as a composite and/or a hybrid to obtain enhanced performance. A polythiophene (PTh) encapsulated $\mathrm{NaFePO}_{4}$ as a cathode in SIBs has been analyzed by Ali and coworkers [246]. The $\mathrm{NaFePO}_{4}$ olivine was synthesized by delithiating $\mathrm{LiFePO}_{4}$, followed by in-situ polymerization and the addition of $\mathrm{NaI}$ [246]. A specific capacity of $142 \mathrm{mAh} \mathrm{g}^{-1}$ was obtained at a current density of $10 \mathrm{~mA} \mathrm{~g}^{-1}$ within a voltage range of 2.2-4.0 $\mathrm{V}$ and with a capacity retention of $94 \%$ over 100 cycles of operation. The addition of the PTh layer enhanced performance by improving conductivity and enabling better stress relieving of the composite [246]. Along similar lines, Fang et al. synthesized a $\mathrm{NaFePO}_{4} / \mathrm{C}$ microsphere hybrid by forming $\mathrm{LiFePO}_{4}$ using lithium acetate, $\mathrm{Fe}\left(\mathrm{NO}_{3}\right)_{3} \cdot 9 \mathrm{H}_{2} \mathrm{O}, \mathrm{NH}_{4} \mathrm{H}_{2} \mathrm{PO}_{4}$, and citric acid as precursors, followed by electrochemical delithiation and subsequent sodiation in a $1 \mathrm{~mol}^{-1} \mathrm{Na}_{2} \mathrm{SO}_{4}$ solution [247]. The olivine cathode was able to provide a specific discharge capacity of $111 \mathrm{mAh} \mathrm{g}^{-1}$ with a capacity retention of $90 \%$ of $\sim 95 \%$ after 240 cycles of operation, at a current density of $0.2 \mathrm{C}$ [247]. The authors have been able to identify a two-stage phase transition of $\mathrm{NaFePO}_{4}$ during the $\mathrm{Na}^{+}$ion intercalation-deintercalation process [247]. Figure 11 demonstrates the important findings of Fang et al.'s work in greater detail, in which Figure 11a,b features SEM and TEM images, which demonstrate the morphology in greater detail. Figure 10c represents the XRD patterns of the various phosphate phases, and Figure 11d-i shows the elemental maps and elemental composition of the different component elements. Figure $11 \mathrm{j}$ features a schematic representation of the electrochemically mediated displacement reaction used to synthesize the $\mathrm{NaFePO}_{4}$ sample, and Figure 11k-m shows the representations of the electrochemical performances of the sample positive electrode. 

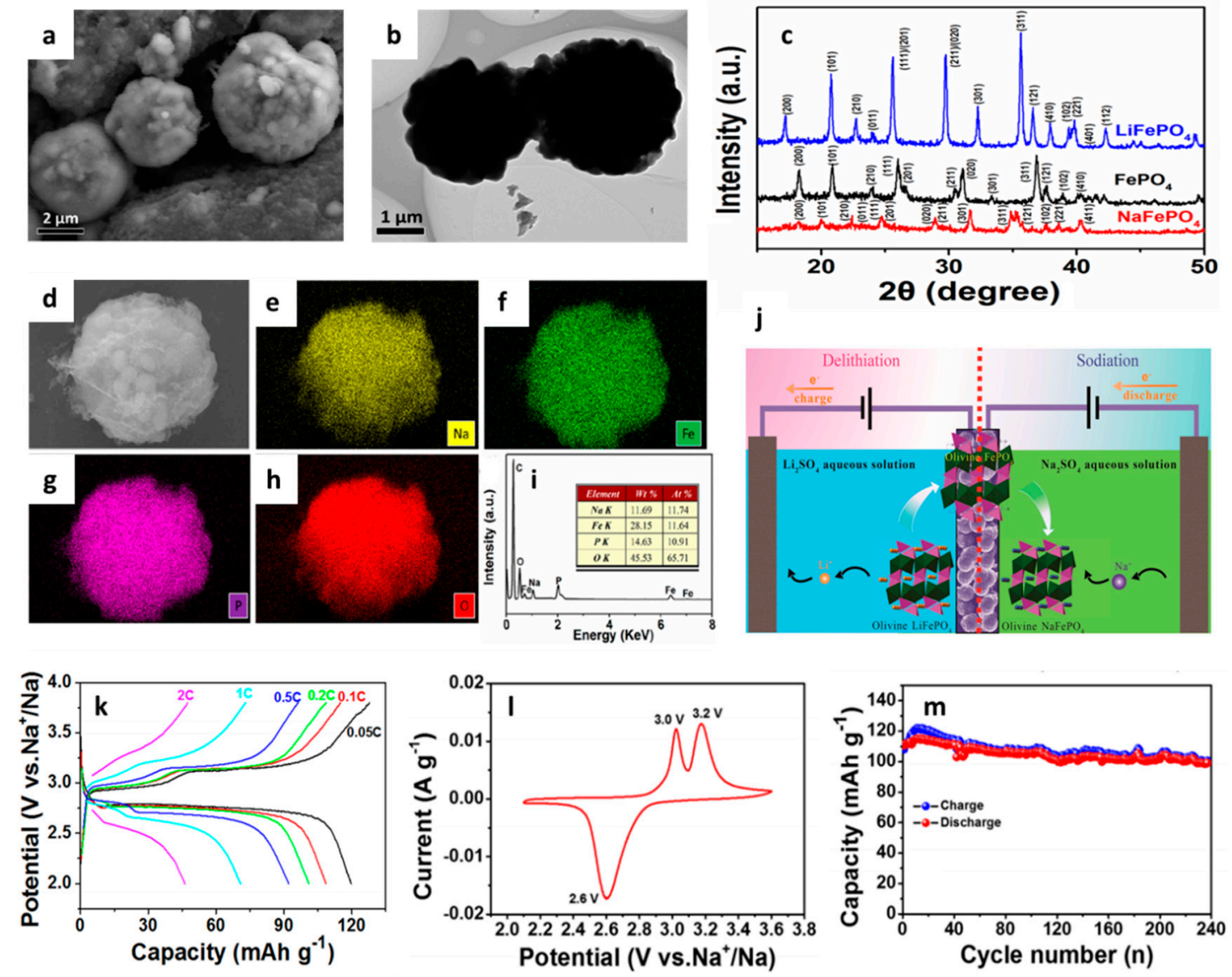

Figure 11. The structural characterization and electrochemical performance analysis of $\mathrm{NaFePO}_{4} / \mathrm{C}$ composite as a cathode in SIBs. (a) SEM images of the $\mathrm{NaFePO}_{4} / \mathrm{C}$ composites demonstrating a rather smooth spherical morphology. (b) TEM image showing the morphology of the microsphere composite in greater detail. (c) XRD pattern of $\mathrm{LiFePO}_{4}$ powder precursor, the delithiated $\mathrm{FePO}_{4}$ sample and the $\mathrm{NaFePO}_{4}$ sample demonstrating the characteristic peaks. (d-h) Elemental maps of the microsphere composite exhibiting the constituent elements and a rather uniform distribution. (j) Schematic representation of the electrochemical displacement reaction that results in the formation of $\mathrm{NaFePO}_{4}$ from $\mathrm{LiFePO}_{4}$. (k) Galvanostatic charging-discharging curves of the half-cell with $\mathrm{NaFePO}_{4} / \mathrm{C}$ cathode at various rates. (l) $\mathrm{CV}$ of the $\mathrm{NaFePO}_{4} / \mathrm{C}$ cathode system vs. $\mathrm{Na} / \mathrm{Na}^{+}$showing the characteristic redox peaks. (m) Capacity retention of the $\mathrm{PB}$ composite cathode for both the charge and discharge cycles. Copyright 2015, American Chemical Society.

\subsubsection{NASICON Compounds and Fluorophosphates}

Hong and Goodenough first proposed the tunnel structure for $\mathrm{Na}^{+}$diffusion in 3D $\mathrm{Na}_{1+\mathrm{x}} \mathrm{Zr}_{2} \mathrm{P}_{3-\mathrm{x}} \mathrm{Si}_{\mathrm{x}} \mathrm{O}_{12}$ [248]. Van Alpen proposed a more accurate formula for NASICON for the first time in 1981, and the first non-stoichiometric single crystal rhombohedral NASICON compound, $\mathrm{Na}_{3.1} \mathrm{Zr}_{1.78} \mathrm{Si}_{1.24} \mathrm{P}_{1.76} \mathrm{O}_{12}$, was developed in 1983 [249,250]. Most of the early work focused on synthesizing NASICON electrodes by high temperature solid state reactions [251]. An important development was the synthesis of NASICON from the solutions of their precursors using sol-gel chemistry, and Engell developed several different NASICON compounds using the respective metal alkoxides in about 1983 [252]. However, the first experimental report for the application of NAISCON in energy storage devices was by Delmas et al., who studied $\mathrm{NaTi}_{2}\left(\mathrm{PO}_{4}\right)_{3}$ as early as 1987 [253]. Since then, NASICON type compounds have been extensively studied and some of the important studies highlighting the applicability of NASICON as positive electrodes in SIBs are provided below.

Kang and coworkers studied a $\mathrm{Na}_{3} \mathrm{~V}_{2}\left(\mathrm{PO}_{4}\right)_{3} / \mathrm{C}$ composite as a cathode in SIBs [254]. The cathode was synthesized using a polyol mediated pyro-synthetic method from its precursors. The authors 
were able to obtain about $117 \mathrm{mAh} \mathrm{g}^{-1}$ at $0.01 \mathrm{C}$ and $65 \mathrm{mAh} \mathrm{g}^{-1}$ (56\% of theoretical capacity) was obtained at a high current density of $2.67 \mathrm{C}$. The porosity of the nanoparticles and the introduction of $\mathrm{C}$ helped to improve the electrochemical performance [254]. Electrospun $\mathrm{Na}_{3} \mathrm{~V}_{2}\left(\mathrm{PO}_{4}\right)_{3} / \mathrm{C}$ nanofibers were studied as SIB cathodes by Liu et al. [255]. The precursors were $\mathrm{NaH}_{2} \mathrm{PO}_{4}, \mathrm{NH}_{4} \mathrm{VO}_{3}$, citric acid, and polyethylene oxide (PEO), which were electrospun, followed by carbonization (in $\mathrm{Ar}$ at $500{ }^{\circ} \mathrm{C}$ ) and vacuum annealing. $94 \mathrm{mAh} \mathrm{g}^{-1}$ was obtained at a current density of $2 \mathrm{C}$ and showed very good stability over 66 cycles of operation [255]. The enhanced performance of NASICON has been attributed to its stability and the uniform contact of the fibers of the composite [255].

A 3D graphene decorated $\mathrm{NaTi}_{2}\left(\mathrm{PO}_{4}\right)_{3}$ (NTO@rGO) was studied as a cathode in SIBs by Fang et al. [256]. Reversible capacities as high as $138 \mathrm{mAh} \mathrm{g}^{-1}$ at $0.1 \mathrm{C}$ and a capacity retention of $77 \%$ over 1000 cycles were obtained, attributable to the 3D structure and improvement of conductivity by graphene addition [256]. Gao et al. examined NASICON structured $\mathrm{Na}_{3} \mathrm{MnZr}\left(\mathrm{PO}_{4}\right)_{3}$ for applications as positive electrodes in SIBs [257]. The material was prepared using a sol-gel technique and provided a specific discharge capacity of $105 \mathrm{mAh} \mathrm{g}^{-1}$ at a current rate of $0.1 \mathrm{C}$ (which was almost equal to the theoretical capacity of $107 \mathrm{mAh} \mathrm{g}^{-1}$ ), which the authors have attributed to the reversible intercalation/deintercalation of $\mathrm{Na}^{+}$ions into the NASICON lattice [257]. However, at higher $\mathrm{C}$ rates, performance decreased due to Jahn-Teller distortion and oxidation of the electrolyte [257].

Liu et al. studied a core shell structured fluorophosphate nanocomposite, $\mathrm{Na}_{3} \mathrm{~V}_{2}\left(\mathrm{PO}_{4}\right)_{2} \mathrm{~F}_{3} @ \mathrm{C}$, (NVPF@C) as a cathode in SIBs [258]. A reversible specific capacity of $125 \mathrm{mAh} \mathrm{g}^{-1}$ was obtained at a current density of $0.5 \mathrm{C}, 84 \mathrm{mAh} \mathrm{g}^{-1}$ at high current densities, such as $50 \mathrm{C}$, and the material showed a $65 \%$ capacity retention, even after 5000 cycles. This high performance and stability could be related to the confinement of the NVPF particles in the mesoporous structure [258]. The important results of Liu et al.'s work are summarized in Figure 12 below. Here, Figure 12a,b is the SEM and TEM images, respectively, of the composite bead, which shows characteristic morphology. Figure 12c shows the XRD patterns of the core shell sample compared to that of the just carbon coated sample. Figure $12 \mathrm{~d}$ represents the HRTEM FFT image of the core shell sample, and Figure 12e-k shows the elemental maps. Figure 12i schematically represents the synthesis procedure and Figure $12 \mathrm{~m}-\mathrm{o}$ demonstrates the electrochemical analysis of the material as a positive electrode in SIBs.

However, the presence of these large polyanionic groups reduces net energy density, and NASICON compounds need carbon or graphene support to improve conductivity and kinetics. Thus, greater work needs to be done to enhance their effectiveness.

Polyanionic materials, especially NASICONs, have attracted significant attention due to their large networks and variable tunnel structures. They are able to easily allow insertion and deinsertion of $\mathrm{Na}+$ ions and are relatively structurally stable, thereby allowing for a long cycle life [259]. Notably, NASICONs exist in an assortment of structures, from orthorhombic $\mathrm{Na}_{3} \mathrm{Ti}_{2}(\mathrm{PO} 4)_{3}$, to rhombohedral, to the monoclinic $\mathrm{Na}_{3} \mathrm{~V}_{2}(\mathrm{PO} 4)_{3}$ [260].

However, low electronic conductivity is one of the primary hindrances to realizing their full potential. Surface functionalization with carbon and making nanoparticles seemed to improve the performance in this case $[19,261]$. Nitrogen doping has been also demonstrated to improve overall electrochemical performance, but it has been observed that $\mathrm{N}$ doped materials are particularly sensitive to moisture, which reduces their effectiveness [262]. The use of vanadium ions in the NASICON structure has also raised toxicity and environmental concerns [263].

The path forward for NASICONs lies in integrating them with high conductivity materials, such as composites with graphene or carbon nanotubes, thereby making nanostructures to improve conductivity and reduce structural defects during synthesis [264,265]. With the advent of sol-gel based techniques for NASICON synthesis, greater control can be had over the structural parameters, and this promises an important path forward [266]. 

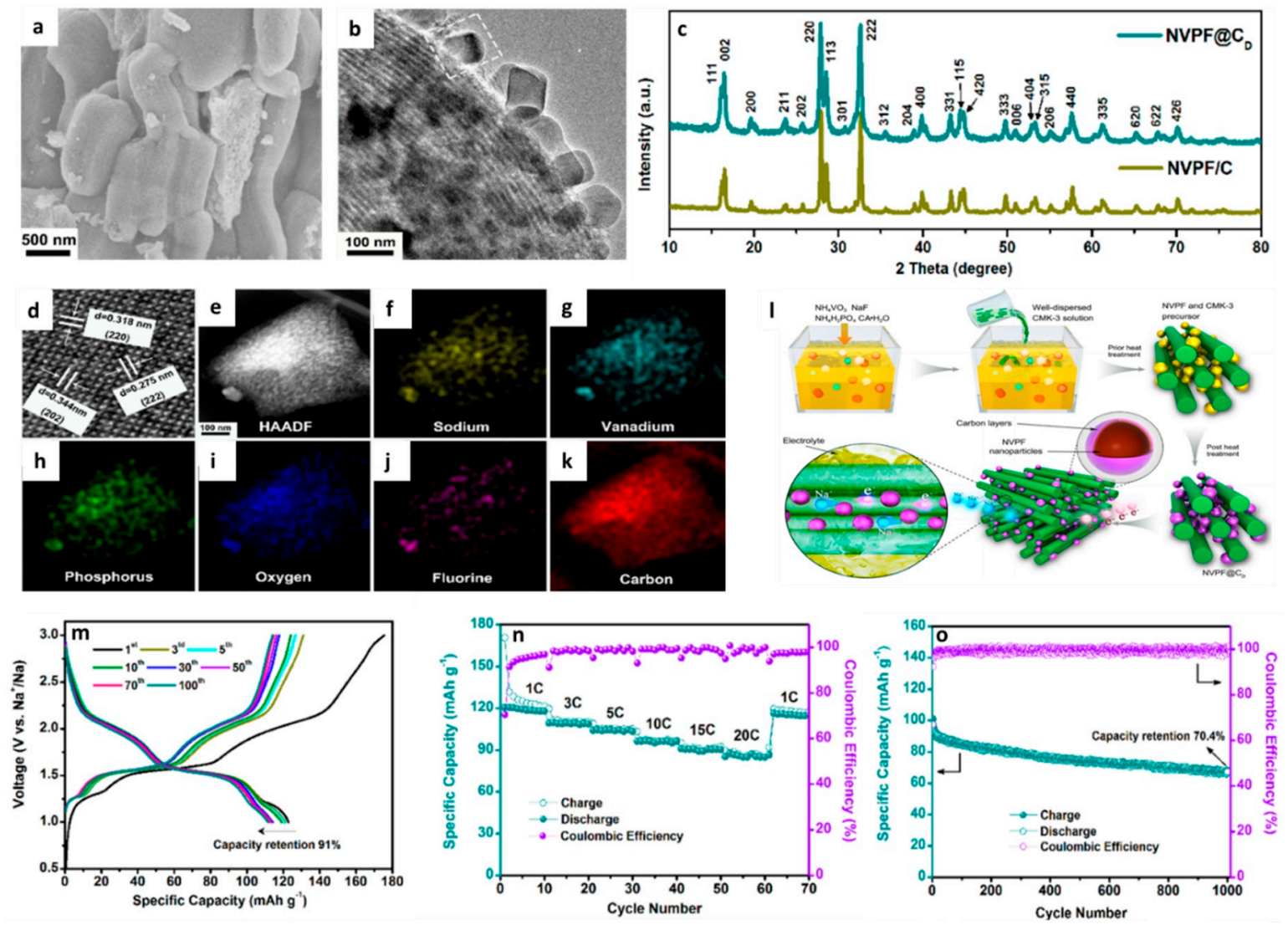

Figure 12. Structural characterization and electrochemical performance analysis of $\mathrm{NaFePO}_{4} / \mathrm{C}$ composite as a cathode in SIBs. (a) SEM images of the $\mathrm{Na}_{3} \mathrm{~V}_{2}\left(\mathrm{PO}_{4}\right)_{2} \mathrm{~F}_{3} @ \mathrm{C}(\mathrm{NVPF} / \mathrm{C})$ composites exhibiting bead like morphology. (b) TEM image showing the morphology demonstrating the "worm-like" mesoporous structure. (c) XRD pattern of NVPF sample with the core-double shell structure $\left(\mathrm{NVPF} @ \mathrm{C}_{\mathrm{d}}\right.$ ) in comparison with the NVPF sample with just simple carbon coating (NVPF@C), demonstrating the characteristic peaks. (d) FFT image of the NVPF@Cd sample clearly demonstrating the carbon coating in the nanocomposite. (e-h) Elemental maps of the NVPF@C $\mathrm{C}_{\mathrm{d}}$ composite depicting the constituent elements uniformly distributed. (j) Schematic representation of the synthesis of the NVPF@Cd nanocomposite from its precursors. (k) Galvanostatic charging-discharging curves of the half-cell with $\mathrm{NVPF} / \mathrm{C}_{\mathrm{d}}$ cathode for various cycles. (1) Rate performance demonstration of the nanocomposite electrode showing its performance at varying $\mathrm{C}$ rates. (m) Capacity retention of the NVPF@C $C_{d}$ composite and its corresponding coulombic efficiency. Copyright 2016, American Chemical Society.

\subsection{Prussian Blue}

Prussian blue (PB), chemically, is a compound with a mixed valency of iron, generally in the +2 and +3 oxidation states. $\mathrm{Fe}_{4}\left[\mathrm{Fe}(\mathrm{CN})_{6}\right]_{3} \cdot \mathrm{nH}_{2} \mathrm{O}$ is the most general formula of an unmodified PB compound [267]. The crystal's structure is usually cubic, with iron atoms alternating at the face centered position associated with $\mathrm{C}-\mathrm{N}$ pairs and the $\mathrm{Fe}^{3+}$ and $\mathrm{Fe}^{2+}$ being surrounded by nitrogen and carbon environments, respectively; this compound can be chemically referred to as a hexacyanoferrate (HCF). There are zeolitic water molecules that are generally contained in some of the octahedral vacant interstitial spaces. Essentially, due to its mixed-valence and open framework structure, PB can be modified by other atoms like $\mathrm{Mn}, \mathrm{Zn}, \mathrm{Ni}$, Co substitutionally for Fe, and these compounds are then designated as prussian blue analogues (PBA). These PBAs provide channels for alkali ion diffusion, and the choice of the transition metal substituting for Fe can enhance the intercalating ionic mobility further by reducing the diffusion barrier. These interesting properties have resulted in significant interest in PBs and PBAs as cathode materials for SIBs. 
PB and PBAs were known in historical times, especially for their applications as pigments [268]. For their application in energy storage devices, they were first studied as $\mathrm{Li}^{+}$ion carries in aprotic media [269]. However, a capacity loss of about $30 \%-40 \%$ was observed after just 10 cycles, resulting in further research on their structure and properties $[267,269]$. The first significant result using PBAs as a cathode for SIBs was published by Wessels et al., who showed a relatively stable performance of copper hexacyanoferrate electrodes in aqueous media for as many as 40,000 cycles [270]. Another important milestone in the development of PB electrodes is the fabrication of low and high quality PBAs by You et al., which demonstrated the role of inherent structural defects and how careful synthesis can improve overall stability and cycle life performance [271]. There has been significantly more research on PBAs since then, and the discussion below focuses on some of the important results.

Lu et al. studied a PB system as a cathode in SIBs [272]. They prepared PB analogues with the general formula, $\mathrm{KMFe}(\mathrm{CN})_{6}(\mathrm{M}=\mathrm{Mn}, \mathrm{Fe}, \mathrm{Co}, \mathrm{Ni}, \mathrm{Zn})$, at room temperature using a substitutional reaction with a salt solution of the " $\mathrm{M}$ " constituent [272]. A discharge capacity of more than $100 \mathrm{mAh} \mathrm{g}^{-1}$ was obtained at a C/20 discharge rate with high capacity retention (>95\%) after 30 cycles of operation [272]. However, coulombic efficiencies were low $(\sim 60 \%-65 \%)$; these low efficiencies have been attributed to interstitial water in the PB analogues [272]. Similarly, You et al. studied "high-quality" (HQ) PB crystals as cathodes in SIBs [271]. Their HQ PB sample had the stoichiometry of $\mathrm{Na}_{0.61} \mathrm{Fe}\left[\mathrm{Fe}(\mathrm{CN})_{6}\right]_{0.94}$ and was prepared by reacting a $\mathrm{Na}_{4} \mathrm{Fe}(\mathrm{CN})_{6}$ precursor with $37 \% \mathrm{HCl}$. A specific capacity of $170 \mathrm{mAh} \mathrm{g}^{-1}$ and a coulombic efficiency of $\sim 100 \%$ were obtained after 150 cycles of operation [271]. Li et al. analyzed a sodium rich prussian blue framework, $\mathrm{Na}_{1+x} \mathrm{FeFe}(\mathrm{CN})_{6}$, as a cathode in an SIB system [273]. The PB framework was prepared in a facile, one-step synthesis process using $\mathrm{Na}_{4} \mathrm{Fe}(\mathrm{CN})_{6}$ and $\mathrm{NaCl}$ as the precursor. A maximum of $103 \mathrm{mAh} \mathrm{g}^{-1}$ was obtained at a current density of $20 \mathrm{~mA} \mathrm{~g}^{-1}$, with a capacity retention of $97 \%$ over 400 cycles [273]. The authors have proposed a low crystalline water content and low vacancies as being responsible for the high stability [273]. A mesoporous $\mathrm{PB}$ analogue, $\mathrm{KNiFe}(\mathrm{CN})_{6}$, synthesized by a template-free technique, was analyzed by Yue et al. [274]. A reversible specific capacity of $65 \mathrm{mAh} \mathrm{g}^{-1}$ at a low current density of $10 \mathrm{~mA} \mathrm{~g}^{-1}$ was obtained with a good rate capability, which, according to the authors, was due to the crystallinity and porosity of the sample [274]. A citrate controlled reaction mechanism was used by $\mathrm{Wu}$ and coworkers to synthesize a low-defect $\mathrm{PB}$ analogue using $\mathrm{CoCl}_{2}, \mathrm{Na}_{3} \mathrm{C}_{6} \mathrm{H}_{5} \mathrm{O}_{7}$, and $\mathrm{Na}_{4} \mathrm{Fe}(\mathrm{CN})_{6}$ as precursors [275]. A specific capacity of $\sim 150 \mathrm{mAh} \mathrm{g}^{-1}$ and $90 \%$ capacity retention were obtained over 200 cycles [275]. Results from Wu's work are demonstrated in Figure 13. Figure 13a,b shows the SEM images of the prussian blue cubes at low and high magnification, whereas Figure $13 \mathrm{c}$ represents the XRD pattern of the PB sample. Elemental maps of the sample are demonstrated in Figure 13d-i, while Figure 13j is the schematic representation of the PB cube. Figure 13k-m shows the electrochemical analysis of the cell.

The large vacant spaces and open network based 3D structure makes PBs interesting and attractive cathode materials [271]. The effective choice of a transition metal during its synthesis helps in stabilizing its cubic structure further [276]. Because of the presence of these vacant open spaces, they can easily intercalate large alkali ions, such as $\mathrm{Na}^{+}, \mathrm{K}^{+}$without much difficulty, thereby satisfying one of the key criteria of SIB cathodes, i.e., their ability to smoothly and reversibly intercalate the bulky $\mathrm{Na}^{+}$ion [277]. A large number of PB analogues have been synthesized, especially within the last decade [278,279].

These advantages notwithstanding, PB suffers from several important shortcomings. Primary among these is the presence of significant amounts of interstitial or zeolitic water. It has been estimated that interstitial water is more than $15 \mathrm{wt} . \%$, and this significantly hinders the long term cycle life by occupying electrochemically active sites [280]. Secondly, it has been found that, for the Fe incorporated PBs (which are also the most common), only the $\mathrm{C}$ coordinated Fe sites are electro-active, indicating that half of the vacant lattice spaces are essentially unused [274,281]. However, later research, with the help of X-ray absorption near edge structure (XANES) and extended X-ray absorption fine structure (EXAFS) analysis, have also demonstrated that the $\mathrm{Cu}$ or the Co edge is also electrochemically active if the compound is CuHCF or CoHCF [282,283]. Results have also shown that the co-precipitation techniques of synthesizing PBs result in approximately $30 \%$ of the lattice vacancies being unavailable 
due to structural defects and distortion (wrapping). Also, it can be observed that the performance of some of the PBAs are $\mathrm{pH}$ dependent (e.g., CuHCF), which limits its performance [284].
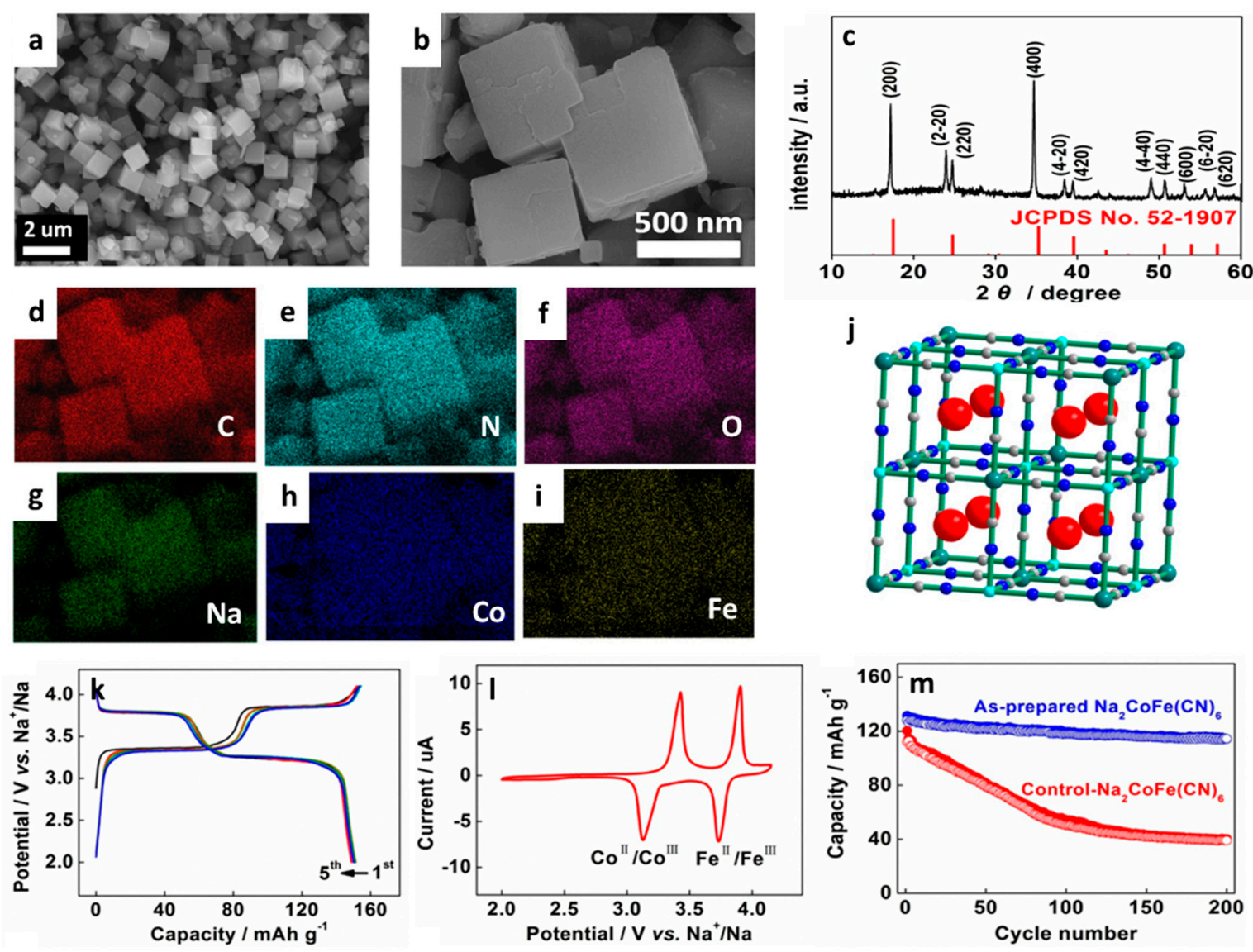

Figure 13. Structural characterization and electrochemical performance analysis of Prussian blue (PB) as a cathode in SIBs. $(\mathbf{a}, \mathbf{b})$ SEM images at low and high magnification of the sodium rich PB crystals depicting an uniform cubical morphology. (c) XRD pattern of the synthesized PB sample demonstrating high degree of crystallinity. (d-i) Elemental mapping of the PB sample demonstrating the different constituent elements with uniform distribution. (j) Schematic representation of the PB crystal showing the FCC (face centered cubic) lattice structure, with the Na atoms occupying the interstitial red sports. (k) Galvanostatic charging-discharging curves of the half-cell with PB cathode. (1) CV of the PB cathode system vs. $\mathrm{Na} / \mathrm{Na}^{+}$showing the characteristic redox peaks (m) Capacity retention of the PB cathode compared with a control, which is a more defect-filled PB structure. Copyright 2016, American Chemical Society.

A significant amount of research is focusing on PBs to be able to overcome these problems. defect free, mesoporous, and other high-surface area $\mathrm{Pb}$ analogues are being synthesized to improve their electrochemical activity [285]. Zeolitic water elimination has been achieved by Goodenough by synthesizing rhombohedral $\mathrm{PB}$ analogue, having only 0.08 moles of $\mathrm{H}_{2} \mathrm{O}$ rather than the usual cubic structure [286]. Overall, it is understood that all the various PB frameworks may not be perfectly suitable cathodes for SIBs. PB analogues have provided some interesting outcomes when $\mathrm{Zn}^{2+}$ is used as the intercalating ion instead of alkali ions [287]. The use of surface functionalized PB analogues and applications in low cost aqueous systems are some of the areas in which PB cathodes look to find future applications [288]. 


\subsection{Organic Materials}

The research into organic electrodes for SIBs goes back approximately 30 years. Carbonyls based on the $\mathrm{C}=\mathrm{O}$ bond have been the predominant electrodes that have found applications in SIBs [289]. However, some of the carbonyls exhibit insulating behavior, which renders them ineffective and has spurred the necessity for further research into other organic compounds as positive electrodes for SIBs $[290,291]$. Quinone compounds are some of the most popular and earliest materials that have been studied as cathodes for SIBs [292]. Following quinones, several other classes of compounds have been studied, such as polyimide and composites of organic molecules, e.g., aniline/o-nitroaniline co-polymers, as studied by Zhao et al. $[293,294]$. There has been further research in this area, and some prominent studies are discussed below.

A low cost polymeric cathode material, p-dopable polytriphenylamine (PTPAn), has been studied in SIBs by Deng et al. [295]. When coupled with an n-type poly(anthraquinonyl sulfide) (PAQS) anode, this all-organic SIB delivered a maximum reversible capacity of $132 \mathrm{mAh} \mathrm{g}^{-1}$ at a $1 \mathrm{C}$ current rate and a specific energy of $55 \mathrm{Wh} \mathrm{kg}^{-1}$ [295]. The electrodes were also able to retain $85 \%$ of their specific capacity over 500 cycles and demonstrated a coulombic efficiency of $299 \%$ [295]. Yao et al. analyzed the feasibility of indigo carmine as a positive electrode material in SIBs [296]. An optimum specific capacity of $100 \mathrm{mAh} \mathrm{g}^{-1}$ was obtained at a voltage of $1.8 \mathrm{~V} \mathrm{vs}$. $\mathrm{Na}^{+} / \mathrm{Na}$ for the material. Approximately $80 \%$ of the initial capacity was retained after 40 cycles of operation at a current density of $10 \mathrm{~mA} \mathrm{~g}^{-1}$ [296].

Polyimides (PIs) derived from aromatic carbonyl precursors as cathode materials in SIBs were analyzed by Wang and coworkers [297]. The PIs obtained from Perylene-3, 4, 9, 10-tetracarboxylic acid-dianhydride (PTCDA) performed the best, with specific power and energy capacities of $20.99 \mathrm{~kW}$ $\mathrm{kg}^{-1}$ and $285 \mathrm{Wh} \mathrm{kg}^{-1}$, along with a capacity retention of $87.5 \%$ of the initial capacity over 5000 cycles of operation [297]. Along similar lines, Luo et al. studied commercially obtained PTCDA directly as a cathode material in SIBs [298]. They were able to obtain a reversible capacity of $145 \mathrm{mAh} \mathrm{g}^{-1}$ along with the ability to provide $91 \mathrm{mAh} \mathrm{g}^{-1}$ at a very high current of $1000 \mathrm{~mA} \mathrm{~g}^{-1}$ and a stable cycling performance [298]. PTCDA was also used as the precursor material to obtain PI, which was then hybridized with MWCNTs for application as cathodes in SIBs, by Manuel et al. [299]. A maximum discharge capacity of $125 \mathrm{mAh} \mathrm{g}^{-1}$ was obtained at a $0.1 \mathrm{C}$ rate, along with $100 \%$ capacity retention and $100 \%$ coulombic efficiency after 70 cycles of operation [299]. The results of this work have been provided in Figure 14. In this, Figure 14a,b shows the SEM image of the 3D network of the PI/MWCNT composite and Figure 14c shows their XRD pattern. The arrangement of the composite is shown schematically in Figure 14d. Figure 14e-g represents the electrochemical performance of the composite.

Organic electrodes have the advantage of being composed of relatively inexpensive precursors [300,301]. Organic electrodes synthesized from quinone and pteridine generally exhibit high capacities [302]. Organometallic polymers demonstrate high rate capacities and kinetics, whereas polyimide electrodes provide high stability (approximately 500 cycles) [303]. However, many organic electrodes suffer from low conductivity and poor coulombic efficiencies. Dissolution in the electrolyte is another area of concern for organic electrodes [219].

Future work in organic electrodes should aim to design the molecule to incorporate a combination of the advantages of its various components, essentially creating a composite. For example, the theoretical capacity of quinone can be fully realized by developing a composite of it with polyimide, thereby taking advantage of the latter's long term stability $[219,304]$. The conductive coating and surface functionalization (with polyaniline) of low conducting polymers is another area that is being explored to enhance the performance of these materials [305]. Considering the relatively cheap cost of precursors, organic electrodes have the ability to be an important class of cathode materials for SIBs.

A tabular listing of some other prominent results for the cathodes discussed above is provided in Table 5 below. 

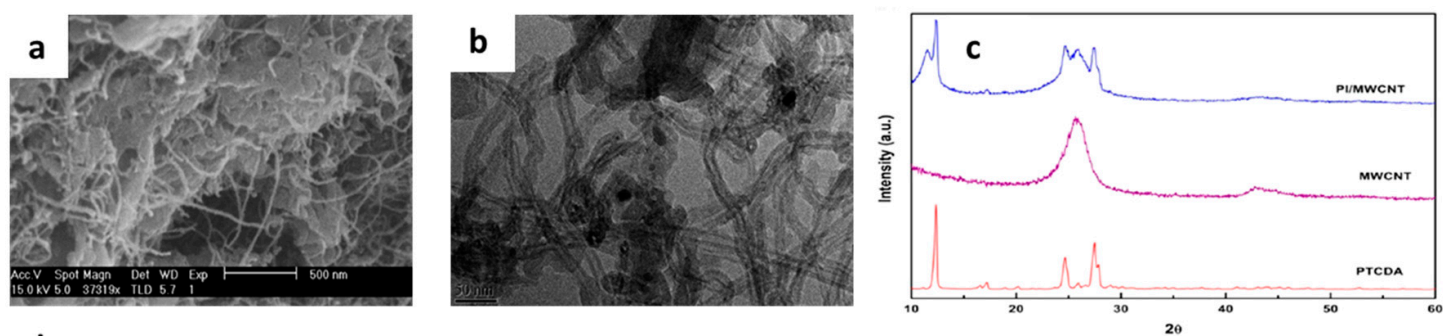

d
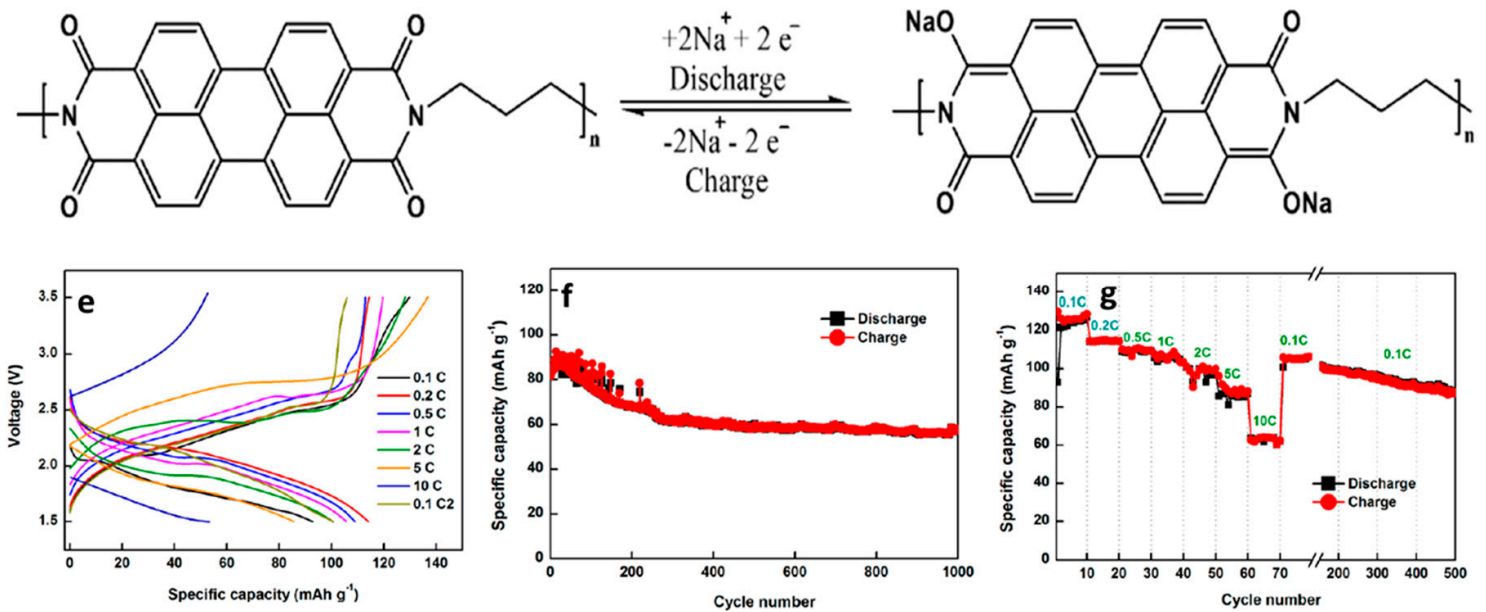

Figure 14. Structural characterization and electrochemical performance analysis of PI/MWCNT composite as a cathode in SIBs. (a) SEM images demonstrating a 3D network of fibers as the morphology of the PI/MWCNT fibers. (b) TEM image exhibiting the fiber network in greater detail. (c) XRD pattern of the PI/MWCNT fiber composite in comparison with its precursors with the characteristic peaks being visible. (d) Schematic reaction map depicting the synthesis of the PI/MWCNT nanocomposite. (e) Galvanostatic charge-discharge graphs of the PI/MWCNT composite as cathode in the SIB. (f) Capacity retention for the composite cathode for both charge and discharge cycles. (g) Rate performance of the PI/MWCNT cathode demonstrating almost all capacity retention when the rate is switched back to lower values. Copyright 2018, American Chemical Society.

Table 5. High performance cathodes for SIBs.

\begin{tabular}{|c|c|c|c|c|}
\hline Type of Cathode & Electrolyte Chemistry & $\begin{array}{c}\text { Voltage } \\
\text { Range (V) }\end{array}$ & Performance * & Reference \\
\hline \multicolumn{5}{|c|}{ Layered TMOs } \\
\hline $\mathrm{Na}_{0.44} \mathrm{MnO}_{2}$ & $1 \mathrm{M} \mathrm{NaClO}_{4}$ in EC:DEC $(1: 1)$ & $2.0-3.8$ & $80 / 2000 / 0.1 C^{b}$ & [306] \\
\hline $\mathrm{Na}_{0.67}\left[\mathrm{Mn}_{0.65} \mathrm{Co}_{0.2} \mathrm{Ni}_{0.15}\right] \mathrm{O}_{2}$ & $1 \mathrm{M} \mathrm{NaPF}_{6}$ in EC:DEC (1:1) & $2.0-4.4$ & $129 / 50 / 20$ & [307] \\
\hline $\mathrm{NaMnTi}_{0.1} \mathrm{Ni}_{0.1} \mathrm{O}_{2}$ & $1 \mathrm{M} \mathrm{NaClO}_{4}$ in PEC & $1.5-4.2$ & $186 / 500 / 0.1 \mathrm{C}^{\mathrm{b}}$ & [308] \\
\hline $\mathrm{Na}_{x} \mathrm{Al}_{0.1} \mathrm{Mn}_{0.9} \mathrm{O}_{2}$ & $1 \mathrm{M} \mathrm{NaPF} 6$ in PEC & $2.0-3.8$ & $160 / 100 / 0.1 C^{b}$ & [309] \\
\hline $\mathrm{Na}\left[\mathrm{Li}_{0.05}\left(\mathrm{Ni}_{0.25} \mathrm{Fe}_{0.25} \mathrm{Mn}_{0.5}\right)_{0.95}\right] \mathrm{O}_{2}$ & $1 \mathrm{M} \mathrm{NaClO}_{4}$ in PEC:FEC $(1: 1)$ & $1.75-4.3$ & $177 / 200 / 0.1 \mathrm{C}^{\mathrm{b}}$ & [310] \\
\hline \multicolumn{5}{|c|}{ Phosphates } \\
\hline Mesoporous amorphous $\mathrm{FePO}_{4}$ & $1 \mathrm{M} \mathrm{NaPF}_{6}$ in EC:DEC (1:1) & $1.5-3.8$ & $151 / 160 / 20$ & [311] \\
\hline Amorphous $\mathrm{FePO}_{4} / \mathrm{CNT}$ & $1 \mathrm{M} \mathrm{NaClO}_{4}$ in EC:DMC (1:1) & $2.25-3.75$ & $66 / 300 / 50$ & [312] \\
\hline $\mathrm{NaFePO}_{4}$ & NaTFSI/BMP-TFSI (IL) & $2.0-3.75$ & $120 / 100 / 0.05 C^{b}$ & [313] \\
\hline $\mathrm{NaFePO}_{4}$ & $1 \mathrm{M} \mathrm{NaPF}_{6}$ in EC:DMC (1:1) & $1.5-4.0$ & $150 / 200 / 0.1 C^{b}$ & [240] \\
\hline $\mathrm{Na}_{2} \mathrm{Fe}_{2} \mathrm{P}_{2} \mathrm{O}_{7}$ & $1 \mathrm{M} \mathrm{NaClO}_{4}$ in $\mathrm{PC}$ & $2.0-4.0$ & $90 / 30 / 0.1 \mathrm{C}^{\mathrm{b}}$ & [314] \\
\hline \multicolumn{5}{|c|}{$\begin{array}{l}\text { NASICON and } \\
\text { Fluorophosphates }\end{array}$} \\
\hline $\mathrm{Na}_{3} \mathrm{~V}_{2}\left(\mathrm{PO}_{4}\right)_{3}$ & $1 \mathrm{M} \mathrm{NaClO}_{4}$ in $\mathrm{PC}$ & $2.5-3.8$ & $66.5 / 50 / 1 \mathrm{C}^{\mathrm{b}}$ & [259] \\
\hline $\mathrm{C}$ coated $\mathrm{Na}_{3} \mathrm{~V}_{2}\left(\mathrm{PO}_{4}\right)_{3}$ & $1 \mathrm{M} \mathrm{NaPF}_{6}$ in EC:DMC (1:1) & $2.5-4.0$ & $113 / 8000 / 2 \mathrm{C}^{\mathrm{b}}$ & [315] \\
\hline Graphene supported $\mathrm{Na}_{3} \mathrm{~V}_{2}\left(\mathrm{PO}_{4}\right)_{3}$ & $1 \mathrm{M} \mathrm{NaClO}_{4}$ in $\mathrm{PC}$ & $2.5-3.8$ & $90 / 100 / 1 C^{b}$ & [316] \\
\hline $\mathrm{Fe}_{2}\left(\mathrm{MoO}_{4}\right)_{3}$ & $1 \mathrm{M} \mathrm{NaClO}{ }_{4}$ in EC:DMC (1:1) & $1.5-3.5$ & $94 / 100 / 1 \mathrm{C}^{\mathrm{b}}$ & [317] \\
\hline $\mathrm{Na}_{3} \mathrm{~V}_{2} \mathrm{O}_{2}\left(\mathrm{PO}_{4}\right)_{2} \mathrm{~F}$ & $1 \mathrm{M} \mathrm{NaClO}_{4}$ in FEC & $2.5-4.3$ & $100 / 1000 / 20 C^{b}$ & [318] \\
\hline
\end{tabular}


Table 5. Cont.

\begin{tabular}{|c|c|c|c|c|}
\hline Type of Cathode & Electrolyte Chemistry & $\begin{array}{c}\text { Voltage } \\
\text { Range (V) }\end{array}$ & Performance * & Reference \\
\hline \multicolumn{5}{|c|}{ PB } \\
\hline $\mathrm{Na}_{4} \mathrm{Fe}(\mathrm{CN})_{6}$ & $1 \mathrm{M} \mathrm{NaClO}_{4}$ in EC/DEC (1:1) & $2.0-4.2$ & $100 / 70 / 5$ & [319] \\
\hline $\mathrm{Na}_{2} \mathrm{NiCO}_{1-x} \mathrm{Fe}(\mathrm{CN})_{6}$ & $1 \mathrm{M} \mathrm{NaPF}_{6}$ in $\mathrm{EC} / \mathrm{DEC}(1: 1)$ & $2.0-4.2$ & $124 / 100 / 50$ & [320] \\
\hline $\mathrm{Na}_{x} \mathrm{CoFe}(\mathrm{CN})_{6}$ & $1 \mathrm{M} \mathrm{Na}_{2} \mathrm{SO}_{4}(\mathrm{pH}=7)$ & $0.5-2.0$ & $100 / 200 / 600$ & [285] \\
\hline $\mathrm{K}_{0.33} \mathrm{FeFe}(\mathrm{CN})_{6} / \mathrm{rGO}$ & $1 \mathrm{M} \mathrm{NaClO} 4$ in EC/DEC $(1: 1)$ & $2.0-3.8$ & $160 / 1000 / 0.5 C^{b}$ & {$[321]$} \\
\hline $\mathrm{Na}_{0.647} \mathrm{Fe}\left[\mathrm{Fe}(\mathrm{CN})_{6}\right]_{0.93} \cdot 2.6 \mathrm{H}_{2} \mathrm{O} / \mathrm{C}$ & $1 \mathrm{M} \mathrm{NaPF}_{6}$ in EC/DEC (1:1) & $2.0-4.0$ & $130 / 200 / 50$ & [279] \\
\hline \multicolumn{5}{|c|}{ Organic } \\
\hline Polyimide (PI) & $1 \mathrm{M} \mathrm{NaPF}_{6}$ in $\mathrm{PC}$ & $1.5-3.0$ & $180 / 50 / 50$ & [322] \\
\hline Anthraquinone based PI & $1 \mathrm{M} \mathrm{NaPF}_{6}$ in DME:DOL $(1: 1)$ & $1.5-3.5$ & $179 / 150 / 50$ & [323] \\
\hline $\begin{array}{l}\text { Poly(benzoquinonyl sulfide) } \\
\text { (PBQS) }\end{array}$ & 1M NaTFSI/DOL DME & $1.5-4.0$ & $268 / 1000 / 50$ & {$[324]$} \\
\hline Disodium rhodizonate & $1 \mathrm{M} \mathrm{NaClO}_{4}$ in $\mathrm{PC}$ & $0.0-3.1$ & $498 / 50 / 50$ & [325] \\
\hline Juglone/rGO & $1 \mathrm{M} \mathrm{NaClO}_{4}$ in EC:DMC (1:1) & $0.0-2.5$ & $760 / 100 / 100$ & [290] \\
\hline
\end{tabular}

* Specific capacity $\left(\mathrm{mAh} \mathrm{g}^{-1}\right) /$ number of cycles/current density $\left(\mathrm{mA} \mathrm{g}^{-1}\right) \cdot{ }^{\mathrm{b}} \mathrm{C}$ rate.

\section{Conclusions}

SIBs are considered to be a highly promising alternative to LIBs. However, in order for that goal to be achievable in the near future, electrode materials must be tailored to provide high energy and power densities. Further the electrode materials must also prove durable and provide a significantly long cycle life, especially since SIBs are being considered for grid scale storage, where reliability and longevity are two of the most important parameters.

It is here that these high-performance materials play a very important role. On the anode side, novel 2D materials like TMDs and layered materials like MXenes have the ability to provide large surface areas and enhanced electronic conductivity, as well as access to a greater number of electrochemical sites. Likewise, considering the cathodes, novel materials like NASICON and polyanionic compounds, PB analogues, etc., are currently at the forefront of SIB technology. These materials provide large open framework structures, thereby allowing easy intercalation of $\mathrm{Na}^{+}$ions and less structural degradation during the intercalation/deintercalation process.

However, considerable challenges still exist in all these cases. Layered materials tend to restack after several cycles, which necessitates using support materials within the layers, essentially making the synthesis complicated. Also, the polyanionic compounds tend to suffer from low electronic conductivity, which also makes a graphene/CNT coating necessary.

Regardless of these challenges, greater research in this area will help to elucidate and improve the understanding of the electrochemical mechanisms involved. This will go a long way in adopting SIBs for commercial purposes and greatly enhancing their feasibility.

Author Contributions: Conceptualization, S.M., S.B.M. and G.S.; Methodology, S.M., S.B.M., D.S. and G.S.; Investigation, S.M., S.B.M. and D.S.; Resources, S.M., S.B.M. and D.S.; Data Curation, S.M., S.B.M. and D.S.; Writing-Original Draft Preparation, S.M., S.B.M. and D.S.; Writing-Review \& Editing, S.M., S.B.M and D.S.; Visualization, S.M., S.B.M. and G.S.; Supervision, S.M. and G.S.; Project Administration, S.M., S.B.M. and G.S.; Funding Acquisition, G.S.

Funding: This research was funded by United States National Science Foundation grant number NSF CAREER CMMI-1454151.

Conflicts of Interest: The authors declare no conflict of interest.

\section{References}

1. Kim, H.; Kim, H.; Ding, Z.; Lee, M.H.; Lim, K.; Yoon, G.; Kang, K. Recent Progress in Electrode Materials for Sodium-Ion Batteries. Adv. Energy Mater. 2016, 6, 1600943. [CrossRef]

2. Höök, M.; Tang, X. Depletion of fossil fuels and anthropogenic climate change-A review. Energy Policy 2013, 52, 797-809. [CrossRef] 
3. Haines, A.; Kovats, R.S.; Campbell-Lendrum, D.; Corvalan, C. Climate change and human health: Impacts, vulnerability and public health. Public Health 2006, 120, 585-596. [CrossRef] [PubMed]

4. Shafiee, S.; Topal, E. When will fossil fuel reserves be diminished? Energy Policy 2009, 37, 181-189. [CrossRef]

5. Kruyt, B.; van Vuuren, D.P.; de Vriesac, H.J.M.; Groenenberg, H. Indicators for energy security. Energy Policy 2009, 37, 2166-2181. [CrossRef]

6. Erdinc, O.; Uzunoglu, M. Optimum design of hybrid renewable energy systems: Overview of different approaches. Renew. Sustain. Energy Rev. 2012, 16, 1412-1425. [CrossRef]

7. Cavallo, A.J. Energy Storage Technologies for Utility Scale Intermittent Renewable Energy Systems. J. Sol. Energy Eng. 2001, 123, 387-389. [CrossRef]

8. Panwar, N.L.; Kaushik, S.C.; Kothari, S. Role of renewable energy sources in environmental protection: A review. Renew. Sustain. Energy Rev. 2011, 15, 1513-1524. [CrossRef]

9. Hall, P.J.; Bain, E.J. Energy-storage technologies and electricity generation. Energy Policy 2008, 36, 4352-4355. [CrossRef]

10. Yang, Z.; Zhang, J.; Kintner-Meyer, M.C.W.; Lu, X.; Choi, D.; Lemmon, J.P.; Liu, J. Electrochemical Energy Storage for Green Grid. Chem. Rev. 2011, 111, 3577-3613. [CrossRef]

11. Goodenough, J.B.; Park, K.-S. The Li-Ion Rechargeable Battery: A Perspective. J. Am. Chem. Soc. 2013, 135, 1167-1176. [CrossRef] [PubMed]

12. Etacheri, V.; Marom, R.; Elazari, R.; Salitra, G.; Aurbach, D. Challenges in the development of advanced Li-ion batteries: A review. Energy Environ. Sci. 2011, 4, 3243-3262. [CrossRef]

13. Nishi, Y. The development of lithium ion secondary batteries. Chem. Rec. 2001, 1, 406-413. [CrossRef] [PubMed]

14. Wakihara, M. Recent developments in lithium ion batteries. Mater. Sci. Eng. R Rep. 2001, 33, 109-134. [CrossRef]

15. Bruce, P.G.; Scrosati, B.; Tarascon, J.-M. Nanomaterials for Rechargeable Lithium Batteries. Angew. Chem. 2008, 47, 2930-2946. [CrossRef]

16. Yabuuchi, N.; Kubota, K.; Dahbi, M.; Komaba, S. Research Development on Sodium-Ion Batteries. Chem. Rev. 2014, 114, 11636-11682. [CrossRef] [PubMed]

17. Vikstrom, H.; Davidsson, S.; Hook, M. Lithium availability and future production outlooks. Appl. Energy 2013, 110, 252-266. [CrossRef]

18. Nitta, N.; Wu, F.; Lee, J.T.; Yushin, G. Li-ion battery materials: Present and future. Mater. Today 2015, 18, 252-264. [CrossRef]

19. Kundu, D.; Talaie, E.; Duffort, V.; Nazar, L.F. The Emerging Chemistry of Sodium Ion Batteries for Electrochemical Energy Storage. Angew. Chem. Int. Ed. 2015, 54, 3431-3448. [CrossRef]

20. Palomares, V.; Serras, P.; Villaluenga, I.; Hueso, K.B.; Carretero-González, J.; Rojo, T. Na-ion batteries, recent advances and present challenges to become low cost energy storage systems. Energy Environ. Sci. 2012, 5, 5884-5901. [CrossRef]

21. Kim, H.; Hong, J.; Park, K.-Y.; Kim, H.; Kim, S.-W.; Kang, K. Aqueous Rechargeable Li and Na Ion Batteries. Chem. Rev. 2014, 114, 11788-11827. [CrossRef]

22. Kim, S.W.; Seo, D.H.; Ma, X.; Ceder, G.; Kang, K. Electrode materials for rechargeable sodium-ion batteries: Potential alternatives to current lithium-ion batteries. Adv. Energy Mater. 2012, 2, 710-721. [CrossRef]

23. Cao, Y.; Xiao, L.; Sushko, M.L.; Wang, W.; Schwenzer, B.; Xiao, J.; Nie, Z.; Saraf, L.V.; Yang, Z.; Liu, J. Sodium Ion Insertion in Hollow Carbon Nanowires for Battery Applications. Nano Lett. 2012, 12, 3783-3787. [CrossRef] [PubMed]

24. Cao, Y.; Xiao, L.; Wang, W.; Choi, D.; Nie, Z.; Yu, J.; Saraf, L.V.; Yang, Z.; Liu, J. Reversible Sodium Ion Insertion in Single Crystalline Manganese Oxide Nanowires with Long Cycle Life. Adv. Mater. 2011, 23, 3155-3160. [CrossRef] [PubMed]

25. Mukherjee, S.; Ren, Z.; Singh, G. Beyond Graphene Anode Materials for Emerging Metal Ion Batteries and Supercapacitors. Nano-Micro Lett. 2018, 10, 70. [CrossRef] [PubMed]

26. Wang, S.; Wang, L.; Zhu, Z.; Hu, Z.; Zhao, Q.; Chen, J. All Organic Sodium-Ion Batteries with $\mathrm{Na}_{4} \mathrm{C}_{8} \mathrm{H}_{2} \mathrm{O}_{6}$. Angew. Chem. 2014, 53, 5892-5896. [CrossRef] [PubMed]

27. Mukherjee, S.; Ren, Z.; Singh, G. Molecular polymer-derived ceramics for applications in electrochemical energy storage devices. J. Phys. D Appl. Phys. 2018, 51, 463001. [CrossRef] 
28. Bhandavat, R.; Pei, Z.; Singh, G. Polymer-derived ceramics as anode material for rechargeable Li-ion batteries: A review. Nanomater. Energy 2012, 1, 324-337. [CrossRef]

29. Doeff, M.M.; Ma, Y.; Visco, S.J.; De Jonghe, L.C. Electrochemical insertion of sodium into carbon. J. Electrochem. Soc. 1993, 140, L169-L170. [CrossRef]

30. Alcántara, R.; Jiménez-Mateos, J.M.; Lavela, P.; Tirado, J.L. Carbon black: A promising electrode material for sodium-ion batteries. Electrochem. Commun. 2001, 3, 639-642. [CrossRef]

31. Alcántara, R.; Madrigal, F.F.; Lavela, P.; Tirado, J.; Mateos, J.J.; De Salazar, C.G.; Stoyanova, R.; Zhecheva, E. Characterisation of mesocarbon microbeads (MCMB) as active electrode material in lithium and sodium cells. Carbon 2000, 38, 1031-1041. [CrossRef]

32. Komaba, S.; Murata, W.; Ishikawa, T.; Yabuuchi, N.; Ozeki, T.; Nakayama, T.; Ogata, A.; Gotoh, K.; Fujiwara, K. Electrochemical Na insertion and solid electrolyte interphase for hard-carbon electrodes and application to Na-Ion batteries. Adv. Funct. Mater. 2011, 21, 3859-3867. [CrossRef]

33. Luo, W.; Jian, Z.; Xing, Z.; Wang, W.; Bommier, C.; Lerner, M.M.; Ji, X. Electrochemically Expandable Soft Carbon as Anodes for Na-Ion Batteries. ACS Cent. Sci. 2015, 1, 516-522. [CrossRef] [PubMed]

34. Yu, L.; Song, H.; Li, Y.; Chen, Y.; Chen, X.; Zhou, J.; Ma, Z.; Wan, X.; Tian, P.; Wu, J. Rod-like ordered mesoporous carbons with various lengths as anode materials for sodium ion battery. Electrochim. Acta 2016, 218, 285-293. [CrossRef]

35. Cao, B.; Liu, H.; Xu, B.; Lei, Y.F.; Chen, X.H.; Song, H.H. Mesoporous soft carbon as an anode material for sodium ion batteries with superior rate and cycling performance. J. Mater. Chem. A 2016, 4, 6472-6478. [CrossRef]

36. Zhu, H.; Shen, F.; Luo, W.; Zhu, S.; Zhao, M.; Natarajan, B.; Dai, J.; Zhou, L.; Ji, X.; Yassar, R.S. Low temperature carbonization of cellulose nanocrystals for high performance carbon anode of sodium-ion batteries. Nano Energy 2017, 33, 37-44. [CrossRef]

37. Wen, Y.; He, K.; Zhu, Y.J.; Han, F.D.; Xu, Y.H.; Matsuda, I.; Ishii, Y.; Cumings, J.; Wang, C.S. Expanded graphite as superior anode for sodium-ion batteries. Nat. Commun. 2014, 5, 10. [CrossRef]

38. Luo, W.; Wan, J.; Ozdemir, B.; Bao, W.; Chen, Y.; Dai, J.; Lin, H.; Xu, Y.; Gu, F.; Barone, V.; et al. Potassium Ion Batteries with Graphitic Materials. Nano Lett. 2015, 15, 7671-7677. [CrossRef]

39. Moriwake, H.; Kuwabara, A.; Fisher, C.A.J.; Ikuhara, Y. Why is sodium-intercalated graphite unstable? RSC Adv. 2017, 7, 36550-36554. [CrossRef]

40. Jache, B.; Adelhelm, P. Use of Graphite as a Highly Reversible Electrode with Superior Cycle Life for Sodium-Ion Batteries by Making Use of Co-Intercalation Phenomena. Angew. Chem. Int. Ed. 2014, 53, 10169-10173. [CrossRef]

41. Yao, X.H.; Ke, Y.J.; Ren, W.H.; Wang, X.P.; Xiong, F.Y.; Yang, W.; Qin, M.S.; Li, Q.; Mai, L.Q. Defect-Rich Soft Carbon Porous Nanosheets for Fast and High-Capacity Sodium-Ion Storage. Adv. Energy Mater. 2019, 9, 1803260. [CrossRef]

42. Cheng, D.L.; Yang, L.C.; Zhu, M. High-performance anode materials for Na-ion batteries. Rare Met. 2018, 37, 167-180. [CrossRef]

43. Yun, Y.S.; Park, K.-Y.; Lee, B.; Cho, S.Y.; Park, Y.-U.; Hong, S.J.; Kim, B.H.; Gwon, H.; Kim, H.; Lee, S.; et al. Sodium-Ion Storage in Pyroprotein-Based Carbon Nanoplates. Adv. Mater. 2015, 27, 6914-6921. [CrossRef] [PubMed]

44. Saurel, D.; Orayech, B.; Xiao, B.; Carriazo, D.; Li, X.; Rojo, T. From Charge Storage Mechanism to Performance: A Roadmap toward High Specific Energy Sodium-Ion Batteries through Carbon Anode Optimization. Adv. Energy Mater. 2018, 8, 1703268. [CrossRef]

45. Luo, W.; Schardt, J.; Bommier, C.; Wang, B.; Razink, J.; Simonsen, J.; Ji, X.L. Carbon nanofibers derived from cellulose nanofibers as a long-life anode material for rechargeable sodium-ion batteries. J. Mater. Chem. A 2013, 1, 10662-10666. [CrossRef]

46. Li, W.H.; Zeng, L.C.; Yang, Z.Z.; Gu, L.; Wang, J.Q.; Liu, X.W.; Cheng, J.X.; Yu, Y. Free-standing and binder-free sodium-ion electrodes with ultralong cycle life and high rate performance based on porous carbon nanofibers. Nanoscale 2014, 6, 693-698. [CrossRef] [PubMed]

47. Lotfabad, E.M.; Ding, J.; Cui, K.; Kohandehghan, A.; Kalisvaart, W.P.; Hazelton, M.; Mitlin, D. High-Density Sodium and Lithium Ion Battery Anodes from Banana Peels. ACS Nano 2014, 8, 7115-7129. [CrossRef]

48. Zhang, F.; Yao, Y.G.; Wan, J.Y.; Henderson, D.; Zhang, X.G.; Hu, L.B. High Temperature Carbonized Grass as a High Performance Sodium Ion Battery Anode. ACS Appl. Mater. Interfaces 2017, 9, 391-397. [CrossRef] 
49. Hou, H.S.; Shao, L.D.; Zhang, Y.; Zou, G.Q.; Chen, J.; Ji, X.B. Large-Area Carbon Nanosheets Doped with Phosphorus: A High-Performance Anode Material for Sodium-Ion Batteries. Adv. Sci. 2017, 4, 1600243. [CrossRef]

50. Hu, X.D.; Sun, X.H.; Yoo, S.J.; Evanko, B.; Fan, F.R.; Cai, S.; Zheng, C.M.; Hu, W.B.; Stucky, G.D. Nitrogen-rich hierarchically porous carbon as a high-rate anode material with ultra-stable cyclability and high capacity for capacitive sodium-ion batteries. Nano Energy 2019, 56, 828-839. [CrossRef]

51. Shen, Y.L.; Sun, S.J.; Yang, M.; Zhao, X.Y. Typha-derived hard carbon for high-performance sodium ion storage. J. Alloys Compd. 2019, 784, 1290-1296. [CrossRef]

52. Zhao, X.; Ding, Y.; Xu, Q.; Yu, X.; Liu, Y.; Shen, H. Low-Temperature Growth of Hard Carbon with Graphite Crystal for Sodium-Ion Storage with High Initial Coulombic Efficiency: A General Method. Adv. Energy Mater. 2019, 9, 1803648. [CrossRef]

53. Kim, H.; Hong, J.; Park, Y.U.; Kim, J.; Hwang, I.; Kang, K. Sodium Storage Behavior in Natural Graphite using Ether-based Electrolyte Systems. Adv. Funct. Mater. 2015, 25, 534-541. [CrossRef]

54. Ding, J.; Wang, H.; Li, Z.; Kohandehghan, A.; Cui, K.; Xu, Z.; Zahiri, B.; Tan, X.; Lotfabad, E.M.; Olsen, B.C.; et al. Carbon Nanosheet Frameworks Derived from Peat Moss as High Performance Sodium Ion Battery Anodes. Acs Nano 2013, 7, 11004-11015. [CrossRef] [PubMed]

55. Fu, L.; Tang, K.; Song, K.; van Aken, P.A.; Yu, Y.; Maier, J. Nitrogen doped porous carbon fibres as anode materials for sodium ion batteries with excellent rate performance. Nanoscale 2014, 6, 1384-1389. [CrossRef] [PubMed]

56. Tang, K.; Fu, L.; White, R.J.; Yu, L.; Titirici, M.-M.; Antonietti, M.; Maier, J. Hollow Carbon Nanospheres with Superior Rate Capability for Sodium-Based Batteries. Adv. Energy Mater. 2012, 2, 873-877. [CrossRef]

57. Li, Y.; Xu, S.; Wu, X.; Yu, J.; Wang, Y.; Hu, Y.-S.; Li, H.; Chen, L.; Huang, X. Amorphous monodispersed hard carbon micro-spherules derived from biomass as a high performance negative electrode material for sodium-ion batteries. J. Mater. Chem. A 2015, 3, 71-77. [CrossRef]

58. Shen, F.; Zhu, H.; Luo, W.; Wan, J.; Zhou, L.; Dai, J.; Zhao, B.; Han, X.; Fu, K.; Hu, L. Chemically Crushed Wood Cellulose Fiber towards High-Performance Sodium-Ion Batteries. ACS Appl. Mater. Interfaces 2015, 7, 23291-23296. [CrossRef]

59. Xie, F.; Xu, Z.; Jensen, A.C.S.; Au, H.; Lu, Y.; Araullo-Peters, V.; Drew, A.J.; Hu, Y.-S.; Titirici, M.-M. Hard-Soft Carbon Composite Anodes with Synergistic Sodium Storage Performance. Adv. Funct. Mater. 2019, 1901072. [CrossRef]

60. Li, Y.; Hu, Y.-S.; Titirici, M.-M.; Chen, L.; Huang, X. Hard Carbon Microtubes Made from Renewable Cotton as High-Performance Anode Material for Sodium-Ion Batteries. Adv. Energy Mater. 2016, 6, 1600659. [CrossRef]

61. Sun, Y.; Lu, P.; Liang, X.; Chen, C.; Xiang, H. High-yield microstructure-controlled amorphous carbon anode materials through a pre-oxidation strategy for sodium ion batteries. J. Alloys Compd. 2019, 786, 468-474. [CrossRef]

62. Li, L.; Zheng, Y.; Zhang, S.L.; Yang, J.P.; Shao, Z.P.; Guo, Z.P. Recent progress on sodium ion batteries: Potential high-performance anodes. Energy Environ. Sci. 2018, 11, 2310-2340. [CrossRef]

63. Chevrier, V.L.; Ceder, G. Challenges for Na-ion Negative Electrodes. J. Electrochem. Soc. 2011, 158, A1011-A1014. [CrossRef]

64. Han, X.; Liu, C.; Sun, J.; Sendek, A.D.; Yang, W. Density functional theory calculations for evaluation of phosphorene as a potential anode material for magnesium batteries. RSC Adv. 2018, 8, 7196-7204. [CrossRef]

65. Liu, Y.; Xu, Y.; Zhu, Y.; Culver, J.N.; Lundgren, C.A.; Xu, K.; Wang, C. Tin-Coated Viral Nanoforests as Sodium-Ion Battery Anodes. ACS Nano 2013, 7, 3627-3634. [CrossRef] [PubMed]

66. Hou, H.; Jing, M.; Yang, Y.; Zhang, Y.; Zhu, Y.; Song, W.; Yang, X.; Ji, X. Sb porous hollow microspheres as advanced anode materials for sodium-ion batteries. J. Mater. Chem. A 2015, 3, 2971-2977. [CrossRef]

67. Yue, C.; Yu, Y.; Sun, S.; He, X.; Chen, B.; Lin, W.; Xu, B.; Zheng, M.; Wu, S.; Li, J.; et al. High Performance 3D $\mathrm{Si} /$ Ge Nanorods Array Anode Buffered by TiN/Ti Interlayer for Sodium-Ion Batteries. Adv. Funct. Mater. 2015, 25, 1386-1392. [CrossRef]

68. Xu, G.-L.; Chen, Z.; Zhong, G.-M.; Liu, Y.; Yang, Y.; Ma, T.; Ren, Y.; Zuo, X.; Wu, X.-H.; Zhang, X. Nanostructured black phosphorus/Ketjenblack-multiwalled carbon nanotubes composite as high performance anode material for sodium-ion batteries. Nano Lett. 2016, 16, 3955-3965. [CrossRef]

69. Xu, Y.H.; Zhu, Y.J.; Liu, Y.H.; Wang, C.S. Electrochemical Performance of Porous Carbon/Tin Composite Anodes for Sodium-Ion and Lithium-Ion Batteries. Adv. Energy Mater. 2013, 3, 128-133. [CrossRef] 
70. Kim, Y.; Ha, K.-H.; Oh, S.M.; Lee, K.T. High-Capacity Anode Materials for Sodium-Ion Batteries. Chem. Eur. J. 2014, 20, 11980-11992. [CrossRef]

71. Zhu, H.L.; Jia, Z.; Chen, Y.C.; Weadock, N.; Wan, J.Y.; Vaaland, O.; Han, X.G.; Li, T.; Hu, L.B. Tin Anode for Sodium-Ion Batteries Using Natural Wood Fiber as a Mechanical Buffer and Electrolyte Reservoir. Nano Lett. 2013, 13, 3093-3100. [CrossRef] [PubMed]

72. Liu, Y.C.; Zhang, N.; Jiao, L.F.; Tao, Z.L.; Chen, J. Ultrasmall Sn Nanoparticles Embedded in Carbon as High-Performance Anode for Sodium-Ion Batteries. Adv. Funct. Mater. 2015, 25, 214-220. [CrossRef]

73. Mao, M.L.; Yan, F.L.; Cui, C.Y.; Ma, J.M.; Zhang, M.; Wang, T.H.; Wang, C.S. Pipe-Wire TiO2-Sn@Carbon Nanofibers Paper Anodes for Lithium and Sodium Ion Batteries. Nano Lett. 2017, 17, 3830-3836. [CrossRef] [PubMed]

74. Sha, M.; Zhang, H.; Nie, Y.T.; Nie, K.Q.; Lv, X.X.; Sun, N.; Xie, X.K.; Ma, Y.Y.; Sun, X.H. Sn nanoparticles@ nitrogen-doped carbon nanofiber composites as high-performance anodes for sodium-ion batteries. J. Mater. Chem. A 2017, 5, 6277-6283. [CrossRef]

75. Pan, L.; Huang, H.J.; Zhong, M.; Niederberger, M. Hydrogel-derived foams of nitrogen-doped carbon loaded with Sn nanodots for high-mass-loading Na-ion storage. Energy Storage Mater. 2019, 16, 519-526. [CrossRef]

76. Darwiche, A.; Marino, C.; Sougrati, M.T.; Fraisse, B.; Stievano, L.; Monconduit, L. Better Cycling Performances of Bulk Sb in Na-Ion Batteries Compared to Li-Ion Systems: An Unexpected Electrochemical Mechanism. J. Am. Chem. Soc. 2012, 134, 20805-20811. [CrossRef] [PubMed]

77. Allan, P.K.; Griffin, J.M.; Darwiche, A.; Borkiewicz, O.J.; Wiaderek, K.M.; Chapman, K.W.; Morris, A.J.; Chupas, P.J.; Monconduit, L.; Grey, C.P. Tracking Sodium-Antimonide Phase Transformations in Sodium-Ion Anodes: Insights from Operando Pair Distribution Function Analysis and Solid-State NMR Spectroscopy. J. Am. Chem. Soc. 2016, 138, 2352-2365. [CrossRef]

78. Zhu, Y.J.; Han, X.G.; Xu, Y.H.; Liu, Y.H.; Zheng, S.Y.; Xu, K.; Hu, L.B.; Wang, C.S. Electrospun Sb/C Fibers for a Stable and Fast Sodium-Ion Battery Anode. ACS Nano 2013, 7, 6378-6386. [CrossRef]

79. Wu, L.; Hu, X.H.; Qian, J.F.; Pei, F.; Wu, F.Y.; Mao, R.J.; Ai, X.P.; Yang, H.X.; Cao, Y.L. Sb-C nanofibers with long cycle life as an anode material for high-performance sodium-ion batteries. Energy Environ. Sci. 2014, 7, 323-328. [CrossRef]

80. Zhao, W.X.; Zou, L.; Ma, X.Q.; Zhang, W.L.; Li, Y.D.; Wang, G.Z.; Zhang, P.; Xia, L.P. Ultrafine Sb nanoparticles embedded in nitrogen-doped carbon nanofibers as ultralong cycle durability and high-rate anode materials for reversible sodium storage. Electrochim. Acta 2019, 300, 396-403. [CrossRef]

81. Cui, C.Y.; Xu, J.T.; Zhang, Y.Q.; Wei, Z.X.; Mao, M.L.; Lian, X.; Wang, S.Y.; Yang, C.Y.; Fan, X.L.; Ma, J.M.; et al. Antimony Nanorod Encapsulated in Cross-Linked Carbon for High-Performance Sodium Ion Battery Anodes. Nano Lett. 2019, 19, 538-544. [CrossRef] [PubMed]

82. Chockla, A.M.; Klavetter, K.C.; Mullins, C.B.; Korgel, B.A. Solution-Grown Germanium Nanowire Anodes for Lithium-Ion Batteries. ACS Appl. Mater. Interfaces 2012, 4, 4658-4664. [CrossRef] [PubMed]

83. Li, W.W.; Wang, X.F.; Liu, B.; Xu, J.; Liang, B.; Luo, T.; Luo, S.J.; Chen, D.; Shen, G.Z. Single-crystalline metal germanate nanowire-carbon textiles as binder-free, self-supported anodes for high-performance lithium storage. Nanoscale 2013, 5, 10291-10299. [CrossRef] [PubMed]

84. Abel, P.R.; Lin, Y.M.; de Souza, T.; Chou, C.Y.; Gupta, A.; Goodenough, J.B.; Hwang, G.S.; Heller, A.; Mullins, C.B. Nanocolumnar Germanium Thin Films as a High-Rate Sodium-Ion Battery Anode Material. J. Phys. Chem. C 2013, 117, 18885-18890. [CrossRef]

85. Stojic, M.; Kostic, D.; Stosic, B. The behavior of sodium in Ge, Si and GaAs. Physica B+C 1986, 138, $125-128$. [CrossRef]

86. Wang, X.; Fan, L.; Gong, D.; Zhu, J.; Zhang, Q.; Lu, B. Core-Shell Ge@Graphene@TiO2 Nanofibers as a High-Capacity and Cycle-Stable Anode for Lithium and Sodium Ion Battery. Adv. Funct. Mater. 2016, 26, 1104-1111. [CrossRef]

87. Luo, W.; Shen, F.; Bommier, C.; Zhu, H.L.; Ji, X.L.; Hu, L.B. Na-Ion Battery Anodes: Materials and Electrochemistry. Acc. Chem. Res. 2016, 49, 231-240. [CrossRef]

88. Qian, J.F.; Wu, X.Y.; Cao, Y.L.; Ai, X.P.; Yang, H.X. High Capacity and Rate Capability of Amorphous Phosphorus for Sodium Ion Batteries. Angew. Chem. Int. Ed. 2013, 52, 4633-4636. [CrossRef]

89. Kim, Y.; Park, Y.; Choi, A.; Choi, N.-S.; Kim, J.; Lee, J.; Ryu, J.H.; Oh, S.M.; Lee, K.T. An Amorphous Red Phosphorus/Carbon Composite as a Promising Anode Material for Sodium Ion Batteries. Adv. Mater. 2013, 25, 3045-3049. [CrossRef] 
90. Liu, S.; Xu, H.; Bian, X.; Feng, J.; Liu, J.; Yang, Y.; Yuan, C.; An, Y.; Fan, R.; Ci, L. Hollow nanoporous red phosphorus as an advanced anode for sodium-ion batteries. J. Mater. Chem. A 2018, 6, 12992-12998. [CrossRef]

91. Yao, S.; Cui, J.; Huang, J.; Huang, J.-Q.; Chong, W.G.; Qin, L.; Mai, Y.-W.; Kim, J.-K. Rational Assembly of Hollow Microporous Carbon Spheres as P Hosts for Long-Life Sodium-Ion Batteries. Adv. Energy Mater. 2018, 8, 1702267. [CrossRef]

92. Jin, H.; Zhang, T.; Chuang, C.; Lu, Y.-R.; Chan, T.-S.; Du, Z.; Ji, H.; Wan, L.-J. Synergy of Black Phosphorus-Graphite-Polyaniline-Based Ternary Composites for Stable High Reversible Capacity Na-Ion Battery Anodes. ACS Appl. Mater. Interfaces 2019, 11, 16656-16661. [CrossRef] [PubMed]

93. Webb, S.A.; Baggetto, L.; Bridges, C.A.; Veith, G.M. The electrochemical reactions of pure indium with Li and Na: Anomalous electrolyte decomposition, benefits of FEC additive, phase transitions and electrode performance. J. Power Sources 2014, 248, 1105-1117. [CrossRef]

94. Darwiche, A.; Dugas, R.; Fraisse, B.; Monconduit, L. Reinstating lead for high-loaded efficient negative electrode for rechargeable sodium-ion battery. J. Power Sources 2016, 304, 1-8. [CrossRef]

95. Liu, S.; Feng, J.K.; Bian, X.F.; Liu, J.; Xu, H. Advanced arrayed bismuth nanorod bundle anode for sodium-ion batteries. J. Mater. Chem. A 2016, 4, 10098-10104. [CrossRef]

96. Wang, C.C.; Wang, L.B.; Li, F.J.; Cheng, F.Y.; Chen, J. Bulk Bismuth as a High-Capacity and Ultralong Cycle-Life Anode for Sodium-Ion Batteries by Coupling with Glyme-Based Electrolytes. Adv. Mater. 2017, 29, 1702212. [CrossRef] [PubMed]

97. Yang, H.; Xu, R.; Yao, Y.; Ye, S.F.; Zhou, X.F.; Yu, Y. Multicore-Shell Bi@N-doped Carbon Nanospheres for High Power Density and Long Cycle Life Sodium- and Potassium-Ion Anodes. Adv. Funct. Mater. 2019, 29, 1809195. [CrossRef]

98. Ji, L.; Gu, M.; Shao, Y.; Li, X.; Engelhard, M.H.; Arey, B.W.; Wang, W.; Nie, Z.; Xiao, J.; Wang, C.; et al. Controlling SEI Formation on SnSb-Porous Carbon Nanofibers for Improved Na Ion Storage. Adv. Mater. 2014, 26, 2901-2908. [CrossRef] [PubMed]

99. Liu, J.; Kopold, P.; Wu, C.; van Aken, P.A.; Maier, J.; Yu, Y. Uniform yolk-shell Sn4P3@C nanospheres as high-capacity and cycle-stable anode materials for sodium-ion batteries. Energy Environ. Sci. 2015, 8, 3531-3538. [CrossRef]

100. Li, W.; Hu, C.; Zhou, M.; Tao, H.; Wang, K.; Cheng, S.; Jiang, K. Carbon-coated Mo3Sb7 composite as anode material for sodium ion batteries with long cycle life. J. Power Sources 2016, 307, 173-180. [CrossRef]

101. Edison, E.; Ling, W.C.; Aravindan, V.; Madhavi, S. Highly Stable Intermetallic FeSn2-Graphite Composite Anode for Sodium-Ion Batteries. ChemElectroChem 2017, 4, 1932-1936. [CrossRef]

102. Gao, H.; Niu, J.; Zhang, C.; Peng, Z.; Zhang, Z. A Dealloying Synthetic Strategy for Nanoporous Bismuth-Antimony Anodes for Sodium Ion Batteries. ACS Nano 2018, 12, 3568-3577. [CrossRef] [PubMed]

103. Nam, D.-H.; Kim, T.-H.; Hong, K.-S.; Kwon, H.-S. Template-Free Electrochemical Synthesis of Sn Nanofibers as High-Performance Anode Materials for Na-Ion Batteries. ACS Nano 2014, 8, 11824-11835. [CrossRef] [PubMed]

104. Zhou, X.; Dai, Z.; Bao, J.; Guo, Y.-G. Wet milled synthesis of an Sb/MWCNT nanocomposite for improved sodium storage. J. Mater. Chem. A 2013, 1, 13727-13731. [CrossRef]

105. Wu, L.; Lu, H.; Xiao, L.; Ai, X.; Yang, H.; Cao, Y. Electrochemical properties and morphological evolution of pitaya-like Sb@C microspheres as high-performance anode for sodium ion batteries. J. Mater. Chem. A 2015, 3, 5708-5713. [CrossRef]

106. Li, P.; Guo, X.; Wang, S.; Zang, R.; Li, X.; Man, Z.; Li, P.; Liu, S.; Wu, Y.; Wang, G. Two-dimensional Sb@TiO2-x nanoplates as a high-performance anode material for sodium-ion batteries. J. Mater. Chem. A 2019, 7, 2553-2559. [CrossRef]

107. Nie, A.; Gan, L.-Y.; Cheng, Y.; Tao, X.; Yuan, Y.; Sharifi-Asl, S.; He, K.; Asayesh-Ardakani, H.; Vasiraju, V.; Lu, J.; et al. Ultrafast and Highly Reversible Sodium Storage in Zinc-Antimony Intermetallic Nanomaterials. Adv. Funct. Mater. 2016, 26, 543-552. [CrossRef]

108. Darwiche, A.; Toiron, M.; Sougrati, M.T.; Fraisse, B.; Stievano, L.; Monconduit, L. Performance and mechanism of FeSb2 as negative electrode for Na-ion batteries. J. Power Sources 2015, 280, 588-592. [CrossRef]

109. Jian, Z.; Zhao, B.; Liu, P.; Li, F.; Zheng, M.; Chen, M.; Shi, Y.; Zhou, H. $\mathrm{Fe}_{2} \mathrm{O}_{3}$ nanocrystals anchored onto graphene nanosheets as the anode material for low-cost sodium-ion batteries. Chem. Commun. 2014, 50, 1215-1217. [CrossRef] 
110. Yang, F.; Yu, F.; Zhang, Z.; Zhang, K.; Lai, Y.; Li, J. Bismuth Nanoparticles Embedded in Carbon Spheres as Anode Materials for Sodium/Lithium-Ion Batteries. Chem. Eur. J. 2016, 22, 2333-2338. [CrossRef]

111. Xie, H.; Kalisvaart, W.P.; Olsen, B.C.; Luber, E.J.; Mitlin, D.; Buriak, J.M. Sn-Bi-Sb alloys as anode materials for sodium ion batteries. J. Mater. Chem. A 2017, 5, 9661-9670. [CrossRef]

112. Kim, Y.; Kim, Y.; Choi, A.; Woo, S.; Mok, D.; Choi, N.-S.; Jung, Y.S.; Ryu, J.H.; Oh, S.M.; Lee, K.T. Tin Phosphide as a Promising Anode Material for Na-Ion Batteries. Adv. Mater. 2014, 26, 4139-4144. [CrossRef] [PubMed]

113. Liu, J.; Wang, S.; Kravchyk, K.; Ibáñez, M.; Krumeich, F.; Widmer, R.; Nasiou, D.; Meyns, M.; Llorca, J.; Arbiol, J.; et al. SnP nanocrystals as anode materials for Na-ion batteries. J. Mater. Chem. A 2018, 6, 10958-10966. [CrossRef]

114. Kim, S.-O.; Manthiram, A. The facile synthesis and enhanced sodium-storage performance of a chemically bonded CuP2/C hybrid anode. Chem. Commun. 2016, 52, 4337-4340. [CrossRef] [PubMed]

115. Delmas, C.; Braconnier, J.-J.; Fouassier, C.; Hagenmuller, P. Electrochemical intercalation of sodium in NaxCoO2 bronzes. Solid State Ion. 1981, 3-4, 165-169. [CrossRef]

116. Tian, L.; Zhuang, Q.; Li, J.; Wu, C.; Shi, Y.; Sun, S. The production of self-assembled $\mathrm{Fe}_{2} \mathrm{O}_{3}$-graphene hybrid materials by a hydrothermal process for improved Li-cycling. Electrochim. Acta 2012, 65, 153-158. [CrossRef]

117. Li, Y.; Zhu, C.; Lu, T.; Guo, Z.; Zhang, D.; Ma, J.; Zhu, S. Simple fabrication of a Fe2O3/carbon composite for use in a high-performance lithium ion battery. Carbon 2013, 52, 565-573. [CrossRef]

118. Zou, M.; Li, J.; Wen, W.; Chen, L.; Guan, L.; Lai, H.; Huang, Z. Silver-incorporated composites of $\mathrm{Fe}_{2} \mathrm{O}_{3}$ carbon nanofibers as anodes for high-performance lithium batteries. J. Power Sources 2014, 270, 468-474. [CrossRef]

119. Shen, L.; Yu, Y. Greener and cheaper. Nat. Energy 2017, 2, 836-837. [CrossRef]

120. Klein, F.; Jache, B.; Bhide, A.; Adelhelm, P. Conversion reactions for sodium-ion batteries. Phys. Chem. Chem. Phys. 2013, 15, 15876-15887. [CrossRef]

121. Wang, X.; Liu, Y.; Wang, Y.; Jiao, L. CuO Quantum Dots Embedded in Carbon Nanofibers as Binder-Free Anode for Sodium Ion Batteries with Enhanced Properties. Small 2016, 12, 4865-4872. [CrossRef] [PubMed]

122. Zhang, N.; Han, X.; Liu, Y.; Hu, X.; Zhao, Q.; Chen, J. 3D Porous $\gamma-\mathrm{Fe}_{2} \mathrm{O}_{3} @ \mathrm{C}$ nanocomposite as high-performance anode material of Na-ion batteries. Adv. Energy Mater. 2015, 5, 1401123. [CrossRef]

123. Wu, L.; Lang, J.; Wang, R.; Guo, R.; Yan, X. Electrospinning Synthesis of Mesoporous MnCoNiOx@Double-Carbon Nanofibers for Sodium-Ion Battery Anodes with Pseudocapacitive Behavior and Long Cycle Life. ACS Appl. Mater. Interfaces 2016, 8, 34342-34352. [CrossRef] [PubMed]

124. Ramakrishnan, K.; Nithya, C.; Kundoly Purushothaman, B.; Kumar, N.; Gopukumar, S. $\mathrm{Sb}_{2} \mathrm{O}_{4} @ \mathrm{rGO}$ nanocomposite anode for high performance sodium-ion batteries. ACS Sustain. Chem. Eng. 2017, 5, 5090-5098. [CrossRef]

125. Li, K.; Zhang, J.; Lin, D.; Wang, D.-W.; Li, B.; Lv, W.; Sun, S.; He, Y.-B.; Kang, F.; Yang, Q.-H.; et al. Evolution of the electrochemical interface in sodium ion batteries with ether electrolytes. Nat. Commun. 2019, 10, 725. [CrossRef]

126. Dinh, C.-T.; Nguyen, T.-D.; Kleitz, F.; Do, T.-O. Shape-controlled synthesis of highly crystalline titania nanocrystals. ACS Nano 2009, 3, 3737-3743. [CrossRef] [PubMed]

127. Li, M.; Ma, C.; Zhu, Q.-C.; Xu, S.-M.; Wei, X.; Wu, Y.-M.; Tang, W.-P.; Wang, K.-X.; Chen, J.-S. Well-ordered mesoporous $\mathrm{Fe}_{2} \mathrm{O}_{3} / \mathrm{C}$ composites as high performance anode materials for sodium-ion batteries. Dalton Trans. 2017, 46, 5025-5032. [CrossRef]

128. Zoller, F.; Peters, K.; Zehetmaier, P.M.; Zeller, P.; Döblinger, M.; Bein, T.; Sofer, Z.K.; Fattakhova-Rohlfing, D. Making Ultrafast High-Capacity Anodes for Lithium-Ion Batteries via Antimony Doping of Nanosized Tin Oxide/Graphene Composites. Adv. Funct. Mater. 2018, 28, 1706529. [CrossRef]

129. Hasa, I.; Verrelli, R.; Hassoun, J. Transition metal oxide-carbon composites as conversion anodes for sodium-ion battery. Electrochim. Acta 2015, 173, 613-618. [CrossRef]

130. Wang, X.; Liu, X.; Wang, G.; Xia, Y.; Wang, H. One-dimensional hybrid nanocomposite of high-density monodispersed $\mathrm{Fe}_{3} \mathrm{O}_{4}$ nanoparticles and carbon nanotubes for high-capacity storage of lithium and sodium. J. Mater. Chem. A 2016, 4, 18532-18542. [CrossRef]

131. Wang, T.; Qu, J.; Legut, D.; Qin, J.; Li, X.; Zhang, Q. Unique Double-Interstitialcy Mechanism and Interfacial Storage Mechanism in the Graphene/Metal Oxide as the Anode for Sodium-Ion Batteries. Nano Lett. 2019, 19, 3122-3130. [CrossRef] [PubMed] 
132. Song, X.; Li, X.; Bai, Z.; Yan, B.; Li, D.; Sun, X. Morphology-dependent performance of nanostructured Ni $3 \mathrm{~S}$ 2 /Ni anode electrodes for high performance sodium ion batteries. Nano Energy 2016, 26, 533-540. [CrossRef]

133. Liu, Q.; Hu, Z.; Chen, M.; Zou, C.; Jin, H.; Wang, S.; Gu, Q.; Chou, S. P2-type $\mathrm{Na}_{2 / 3} \mathrm{Ni}_{1 / 3} \mathrm{Mn}_{2 / 3} \mathrm{O}_{2}$ as a cathode material with high-rate and long-life for sodium ion storage. J. Mater. Chem. A 2019, 7, 9215-9221. [CrossRef]

134. Hosono, E.; Saito, T.; Hoshino, J.; Okubo, M.; Saito, Y.; Nishio-Hamane, D.; Kudo, T.; Zhou, H. High power Na-ion rechargeable battery with single-crystalline $\mathrm{Na} 0.44 \mathrm{MnO} 2$ nanowire electrode. J. Power Sources 2012, 217, 43-46. [CrossRef]

135. Qi, L.-Y.; Zhang, Y.-W.; Zuo, Z.-C.; Xin, Y.-L.; Yang, C.-K.; Wu, B.; Zhang, X.-X.; Zhou, H.-H. In situ quantization of ferroferric oxide embedded in $3 \mathrm{D}$ microcarbon for ultrahigh performance sodium-ion batteries. J. Mater. Chem. A 2016, 4, 8822-8829. [CrossRef]

136. Wang, Y.; Wang, C.; Wang, Y.; Liu, H.; Huang, Z. Superior sodium-ion storage performance of $\mathrm{Co}_{3} \mathrm{O}_{4} @$ nitrogen-doped carbon: Derived from a metal-organic framework. J. Mater. Chem. A 2016, 4, 5428-5435. [CrossRef]

137. Lee, J.-I.; Song, J.; Cha, Y.; Fu, S.; Zhu, C.; Li, X.; Lin, Y.; Song, M.-K. Multifunctional SnO $2 / 3 \mathrm{D}$ graphene hybrid materials for sodium-ion and lithium-ion batteries with excellent rate capability and long cycle life. Nano Res. 2017, 10, 4398-4414. [CrossRef]

138. Yang, L.; Zhu, Y.-E.; Sheng, J.; Li, F.; Tang, B.; Zhang, Y.; Zhou, Z. T-Nb2O5/C Nanofibers Prepared through Electrospinning with Prolonged Cycle Durability for High-Rate Sodium-Ion Batteries Induced by Pseudocapacitance. Small 2017, 13, 1702588. [CrossRef]

139. Cao, K.; Jiao, L.; Pang, W.K.; Liu, H.; Zhou, T.; Guo, Z.; Wang, Y.; Yuan, H. $\mathrm{Na}_{2} \mathrm{Ti}_{6} \mathrm{O}_{13}$ Nanorods with Dominant Large Interlayer Spacing Exposed Facet for High-Performance Na-Ion Batteries. Small 2016, 12, 2991-2997. [CrossRef]

140. Li, N.; Liao, S.; Sun, Y.; Song, H.W.; Wang, C.X. Uniformly dispersed self-assembled growth of $\mathrm{Sb}_{2} \mathrm{O}_{3} / \mathrm{Sb} @$ graphene nanocomposites on a 3D carbon sheet network for high Na-storage capacity and excellent stability. J. Mater. Chem. A 2015, 3, 5820-5828. [CrossRef]

141. Cai, Y.; Fang, G.; Zhou, J.; Liu, S.; Luo, Z.; Pan, A.; Cao, G.; Liang, S. Metal-organic framework-derived porous shuttle-like vanadium oxides for sodium-ion battery application. Nano Res. 2018, 11, 449-463. [CrossRef]

142. Wang, X.; Cao, K.; Wang, Y.; Jiao, L. Controllable N-Doped $\mathrm{CuCo}_{2} \mathrm{O}_{4} @ \mathrm{C}$ Film as a Self-Supported Anode for Ultrastable Sodium-Ion Batteries. Small 2017, 13, 1700873. [CrossRef] [PubMed]

143. Zhou, M.; Xu, Y.; Wang, C.; Li, Q.; Xiang, J.; Liang, L.; Wu, M.; Zhao, H.; Lei, Y. Amorphous TiO 2 inverse opal anode for high-rate sodium ion batteries. Nano Energy 2017, 31, 514-524. [CrossRef]

144. Kalubarme, R.S.; Inamdar, A.I.; Bhange, D.S.; Im, H.; Gosavi, S.W.; Park, C.-J. Nickel-titanium oxide as a novel anode material for rechargeable sodium-ion batteries. J. Mater. Chem. A 2016, 4, 17419-17430. [CrossRef]

145. Tang, Y.; Liu, L.; Zhang, Y.; Zhao, H.; Kong, L.; Gao, S. Confined formation of monoclinic $\mathrm{Na}_{4} \mathrm{Ti}_{5} \mathrm{O}_{12}$ nanoparticles embedded into porous CNTs: Towards enhanced electrochemical performances for sodium ion batteries. New J. Chem. 2018, 42, 19340-19343. [CrossRef]

146. Wang, S.; Cao, F.; Li, Y.; Zhang, Z.; Zhou, D.; Yang, Y.; Tang, Z. MoS2-Coupled Carbon Nanosheets Encapsulated on Sodium Titanate Nanowires as Super-Durable Anode Material for Sodium-Ion Batteries. Adv. Sci. 2019, 6, 1900028. [CrossRef] [PubMed]

147. Raccichini, R.; Varzi, A.; Passerini, S.; Scrosati, B. The role of graphene for electrochemical energy storage. Nat. Mater. 2014, 14, 271-279. [CrossRef]

148. Ying, H.; Han, W.-Q. Metallic Sn-Based Anode Materials: Application in High-Performance Lithium-Ion and Sodium-Ion Batteries. Adv. Sci. 2017, 4, 1700298. [CrossRef]

149. Li, D.; Kaner, R.B. Graphene-Based Materials. Science 2008, 320, 1170-1171. [CrossRef]

150. Liu, N.; Chortos, A.; Lei, T.; Jin, L.; Kim, T.R.; Bae, W.-G.; Zhu, C.; Wang, S.; Pfattner, R.; Chen, X.; et al. Ultratransparent and stretchable graphene electrodes. Sci. Adv. 2017, 3, e1700159. [CrossRef]

151. Kim, K.S.; Zhao, Y.; Jang, H.; Lee, S.Y.; Kim, J.M.; Kim, K.S.; Ahn, J.-H.; Kim, P.; Choi, J.-Y.; Hong, B.H. Large-scale pattern growth of graphene films for stretchable transparent electrodes. Nature 2009, 457, 706-710. [CrossRef] [PubMed]

152. Li, G.; Huang, B.; Pan, Z.; Su, X.; Shao, Z.; An, L. Advances in three-dimensional graphene-based materials: Configurations, preparation and application in secondary metal ( $\mathrm{Li}, \mathrm{Na}, \mathrm{K}, \mathrm{Mg}, \mathrm{Al})$-ion batteries. Energy Environ. Sci. 2019. [CrossRef] 
153. Liu, J.; Liu, X.W. Two-dimensional nanoarchitectures for lithium storage. Adv. Mater. 2012, 24, 4097-4111. [CrossRef] [PubMed]

154. Sun, H.; Mei, L.; Liang, J.; Zhao, Z.; Lee, C.; Fei, H.; Ding, M.; Lau, J.; Li, M.; Wang, C.; et al. Three-dimensional holey-graphene/niobia composite architectures for ultrahigh-rate energy storage. Science 2017, 356, 599-604. [CrossRef] [PubMed]

155. Xu, X.; Zeng, H.; Han, D.; Qiao, K.; Xing, W.; Rood, M.J.; Yan, Z. Nitrogen and Sulfur Co-Doped Graphene Nanosheets to Improve Anode Materials for Sodium-Ion Batteries. ACS Appl. Mater. Interfaces 2018, 10, 37172-37180. [CrossRef] [PubMed]

156. Pan, J.; Chen, S.; Fu, Q.; Sun, Y.; Zhang, Y.; Lin, N.; Gao, P.; Yang, J.; Qian, Y. Layered-Structure SbPO4/Reduced Graphene Oxide: An Advanced Anode Material for Sodium Ion Batteries. ACS Nano 2018, 12, 12869-12878. [CrossRef] [PubMed]

157. Liu, J.; Zhang, Y.; Zhang, L.; Xie, F.; Vasileff, A.; Qiao, S.-Z. Graphitic Carbon Nitride (g-C3N4)-Derived N-Rich Graphene with Tuneable Interlayer Distance as a High-Rate Anode for Sodium-Ion Batteries. Adv. Mater. 2019, 1901261. [CrossRef]

158. Zhang, Y.; Wang, G.; Wang, L.; Tang, L.; Zhu, M.; Wu, C.; Dou, S.-X.; Wu, M. Graphene-Encapsulated CuP2: A Promising Anode Material with High Reversible Capacity and Superior Rate-Performance for Sodium-Ion Batteries. Nano Lett. 2019, 19, 2575-2582. [CrossRef]

159. Chen, W.; Zhang, X.; Mi, L.; Liu, C.; Zhang, J.; Cui, S.; Feng, X.; Cao, Y.; Shen, C. High-Performance Flexible Freestanding Anode with Hierarchical 3D Carbon-Networks/Fe7S8/Graphene for Applicable Sodium-Ion Batteries. Adv. Mater. 2019, 31, 1806664. [CrossRef]

160. Ling, C.; Mizuno, F. Boron-doped graphene as a promising anode for Na-ion batteries. Phys. Chem. Chem. Phys. 2014, 16, 10419-10424. [CrossRef]

161. Yang, Y.; Tang, D.-M.; Zhang, C.; Zhang, Y.; Liang, Q.; Chen, S.; Weng, Q.; Zhou, M.; Xue, Y.; Liu, J.; et al. "Protrusions" or "holes" in graphene: Which is the better choice for sodium ion storage? Energy Environ. Sci. 2017, 10, 979-986. [CrossRef]

162. Guo, X.; Zheng, S.; Zhang, G.; Xiao, X.; Li, X.; Xu, Y.; Xue, H.; Pang, H. Nanostructured graphene-based materials for flexible energy storage. Energy Storage Mater. 2017, 9, 150-169. [CrossRef]

163. Samuel Reich, E. Phosphorene excites materials scientists. Nature 2014, 506, 19. [CrossRef] [PubMed]

164. Liu, H.; Neal, A.T.; Zhu, Z.; Luo, Z.; Xu, X.; Tománek, D.; Ye, P.D. Phosphorene: An Unexplored 2D Semiconductor with a High Hole Mobility. ACS Nano 2014, 8, 4033-4041. [CrossRef]

165. Sun, J.; Zheng, G.; Lee, H.-W.; Liu, N.; Wang, H.; Yao, H.; Yang, W.; Cui, Y. Formation of Stable Phosphorus-Carbon Bond for Enhanced Performance in Black Phosphorus Nanoparticle-Graphite Composite Battery Anodes. Nano Lett. 2014, 14, 4573-4580. [CrossRef]

166. Zhang, Y.; Wang, H.; Luo, Z.; Tan, H.T.; Li, B.; Sun, S.; Li, Z.; Zong, Y.; Xu, Z.J.; Yang, Y.; et al. An Air-Stable Densely Packed Phosphorene-Graphene Composite Toward Advanced Lithium Storage Properties. Adv. Energy Mater. 2016, 6, 1600453. [CrossRef]

167. Khandelwal, A.; Mani, K.; Karigerasi, M.H.; Lahiri, I. Phosphorene-The two-dimensional black phosphorous: Properties, synthesis and applications. Mater. Sci. Eng. B 2017, 221, 17-34. [CrossRef]

168. Padilha, J.E.; Fazzio, A.; da Silva, A.J.R. van der Waals Heterostructure of Phosphorene and Graphene: Tuning the Schottky Barrier and Doping by Electrostatic Gating. Phys. Rev. Lett. 2015, 114, 066803. [CrossRef]

169. Tao, Y.; Huang, T.; Ding, C.; Yu, F.; Tan, D.; Wang, F.; Xie, Q.; Yao, S. Few-layer phosphorene: An emerging electrode material for electrochemical energy storage. Appl. Mater. Today 2019, 15, 18-33. [CrossRef]

170. Sresht, V.; Pádua, A.A.H.; Blankschtein, D. Liquid-Phase Exfoliation of Phosphorene: Design Rules from Molecular Dynamics Simulations. ACS Nano 2015, 9, 8255-8268. [CrossRef]

171. Liu, N.; Becton, M.; Zhang, L.; Chen, H.; Zeng, X.; Pidaparti, R.; Wang, X. A coarse-grained model for mechanical behavior of phosphorene sheets. Phys. Chem. Chem. Phys. 2019, 21, 1884-1894. [CrossRef] [PubMed]

172. Sun, Z.; Zhang, Y.; Yu, H.; Yan, C.; Liu, Y.; Hong, S.; Tao, H.; Robertson, A.W.; Wang, Z.; Pádua, A.A.H. New solvent-stabilized few-layer black phosphorus for antibacterial applications. Nanoscale 2018, 10, 12543-12553. [CrossRef] [PubMed]

173. Huang, Z.; Hou, H.; Zhang, Y.; Wang, C.; Qiu, X.; Ji, X. Layer-Tunable Phosphorene Modulated by the Cation Insertion Rate as a Sodium-Storage Anode. Adv. Mater. 2017, 29, 1702372. [CrossRef] [PubMed] 
174. Wang, G.; Shen, X.; Yao, J.; Park, J. Graphene nanosheets for enhanced lithium storage in lithium ion batteries. Carbon 2009, 47, 2049-2053. [CrossRef]

175. Sun, J.; Lee, H.-W.; Pasta, M.; Yuan, H.; Zheng, G.; Sun, Y.; Li, Y.; Cui, Y. A phosphorene-graphene hybrid material as a high-capacity anode for sodium-ion batteries. Nat. Nanotechnol. 2015, 10, 980-985. [CrossRef] [PubMed]

176. Batmunkh, M.; Bat-Erdene, M.; Shapter, J.G. Phosphorene and Phosphorene-Based Materials—Prospects for Future Applications. Adv. Mater. 2016, 28, 8586-8617. [CrossRef] [PubMed]

177. Yang, Y.; Hou, H.; Zou, G.; Shi, W.; Shuai, H.; Li, J.; Ji, X. Electrochemical exfoliation of graphene-like two-dimensional nanomaterials. Nanoscale 2019, 11, 16-33. [CrossRef]

178. Wu, S.; Hui, K.S.; Hui, K.N. 2D Black Phosphorus: From Preparation to Applications for Electrochemical Energy Storage. Adv. Sci. 2018, 5, 1700491. [CrossRef]

179. Evaristo, M.; Polcar, T.; Cavaleiro, A. Tribological behaviour of C-alloyed transition metal dichalcogenides (TMD) coatings in different environments. Int. J. Mech. Mater. Des. 2008, 4, 137-143. [CrossRef]

180. Yang, E.; Ji, H.; Jung, Y. Two-Dimensional Transition Metal Dichalcogenide Monolayers as Promising Sodium Ion Battery Anodes. J. Phys. Chem. C 2015, 119, 26374-26380. [CrossRef]

181. Kang, W.; Wang, Y.; Xu, J. Recent progress in layered metal dichalcogenide nanostructures as electrodes for high-performance sodium-ion batteries. J. Mater. Chem. A 2017, 5, 7667-7690. [CrossRef]

182. Wang, Q.H.; Kalantar-Zadeh, K.; Kis, A.; Coleman, J.N.; Strano, M.S. Electronics and optoelectronics of two-dimensional transition metal dichalcogenides. Nat. Nanotechnol. 2012, 7, 699-712. [CrossRef] [PubMed]

183. Mak, K.F.; Lee, C.; Hone, J.; Shan, J.; Heinz, T.F. Atomically Thin $\mathrm{MoS}_{2}$ : A New Direct-Gap Semiconductor. Phys. Rev. Lett. 2010, 105, 136805. [CrossRef] [PubMed]

184. Splendiani, A.; Sun, L.; Zhang, Y.; Li, T.; Kim, J.; Chim, C.Y.; Galli, G.; Wang, F. Emerging photoluminescence in monolayer $\mathrm{MoS}_{2}$. Nano Lett. 2010, 10, 1271-1275. [CrossRef]

185. Joensen, P.; Frindt, R.F.; Morrison, S.R. Single-layer MoS $_{2}$. Mater. Res. Bull. 1986, 21, 457-461. [CrossRef]

186. Kolobov, A.V.; Tominaga, J. Two-Dimensional Transition-Metal Dichalcogenides; Springer: Cham, Switzerland, 2016; Volume 239.

187. Park, J.; Kim, J.-S.; Park, J.-W.; Nam, T.-H.; Kim, K.-W.; Ahn, J.-H.; Wang, G.; Ahn, H.-J. Discharge mechanism of $\mathrm{MoS}_{2}$ for sodium ion battery: Electrochemical measurements and characterization. Electrochim. Acta 2013, 92, 427-432. [CrossRef]

188. Wang, J.; Luo, C.; Gao, T.; Langrock, A.; Mignerey, A.C.; Wang, C. An Advanced MoS $2 /$ Carbon Anode for High-Performance Sodium-Ion Batteries. Small 2015, 11, 473-481. [CrossRef]

189. Zhang, L.; Sun, D.; Kang, J.; Feng, J.; Bechtel, H.A.; Wang, L.-W.; Cairns, E.J.; Guo, J. Electrochemical Reaction Mechanism of the $\mathrm{MoS}_{2}$ Electrode in a Lithium-Ion Cell Revealed by in Situ and Operando X-ray Absorption Spectroscopy. Nano Lett. 2018, 18, 1466-1475. [CrossRef]

190. David, L.; Singh, G. Reduced Graphene Oxide Paper Electrode: Opposing Effect of Thermal Annealing on Li and Na Cyclability. J. Phys. Chem. C 2014, 118, 28401-28408. [CrossRef]

191. Xie, X.; Makaryan, T.; Zhao, M.; Van Aken, K.L.; Gogotsi, Y.; Wang, G. MoS 2 Nanosheets Vertically Aligned on Carbon Paper: A Freestanding Electrode for Highly Reversible Sodium-Ion Batteries. Adv. Energy Mater. 2016, 6, 1502161. [CrossRef]

192. Xie, X.; Ao, Z.; Su, D.; Zhang, J.; Wang, G. MoS 2 /Graphene Composite Anodes with Enhanced Performance for Sodium-Ion Batteries: The Role of the Two-Dimensional Heterointerface. Adv. Funct. Mater. 2015, 25, 1393-1403. [CrossRef]

193. Cho, J.S.; Ju, H.S.; Lee, J.-K.; Kang, Y.C. Carbon/two-dimensional MoTe2 core/shell-structured microspheres as an anode material for Na-ion batteries. Nanoscale 2017, 9, 1942-1950. [CrossRef] [PubMed]

194. Wang, Z.; Chen, T.; Chen, W.; Chang, K.; Ma, L.; Huang, G.; Chen, D.; Lee, J.Y. CTAB-assisted synthesis of single-layer MoS2-graphene composites as anode materials of Li-ion batteries. J. Mater. Chem. A 2013, 1, 2202-2210. [CrossRef]

195. Ai, K.; Ruan, C.; Shen, M.; Lu, L. $\mathrm{MoS}_{2}$ Nanosheets with Widened Interlayer Spacing for High-Efficiency Removal of Mercury in Aquatic Systems. Adv. Funct. Mater. 2016, 26, 5542-5549. [CrossRef]

196. Niu, F.; Yang, J.; Wang, N.; Zhang, D.; Fan, W.; Yang, J.; Qian, Y. MoSe 2 -Covered N,P-Doped Carbon Nanosheets as a Long-Life and High-Rate Anode Material for Sodium-Ion Batteries. Adv. Funct. Mater. 2017, 27, 1700522. [CrossRef] 
197. Naguib, M.; Mochalin, V.N.; Barsoum, M.W.; Gogotsi, Y. 25th Anniversary Article: MXenes: A New Family of Two-Dimensional Materials. Adv. Mater. 2014, 26, 992-1005. [CrossRef]

198. Naguib, M.; Kurtoglu, M.; Presser, V.; Lu, J.; Niu, J.; Heon, M.; Hultman, L.; Gogotsi, Y.; Barsoum, M.W. Two-Dimensional Nanocrystals Produced by Exfoliation of Ti3AlC2. Adv. Mater. 2011, 23, 4248-4253. [CrossRef]

199. Mukherjee, S.; Singh, G. Two-Dimensional Anode Materials for Non-lithium Metal-Ion Batteries. ACS Appl. Energy Mater. 2019, 2, 932-955. [CrossRef]

200. Pang, J.; Mendes, R.G.; Bachmatiuk, A.; Zhao, L.; Ta, H.Q.; Gemming, T.; Liu, H.; Liu, Z.; Rummeli, M.H. Applications of 2D MXenes in energy conversion and storage systems. Chem. Soc. Rev. 2019, 48, 72-133. [CrossRef]

201. Naguib, M.; Mashtalir, O.; Carle, J.; Presser, V.; Lu, J.; Hultman, L.; Gogotsi, Y.; Barsoum, M.W. Two-Dimensional Transition Metal Carbides. ACS Nano 2012, 6, 1322-1331. [CrossRef]

202. Lukatskaya, M.; Mashtalir, O.; Ren, C.; Dall'Agnese, Y.; Rozier, P.; Taberna, P.; Naguib, M.; Simon, P.; Barsoum, M.; Gogotsi, Y. Cation Intercalation and High Volumetric Capacitance of Two-Dimensional Titanium Carbide. Science 2013, 341, 1502-1505. [CrossRef] [PubMed]

203. Xie, Y.; Dall'Agnese, Y.; Naguib, M.; Gogotsi, Y.; Barsoum, M.W.; Zhuang, H.L.; Kent, P.R.C. Prediction and Characterization of MXene Nanosheet Anodes for Non-Lithium-Ion Batteries. ACS Nano 2014, 8, 9606-9615. [CrossRef] [PubMed]

204. Yu, Y.-X. Prediction of Mobility, Enhanced Storage Capacity, and Volume Change during Sodiation on Interlayer-Expanded Functionalized $\mathrm{Ti}_{3} \mathrm{C}_{2}$ MXene Anode Materials for Sodium-Ion Batteries. J. Phys. Chem. C 2016, 120, 5288-5296. [CrossRef]

205. Zhao, M.-Q.; Xie, X.; Ren, C.E.; Makaryan, T.; Anasori, B.; Wang, G.; Gogotsi, Y. Hollow MXene Spheres and 3D Macroporous MXene Frameworks for Na-Ion Storage. Adv. Mater. 2017, 29, 1702410. [CrossRef] [PubMed]

206. Xie, X.; Kretschmer, K.; Anasori, B.; Sun, B.; Wang, G.; Gogotsi, Y. Porous Ti3C2Tx MXene for Ultrahigh-Rate Sodium-Ion Storage with Long Cycle Life. ACS Appl. Nano Mater. 2018, 1, 505-511. [CrossRef]

207. Xie, X.; Zhao, M.-Q.; Anasori, B.; Maleski, K.; Ren, C.E.; Li, J.; Byles, B.W.; Pomerantseva, E.; Wang, G.; Gogotsi, Y. Porous heterostructured MXene/carbon nanotube composite paper with high volumetric capacity for sodium-based energy storage devices. Nano Energy 2016, 26, 513-523. [CrossRef]

208. Kim, K.-T.; Ali, G.; Chung, K.Y.; Yoon, C.S.; Yashiro, H.; Sun, Y.-K.; Lu, J.; Amine, K.; Myung, S.-T. Anatase Titania Nanorods as an Intercalation Anode Material for Rechargeable Sodium Batteries. Nano Lett. 2014, 14, 416-422. [CrossRef] [PubMed]

209. Wang, X.; Kajiyama, S.; Iinuma, H.; Hosono, E.; Oro, S.; Moriguchi, I.; Okubo, M.; Yamada, A. Pseudocapacitance of MXene nanosheets for high-power sodium-ion hybrid capacitors. Nat. Commun. 2015, 6, 6544. [CrossRef]

210. Yang, E.; Ji, H.; Kim, J.; Kim, H.; Jung, Y. Exploring the possibilities of two-dimensional transition metal carbides as anode materials for sodium batteries. Phys. Chem. Chem. Phys. 2015, 17, 5000-5005. [CrossRef]

211. Mashtalir, O.; Cook, K.M.; Mochalin, V.N.; Crowe, M.; Barsoum, M.W.; Gogotsi, Y. Dye adsorption and decomposition on two-dimensional titanium carbide in aqueous media. J. Mater. Chem. A 2014, 2, 14334-14338. [CrossRef]

212. Zhang, C.; Wang, X.; Liang, Q.; Liu, X.; Weng, Q.; Liu, J.; Yang, Y.; Dai, Z.; Ding, K.; Bando, Y.; et al. Amorphous Phosphorus/Nitrogen-Doped Graphene Paper for Ultrastable Sodium-Ion Batteries. Nano Lett. 2016, 16, 2054-2060. [CrossRef] [PubMed]

213. Zhao, J.; Zhang, Y.-Z.; Zhang, F.; Liang, H.; Ming, F.; Alshareef, H.N.; Gao, Z. Partially Reduced Holey Graphene Oxide as High Performance Anode for Sodium-Ion Batteries. Adv. Energy Mater. 2019, 9, 1803215. [CrossRef]

214. Wang, S.; Gong, F.; Yang, S.; Liao, J.; Wu, M.; Xu, Z.; Chen, C.; Yang, X.; Zhao, F.; Wang, B.; et al. Graphene Oxide-Template Controlled Cuboid-Shaped High-Capacity VS4 Nanoparticles as Anode for Sodium-Ion Batteries. Adv. Funct. Mater. 2018, 28, 1801806. [CrossRef]

215. Liu, S.; Xu, H.; Bian, X.; Feng, J.; Liu, J.; Yang, Y.; Yuan, C.; An, Y.; Fan, R.; Ci, L. Nanoporous Red Phosphorus on Reduced Graphene Oxide as Superior Anode for Sodium-Ion Batteries. ACS Nano 2018, 12, 7380-7387. [CrossRef] [PubMed] 
216. Shen, L.; Wang, Y.; Lv, H.; Chen, S.; van Aken, P.A.; Wu, X.; Maier, J.; Yu, Y. Ultrathin Ti2Nb2O9 Nanosheets with Pseudocapacitive Properties as Superior Anode for Sodium-Ion Batteries. Adv. Mater. 2018, 30, 1804378. [CrossRef]

217. Li, G.; Luo, D.; Wang, X.; Seo, M.H.; Hemmati, S.; Yu, A.; Chen, Z. Enhanced Reversible Sodium-Ion Intercalation by Synergistic Coupling of Few-Layered MoS2 and S-Doped Graphene. Adv. Funct. Mater. 2017, 27, 1702562. [CrossRef]

218. Lu, Y.; Zhao, Q.; Zhang, N.; Lei, K.; Li, F.; Chen, J. Facile Spraying Synthesis and High-Performance Sodium Storage of Mesoporous MoS2/C Microspheres. Adv. Funct. Mater. 2016, 26, 911-918. [CrossRef]

219. Wang, L.P.; Yu, L.; Wang, X.; Srinivasan, M.; Xu, Z.J. Recent developments in electrode materials for sodium ion batteries. J. Mater. Chem. A 2015, 3, 9353-9378. [CrossRef]

220. Whittingham, M.S. Lithium Batteries and Cathode Materials. Chem. Rev. 2004, 104, 4271-4302. [CrossRef]

221. Li, M.; Lu, J.; Chen, Z.; Amine, K. 30 Years of Lithium-Ion Batteries. Adv. Mater. 2018, 30, 1800561. [CrossRef]

222. Delmas, C.; Olazcuaga, R.; Le Flem, G.; Hagenmuller, P.; Cherkaoui, F.; Brochu, R. Crystal chemistry of the $\mathrm{Na}_{1+x} \mathrm{Zr}_{2-x} \mathrm{Lx}(\mathrm{PO} 4)_{3}(\mathrm{~L}=\mathrm{Cr}$, In, Yb) solid solutions. Mater. Res. Bull. 1981, 16, 285-290. [CrossRef]

223. Shibata, T.; Kobayashi, W.; Moritomo, Y. Sodium Ion Diffusion in Layered NaxCoO2. Appl. Phys. Express 2013, 6, 097101. [CrossRef]

224. Yabuuchi, N.; Yoshida, H.; Komaba, S. Crystal Structures and Electrode Performance of Alpha-NaFeO2 for Rechargeable Sodium Batteries. Electrochemistry 2012, 80, 716-719. [CrossRef]

225. Yoshida, H.; Yabuuchi, N.; Komaba, S. NaFe0.5Co0.5O2 as high energy and power positive electrode for Na-ion batteries. Electrochem. Commun. 2013, 34, 60-63. [CrossRef]

226. Yabuuchi, N.; Kajiyama, M.; Iwatate, J.; Nishikawa, H.; Hitomi, S.; Okuyama, R.; Usui, R.; Yamada, Y.; Komaba, S. P2-type $\mathrm{Nax}\left[\mathrm{Fe}_{1 / 2} \mathrm{Mn}_{1 / 2}\right] \mathrm{O}_{2}$ made from earth-abundant elements for rechargeable Na batteries. Nat. Mater. 2012, 11, 512-517. [CrossRef] [PubMed]

227. Xiang, X.; Zhang, K.; Chen, J. Recent Advances and Prospects of Cathode Materials for Sodium-Ion Batteries. Adv. Mater. 2015, 27, 5343-5364. [CrossRef]

228. Li, X.; Wu, D.; Zhou, Y.-N.; Liu, L.; Yang, X.-Q.; Ceder, G. O3-type Na(Mn0.25Fe0.25Co0.25Ni0.25)O2: A quaternary layered cathode compound for rechargeable Na ion batteries. Electrochemistry Communications 2014, 49, 51-54. [CrossRef]

229. Zhou, C.; Yang, L.; Zhou, C.; Lu, B.; Liu, J.; Ouyang, L.; Hu, R.; Liu, J.; Zhu, M. Co-Substitution Enhances the Rate Capability and Stabilizes the Cyclic Performance of O3-Type Cathode NaNi0.45-xMn0.25Ti0.3CoxO2 for Sodium-Ion Storage at High Voltage. ACS Appl. Mater. Interfaces 2019, 11, 7906-7913. [CrossRef]

230. Hasa, I.; Buchholz, D.; Passerini, S.; Scrosati, B.; Hassoun, J. High Performance $\mathrm{Na}_{0.5}\left[\mathrm{Ni}_{0.23} \mathrm{Fe}_{0.13} \mathrm{Mn}_{0.63}\right] \mathrm{O}_{2}$ Cathode for Sodium-Ion Batteries. Adv. Energy Mater. 2014, 4, 1400083. [CrossRef]

231. You, Y.; Kim, S.O.; Manthiram, A. A Honeycomb-Layered Oxide Cathode for Sodium-Ion Batteries with Suppressed P3-O1 Phase Transition. Adv. Energy Mater. 2017, 7, 1601698. [CrossRef]

232. Kim, D.; Lee, E.; Slater, M.; Lu, W.; Rood, S.; Johnson, C.S. Layered $N a\left[N_{1 / 3} \mathrm{Fe}_{1 / 3} \mathrm{Mn}_{1 / 3}\right] \mathrm{O}_{2}$ cathodes for Na-ion battery application. Electrochem. Commun. 2012, 18, 66-69. [CrossRef]

233. Sathiya, M.; Hemalatha, K.; Ramesha, K.; Tarascon, J.M.; Prakash, A.S. Synthesis, Structure, and Electrochemical Properties of the Layered Sodium Insertion Cathode Material: NaNi1/3Mn1/3Co1/3O2. Chem. Mater. 2012, 24, 1846-1853. [CrossRef]

234. Wang, Y.; Yu, X.; Xu, S.; Bai, J.; Xiao, R.; Hu, Y.-S.; Li, H.; Yang, X.-Q.; Chen, L.; Huang, X. A zero-strain layered metal oxide as the negative electrode for long-life sodium-ion batteries. Nat. Commun. 2013, 4, 2365. [CrossRef] [PubMed]

235. Mukherjee, S.; Schuppert, N.; Bates, A.; Lee, S.C.; Park, S. Novel mesoporous microspheres of Al and Ni doped LMO spinels and their performance as cathodes in secondary lithium ion batteries. Int. J. Green Energy 2017, 14, 656-664. [CrossRef]

236. Kim, D.; Kang, S.-H.; Slater, M.; Rood, S.; Vaughey, J.T.; Karan, N.; Balasubramanian, M.; Johnson, C.S. Enabling Sodium Batteries Using Lithium-Substituted Sodium Layered Transition Metal Oxide Cathodes. Adv. Energy Mater. 2011, 1, 333-336. [CrossRef]

237. Billaud, J.; Singh, G.; Armstrong, A.R.; Gonzalo, E.; Roddatis, V.; Armand, M.; Rojo, T.; Bruce, P.G. $\mathrm{Na}_{0.67} \mathrm{Mn}_{1-x} \mathrm{Mg}_{\mathrm{x}} \mathrm{O}_{2}(0 \leq \mathrm{x} \leq 0.2)$ : A high capacity cathode for sodium-ion batteries. Energy Environ. Sci. 2014, 7, 1387-1391. [CrossRef] 
238. Hamani, D.; Ati, M.; Tarascon, J.M.; Rozier, P. NaxVO2 as possible electrode for Na-ion batteries. Electrochem. Commun. 2011, 13, 938-941. [CrossRef]

239. Jian, Z.; Hu, Y.S.; Ji, X.; Chen, W. NASICON-Structured Materials for Energy Storage. Adv. Mater. 2017, 29, 1601925. [CrossRef]

240. Tang, W.; Song, X.; Du, Y.; Peng, C.; Lin, M.; Xi, S.; Tian, B.; Zheng, J.; Wu, Y.; Pan, F.; et al. High-performance $\mathrm{NaFePO} 4$ formed by aqueous ion-exchange and its mechanism for advanced sodium ion batteries. J. Mater. Chem. A 2016, 4, 4882-4892. [CrossRef]

241. Galceran, M.; Saurel, D.; Acebedo, B.; Roddatis, V.V.; Martin, E.; Rojo, T.; Casas-Cabanas, M. The mechanism of NaFePO4 (de)sodiation determined by in situ X-ray diffraction. Phys. Chem. Chem. Phys. 2014, 16, 8837-8842. [CrossRef]

242. Boucher, F.; Gaubicher, J.; Cuisinier, M.; Guyomard, D.; Moreau, P. Elucidation of the Na2/3FePO4 and $\mathrm{Li} / 3 \mathrm{FePO} 4$ Intermediate Superstructure Revealing a Pseudouniform Ordering in 2D. J. Am. Chem. Soc. 2014, 136, 9144-9157. [CrossRef] [PubMed]

243. Kim, J.; Seo, D.-H.; Kim, H.; Park, I.; Yoo, J.-K.; Jung, S.-K.; Park, Y.-U.; Goddard Iii, W.A.; Kang, K. Unexpected discovery of low-cost maricite $\mathrm{NaFePO} 4$ as a high-performance electrode for Na-ion batteries. Energy Environ. Sci. 2015, 8, 540-545. [CrossRef]

244. Oh, S.-M.; Myung, S.-T.; Hassoun, J.; Scrosati, B.; Sun, Y.-K. Reversible $\mathrm{NaFePO}_{4}$ electrode for sodium secondary batteries. Electrochem. Commun. 2012, 22, 149-152. [CrossRef]

245. Li, C.; Miao, X.; Chu, W.; Wu, P.; Tong, D.G. Hollow amorphous NaFePO4 nanospheres as a high-capacity and high-rate cathode for sodiumion batteries. J. Mater. Chem. A 2015, 3, 8265-8271. [CrossRef]

246. Ali, G.; Lee, J.-H.; Susanto, D.; Choi, S.-W.; Cho, B.W.; Nam, K.-W.; Chung, K.Y. Polythiophene-Wrapped Olivine NaFePO4 as a Cathode for Na-Ion Batteries. Appl. Mater. Interfaces 2016, 8, 15422-15429. [CrossRef] [PubMed]

247. Fang, Y.; Liu, Q.; Xiao, L.; Ai, X.; Yang, H.; Cao, Y. High-Performance Olivine NaFePO4 Microsphere Cathode Synthesized by Aqueous Electrochemical Displacement Method for Sodium Ion Batteries. ACS Appl. Mater. Interfaces 2015, 7, 17977-17984. [CrossRef] [PubMed]

248. Goodenough, J.B.; Hong, H.Y.P.; Kafalas, J.A. Fast $\mathrm{Na}^{+}$-ion transport in skeleton structures. Mater. Res. Bull. 1976, 11, 203-220. [CrossRef]

249. Alpen, U.V.; Bell, M.F.; Höfer, H.H. Compositional dependence of the electrochemical and structural parameters in the Nasicon system $\left(\mathrm{Na}_{1+x} \mathrm{SixZr}_{2} \mathrm{P}_{3-\mathrm{x}} \mathrm{O}_{12}\right)$. Solid State Ion. 1981, 3-4, 215-218.

250. Clearfield, A.; Jerus, P.; Cotman, R.N. Hydrothermal and solid state synthesis of sodium zirconium silicophosphates. Solid State Ion. 1981, 5, 301-304. [CrossRef]

251. Tamura, S.; Imanaka, N.; Adachi, G. Trivalent ion conduction in NASICON type solid electrolyte prepared by ball milling. Solid State Ion. 2002, 154-155, 767-771. [CrossRef]

252. Engell, J.; Mortensen, S.; Møller, L. Fabrication of Nasicon electrolytes from metal alkoxide derived gels. Solid State Ion. 1983, 9-10, 877-884. [CrossRef]

253. Delmas, C.; Cherkaoui, F.; Nadiri, A.; Hagenmuller, P. A nasicon-type phase as intercalation electrode: NaTi2(PO4)3. Mater. Res. Bull. 1987, 22, 631-639. [CrossRef]

254. Kang, J.; Baek, S.; Mathew, V.; Gim, J.; Song, J.; Park, H.; Chae, E.; Rai, A.K.; Kim, J. High rate performance of a Na3V2(PO4)3/C cathode prepared by pyro-synthesis for sodium-ion batteries. J. Mater. Chem. 2012, 22, 20857-20860. [CrossRef]

255. Liu, J.; Tang, K.; Song, K.; Aken, P.A.V.; Yu, Y.; Maie, J. Electrospun Na3V2(PO4)3/C nanofibers as stable cathode materials for sodium-ion batteries. Nanoscale 2014, 6, 5081-5086. [CrossRef] [PubMed]

256. Fang, Y.; Xiao, L.; Qian, J.; Cao, Y.; Ai, X.; Huang, Y.; Yang, H. 3D Graphene Decorated NaTi2(PO4)3 Microspheres as a Superior High-Rate and Ultracycle-Stable Anode Material for Sodium Ion Batteries. Adv. Energy Mater. 2016, 6, 1502197. [CrossRef]

257. Gao, H.; Seymour, I.D.; Xin, S.; Xue, L.; Henkelman, G.; Goodenough, J.B. Na3MnZr(PO4)3: A High-Voltage Cathode for Sodium Batteries. J. Am. Chem. Soc. 2018, 140, 18192-18199. [CrossRef]

258. Liu, Q.; Meng, X.; Wei, Z.; Wang, D.; Gao, Y.; Wei, Y.; Du, F.; Chen, G. Core/Double-Shell Structured Na3V2(PO4)2F3@C Nanocomposite as the High Power and Long Lifespan Cathode for Sodium-Ion Batteries. ACS Appl. Mater. Interfaces 2016, 8, 31709-31715. [CrossRef] 
259. Lim, S.Y.; Kim, H.; Shakoor, R.A.; Jung, Y.; Choi, J.W. Electrochemical and Thermal Properties of NASICON Structured Na3V2(PO4)3 as a Sodium Rechargeable Battery Cathode: A Combined Experimental and Theoretical Study. J. Electrochem. Soc. 2012, 159, A1393-A1397. [CrossRef]

260. Chen, S.; Wu, C.; Shen, L.; Zhu, C.; Huang, Y.; Xi, K.; Maier, J.; Yu, Y. Challenges and Perspectives for NASICON-Type Electrode Materials for Advanced Sodium-Ion Batteries. Adv. Mater. 2017, $29,1700431$. [CrossRef]

261. Anantharamulu, N.; Rao, K.K.; Rambabu, G.; Kumar, B.V.; Radha, V.; Vithal, M. A wide-ranging review on Nasicon type materials. J. Mater. Sci. 2011, 46, 2821-2837. [CrossRef]

262. Kim, H.; Lim, H.; Kim, H.-S.; Kim, K.J.; Byun, D.; Choi, W. Polydopamine-derived N-doped carbon-wrapped Na3V2(PO4)3 cathode with superior rate capability and cycling stability for sodium-ion batteries. Nano Res. 2019, 12, 397-404. [CrossRef]

263. Aragón, M.J.; Lavela, P.; Ortiz, G.F.; Alcántara, R.; Tirado, J.L. Insight into the Electrochemical Sodium Insertion of Vanadium Superstoichiometric NASICON Phosphate. Inorg. Chem. 2017, 56, 11845-11853. [CrossRef] [PubMed]

264. Pang, G.; Yuan, C.; Nie, P.; Ding, B.; Zhu, J.; Zhang, X. Synthesis of NASICON-type structured NaTi2(PO4)3-graphene nanocomposite as an anode for aqueous rechargeable Na-ion batteries. Nanoscale 2014, 6, 6328-6334. [CrossRef] [PubMed]

265. Wang, D.; Liu, Q.; Chen, C.; Li, M.; Meng, X.; Bie, X.; Wei, Y.; Huang, Y.; Du, F.; Wang, C.; et al. NASICON-Structured NaTi2(PO4)3@C Nanocomposite as the Low Operation-Voltage Anode Material for High-Performance Sodium-Ion Batteries. ACS Appl. Mater. Interfaces 2016, 8, 2238-2246. [CrossRef] [PubMed]

266. Di Vona, M.L.; Licoccia, S.; Montanaro, L.; Traversa, E. Sol-Gel Synthesis of NASICON: 1D and 2D NMR Investigation. Chem. Mater. 1999, 11, 1336-1341. [CrossRef]

267. Paolella, A.; Faure, C.; Timoshevskii, V.; Marras, S.; Bertoni, G.; Guerfi, A.; Vijh, A.; Armand, M.; Zaghib, K. A review on hexacyanoferrate-based materials for energy storage and smart windows: Challenges and perspectives. J. Mater. Chem. A 2017, 5, 18919-18932. [CrossRef]

268. Karyakin, A.A. Prussian Blue and Its Analogues: Electrochemistry and Analytical Applications. Electroanalysis 2001, 13, 813-819. [CrossRef]

269. Ma, F.; Li, Q.; Wang, T.; Zhang, H.; Wu, G. Energy storage materials derived from Prussian blue analogues. Sci. Bull. 2017, 62, 358-368. [CrossRef]

270. Pasta, M.; Wessells, C.D.; Huggins, R.A.; Cui, Y. A high-rate and long cycle life aqueous electrolyte battery for grid-scale energy storage. Nat. Commun. 2012, 3, 1149. [CrossRef]

271. You, Y.; Wu, X.-L.; Yin, Y.-X.; Guo, Y.-G. High-quality Prussian blue crystals as superior cathode materials for room-temperature sodium-ion batteries. Energy Environ. Sci. 2014, 7, 1643-1647. [CrossRef]

272. Lu, Y.; Wang, L.; Cheng, J.; Goodenough, J.B. Prussian blue: A new framework of electrode materials for sodium batteries. Chem. Commun. 2012, 48, 6544-6546. [CrossRef] [PubMed]

273. Li, W.-J.; Chou, S.-L.; Wang, J.-Z.; Kang, Y.-M.; Wang, J.-L.; Liu, Y.; Gu, Q.-F.; Liu, H.-K.; Dou, S.-X. Facile Method To Synthesize Na-Enriched Na1+xFeFe(CN)6 Frameworks as Cathode with Superior Electrochemical Performance for Sodium-Ion Batteries. Chem. Mater. 2015, 27, 1997-2003. [CrossRef]

274. Yue, Y.; Binder, A.J.; Guo, B.; Zhang, Z.; Qiao, Z.-A.; Tian, C.; Dai, S. Mesoporous Prussian Blue Analogues: Template-Free Synthesis and Sodium-Ion Battery Applications. Angew. Chem. 2014, 53, 3134-3137. [CrossRef] [PubMed]

275. Wu, X.; Wu, C.; Wei, C.; Hu, L.; Qian, J.; Cao, Y.; Ai, X.; Wang, J.; Yang, H. Highly Crystallized Na2CoFe(CN)6 with Suppressed Lattice Defects as Superior Cathode Material for Sodium-Ion Batteries. ACS Appl. Mater. Interfaces 2016, 8, 5393-5399. [CrossRef]

276. Yang, D.; Xu, J.; Liao, X.-Z.; He, Y.-S.; Liu, H.; Ma, Z.-F. Structure optimization of Prussian blue analogue cathode materials for advanced sodium ion batteries. Chem. Commun. 2014, 50, 13377-13380. [CrossRef] [PubMed]

277. Fu, H.; Liu, C.; Zhang, C.; Ma, W.; Wang, K.; Li, Z.; Lu, X.; Cao, G. Enhanced storage of sodium ions in Prussian blue cathode material through nickel doping. J. Mater. Chem. A 2017, 5, 9604-9610. [CrossRef]

278. Mukherjee, S.; Bates, A.; Schuppert, N.; Son, B.; Kim, J.G.; Choi, J.S.; Choi, M.J.; Lee, D.-H.; Kwon, O.; Jasinski, J.; et al. A study of a novel Na ion battery and its anodic degradation using sodium rich prussian blue cathode coupled with different titanium based oxide anodes. J. Power Sources 2015, 286, 276-289. [CrossRef] 
279. Jiang, Y.; Yu, S.; Wang, B.; Li, Y.; Sun, W.; Lu, Y.; Yan, M.; Song, B.; Dou, S. Prussian Blue@C Composite as an Ultrahigh-Rate and Long-Life Sodium-Ion Battery Cathode. Adv. Funct. Mater. 2016, 26, 5315-5321. [CrossRef]

280. Itaya, K.; Shoji, N.; Uchida, I. Catalysis of the reduction of molecular oxygen to water at Prussian blue modified electrodes. J. Am. Chem. Soc. 1984, 106, 3423-3429. [CrossRef]

281. Kaye, S.S.; Long, J.R. Hydrogen Storage in the Dehydrated Prussian Blue Analogues $\mathrm{M}_{3}\left[\mathrm{Co}(\mathrm{CN})_{6}\right]_{2}(\mathrm{M}=\mathrm{Mn}$, $\mathrm{Fe}, \mathrm{Co}, \mathrm{Ni}, \mathrm{Cu}, \mathrm{Zn})$. J. Am. Chem. Soc. 2005, 127, 6506-6507. [CrossRef]

282. Mullaliu, A.; Conti, P.; Aquilanti, G.; Plaisier, J.R.; Stievano, L.; Giorgetti, M. Operando XAFS and XRD Study of a Prussian Blue Analogue Cathode Material: Iron Hexacyanocobaltate. Condens. Matter 2018, 3, 36. [CrossRef]

283. Mullaliu, A.; Aquilanti, G.; Conti, P.; Plaisier, J.R.; Fehse, M.; Stievano, L.; Giorgetti, M. Copper Electroactivity in Prussian Blue-Based Cathode Disclosed by Operando XAS. J. Phys. Chem. C 2018, 122, 15868-15877. [CrossRef]

284. Wessells, C.D.; Huggins, R.A.; Cui, Y. Copper hexacyanoferrate battery electrodes with long cycle life and high power. Nat. Commun. 2011, 2, 550. [CrossRef] [PubMed]

285. Wu, X.; Sun, M.; Guo, S.; Qian, J.; Liu, Y.; Cao, Y.; Ai, X.; Yang, H. Vacancy-Free Prussian Blue Nanocrystals with High Capacity and Superior Cyclability for Aqueous Sodium-Ion Batteries. ChemNanoMat 2015, 1, 188-193. [CrossRef]

286. Wang, L.; Song, J.; Qiao, R.; Wray, L.A.; Hossain, M.A.; Chuang, Y.-D.; Yang, W.; Lu, Y.; Evans, D.; Lee, J.-J.; et al. Rhombohedral Prussian White as Cathode for Rechargeable Sodium-Ion Batteries. J. Am. Chem. Soc. 2015, 137, 2548-2554. [CrossRef] [PubMed]

287. Trócoli, R.; La Mantia, F. An Aqueous Zinc-Ion Battery Based on Copper Hexacyanoferrate. ChemSusChem 2015, 8, 481-485. [CrossRef] [PubMed]

288. Yang, J.-H.; Myoung, N.; Hong, H.-G. Facile and controllable synthesis of Prussian blue on chitosan-functionalized graphene nanosheets for the electrochemical detection of hydrogen peroxide. Electrochim. Acta 2012, 81, 37-43. [CrossRef]

289. Wu, X.; Jin, S.; Zhang, Z.; Jiang, L.; Mu, L.; Hu, Y.-S.; Li, H.; Chen, X.; Armand, M.; Chen, L.; et al. Unraveling the storage mechanism in organic carbonyl electrodes for sodium-ion batteries. Sci. Adv. 2015, 1, e1500330. [CrossRef] [PubMed]

290. Wang, H.; Hu, P.; Yang, J.; Gong, G.; Guo, L.; Chen, X. Renewable-Juglone-Based High-Performance Sodium-Ion Batteries. Adv. Mater. 2015, 27, 2348-2354. [CrossRef]

291. Larcher, D.; Tarascon, J.M. Towards greener and more sustainable batteries for electrical energy storage. Nat. Chem. 2014, 7, 19-29. [CrossRef]

292. Wu, Y.; Zeng, R.; Nan, J.; Shu, D.; Qiu, Y.; Chou, S.-L. Quinone Electrode Materials for Rechargeable Lithium/Sodium Ion Batteries. Adv. Energy Mater. 2017, 7, 1700278. [CrossRef]

293. Song, Z.; Zhan, H.; Zhou, Y. Polyimides: Promising Energy-Storage Materials. Angew. Chem. Int. Ed. 2010, 49, 8444-8448. [CrossRef] [PubMed]

294. Zhao, R.; Zhu, L.; Cao, Y.; Ai, X.; Yang, H.X. An aniline-nitroaniline copolymer as a high capacity cathode for Na-ion batteries. Electrochem. Commun. 2012, 21, 36-38. [CrossRef]

295. Deng, W.; Liang, X.; Wu, X.; Qian, J.; Cao, Y.; Ai, X.; Feng, J.; Yang, H. A low cost, all-organic Na-ion Battery Based on Polymeric Cathode and Anode. Sci. Rep. 2013, 3, 2671. [CrossRef]

296. Yao, M.; Kuratani, K.; Kojima, T.; Takeichi, N.; Senoh, H.; Kiyobayashi, T. Indigo carmine: An organic crystal as a positive-electrode material for rechargeable sodium batteries. Sci. Rep. 2014, 4, 3650. [CrossRef] [PubMed]

297. Wang, H.-G.; Yuan, S.; Ma, D.-L.; Huang, X.-L.; Meng, F.-L.; Zhang, X.-B. Tailored Aromatic Carbonyl Derivative Polyimides for HighPower and Long-Cycle Sodium-Organic Batteries. Adv. Energy Mater. 2014, 4, 1601651. [CrossRef]

298. Luo, W.; Allen, M.; Raju, V.; Ji, X. An Organic Pigment as a High-Performance Cathode for Sodium-Ion Batteries. Adv. Energy Mater. 2014, 4, 1400544. [CrossRef]

299. Manuel, J.; Zhao, X.; Cho, K.-K.; Kim, J.-K.; Ahn, J.-H. Ultralong Life Organic Sodium Ion Batteries Using a Polyimide/Multiwalled Carbon Nanotubes Nanocomposite and Gel Polymer Electrolyte. ACS Sustain. Chem. Eng. 2018, 6, 8159-8166. [CrossRef] 
300. Xie, J.; Zhang, Q. Recent progress in rechargeable lithium batteries with organic materials as promising electrodes. J. Mater. Chem. A 2016, 4, 7091-7106. [CrossRef]

301. Xie, J.; Gu, P.; Zhang, Q. Nanostructured Conjugated Polymers: Toward High-Performance Organic Electrodes for Rechargeable Batteries. ACS Energy Lett. 2017, 2, 1985-1996. [CrossRef]

302. Liang, Y.; Jing, Y.; Gheytani, S.; Lee, K.-Y.; Liu, P.; Facchetti, A.; Yao, Y. Universal quinone electrodes for long cycle life aqueous rechargeable batteries. Nat. Mater. 2017, 16, 841-848. [CrossRef] [PubMed]

303. Tamura, K.; Akutagawa, N.; Satoh, M.; Wada, J.; Masuda, T. Charge/Discharge Properties of Organometallic Batteries Fabricated with Ferrocene-Containing Polymers. Macromol. Rapid Commun. 2008, 29, 1944-1949. [CrossRef]

304. Nakahara, K.; Iwasa, S.; Satoh, M.; Morioka, Y.; Iriyama, J.; Suguro, M.; Hasegawa, E. Rechargeable batteries with organic radical cathodes. Chem. Phys. Lett. 2002, 359, 351-354. [CrossRef]

305. Renault, S.; Brandell, D.; Gustafsson, T.; Edström, K. Improving the electrochemical performance of organic Li-ion battery electrodes. Chem. Commun. 2013, 49, 1945-1947. [CrossRef] [PubMed]

306. Liu, Q.; Hu, Z.; Chen, M.; Gu, Q.; Dou, Y.; Sun, Z.; Chou, S.; Dou, S.X. Multiangular Rod-Shaped $\mathrm{Na}_{0.44} \mathrm{MnO}_{2}$ as Cathode Materials with High Rate and Long Life for Sodium-Ion Batteries. ACS Appl. Mater. Interfaces 2017, 9, 3644-3652. [CrossRef] [PubMed]

307. Yuan, D.; He, W.; Pei, F.; Wu, F.; Wu, Y.; Qian, J.; Cao, Y.; Ai, X.; Yang, H. Synthesis and electrochemical behaviors of layered $\mathrm{Na}_{0.67}\left[\mathrm{Mn}_{0.65} \mathrm{Co}_{0.2} \mathrm{Ni}_{0.15} \mathrm{O}_{2}\right.$ microflakes as a stable cathode material for sodium-ion batteries. J. Mater. Chem. A 2013, 1, 3895-3899. [CrossRef]

308. Guo, S.; Li, Q.; Liu, P.; Chen, M.; Zhou, H. Environmentally stable interface of layered oxide cathodes for sodium-ion batteries. Nat. Commun. 2017, 8, 135. [CrossRef]

309. Han, D.-W.; Ku, J.-H.; Kim, R.-H.; Yun, D.-J.; Lee, S.-S.; Doo, S.-G. Aluminum Manganese Oxides with Mixed Crystal Structure: High-Energy-Density Cathodes for Rechargeable Sodium Batteries. ChemSusChem 2014, 7, 1870-1875. [CrossRef]

310. Oh, S.-M.; Myung, S.-T.; Hwang, J.-Y.; Scrosati, B.; Amine, K.; Sun, Y.-K. High Capacity O3-Type $\mathrm{Na}\left[\mathrm{Li}_{0.05}\left(\mathrm{Ni}_{0.25} \mathrm{Fe}_{0.25} \mathrm{Mn}_{0.5}\right)_{0.95}\right] \mathrm{O}_{2}$ Cathode for Sodium Ion Batteries. Chem. Mater. 2014, 26, 6165-6171. [CrossRef]

311. Fang, Y.; Xiao, L.; Qian, J.; Ai, X.; Yang, H.; Cao, Y. Mesoporous Amorphous $\mathrm{FePO}_{4}$ Nanospheres as High-Performance Cathode Material for Sodium-Ion Batteries. Nano Lett. 2014, 14, 3539-3543. [CrossRef]

312. Liu, Y.; Xu, Y.; Han, X.; Pellegrinelli, C.; Zhu, Y.; Zhu, H.; Wan, J.; Chung, A.C.; Vaaland, O.; Wang, C.; et al. Porous Amorphous $\mathrm{FePO}_{4}$ Nanoparticles Connected by Single-Wall Carbon Nanotubes for Sodium Ion Battery Cathodes. Nano Lett. 2012, 12, 5664-5668. [CrossRef] [PubMed]

313. Wongittharom, N.; Lee, T.-C.; Wang, C.-H.; Wang, Y.-C.; Chang, J.-K. Electrochemical performance of $\mathrm{Na} / \mathrm{NaFePO}_{4}$ sodium-ion batteries with ionic liquid electrolytes. J. Mater. Chem. A 2014, 2, 5655-5661. [CrossRef]

314. Barpanda, P.; Liu, G.; Ling, C.D.; Tamaru, M.; Avdeev, M.; Chung, S.-C.; Yamada, Y.; Yamada, A. $\mathrm{Na}_{2} \mathrm{FeP}_{2} \mathrm{O}_{7}$ : A Safe Cathode for Rechargeable Sodium-ion Batteries. Chem. Mater. 2013, 25, 3480-3487. [CrossRef]

315. Zhang, Q.; Wang, W.; Wang, Y.; Feng, P.; Wang, K.; Cheng, S.; Jiang, K. Controllable construction of 3D-skeleton-carbon coated $\mathrm{Na}_{3} \mathrm{~V}_{2}\left(\mathrm{PO}_{4}\right)_{3}$ for high-performance sodium ion battery cathode. Nano Energy 2016, 20, 11-19. [CrossRef]

316. Jung, Y.H.; Lim, C.H.; Kim, D.K. Graphene-supported $\mathrm{Na}_{3} \mathrm{~V}_{2}\left(\mathrm{PO}_{4}\right)_{3}$ as a high rate cathode material for sodium-ion batteries. J. Mater. Chem. A 2013, 1, 11350-11354. [CrossRef]

317. Sun, Q.; Ren, Q.-Q.; Fu, Z.-W. NASICON-type $\mathrm{Fe}_{2}\left(\mathrm{MoO}_{4}\right)_{3}$ thin film as cathode for rechargeable sodium ion battery. Electrochem. Commun. 2012, 23, 145-148. [CrossRef]

318. Peng, M.; Li, B.; Yan, H.; Zhang, D.; Wang, X.; Xia, D.; Guo, G. Ruthenium-Oxide-Coated Sodium Vanadium Fluorophosphate Nanowires as High-Power Cathode Materials for Sodium-Ion Batteries. Angew. Chem. 2015, 54, 6452-6456. [CrossRef]

319. Yu, S.-H.; Shokouhimehr, M.; Hyeon, T.; Sung, Y.-E. Iron Hexacyanoferrate Nanoparticles as Cathode Materials for Lithium and Sodium Rechargeable Batteries. ECS Electrochem. Lett. 2013, 2, A39-A41. [CrossRef]

320. Xie, M.; Xu, M.; Huang, Y.; Chen, R.; Zhang, X.; Lia, L.; Wu, F. $\mathrm{Na}_{2} \mathrm{Ni}_{\mathrm{x}} \mathrm{Co}_{1-\mathrm{x}} \mathrm{Fe}(\mathrm{CN})_{6}$ : A class of Prussian blue analogs with transition metal elements as cathode materials for sodium ion batteries. Electrochem. Commun. 2015, 59, 91-94. [CrossRef] 
321. Wang, H.; Wang, L.; Chen, S.; Li, G.; Quan, J.; Xu, E.; Song, L.; Jiang, Y. Crystallographic-plane tuned Prussian-blue wrapped with RGO: A high-capacity, long-life cathode for sodium-ion batteries. J. Mater. Chem. A 2017, 5, 3569-3577. [CrossRef]

322. Banda, H.; Damien, D.; Nagarajan, K.; Hariharan, M.; Shaijumon, M.M. A polyimide based all-organic sodium ion battery. J. Mater. Chem. A 2015, 3, 10453-10458. [CrossRef]

323. Xu, F.; Xia, J.; Shi, W. Anthraquinone-based polyimide cathodes for sodium secondary batteries. Electrochem. Commun. 2015, 60, 117-120. [CrossRef]

324. Song, Z.; Qian, Y.; Zhang, T.; Otani, M.; Zhou, H. Poly(benzoquinonyl sulfide) as a High-Energy Organic Cathode for Rechargeable Li and Na Batteries. Adv. Sci. 2015, 2, 1500124. [CrossRef] [PubMed]

325. Lee, M.; Hong, J.; Lopez, J.; Sun, Y.; Feng, D.; Lim, K.; Chueh, W.C.; Toney, M.F.; Cui, Y.; Bao, Z. Highperformance sodium-organic battery by realizing four-sodium storage in disodium rhodizonate. Nat. Energy 2017, 2, 861-868. [CrossRef]

(C) 2019 by the authors. Licensee MDPI, Basel, Switzerland. This article is an open access article distributed under the terms and conditions of the Creative Commons Attribution (CC BY) license (http://creativecommons.org/licenses/by/4.0/). 